\title{
A STUDY OF THE FATIGUE PROPERTIES OF LIGHTWEIGHT AGGREGATE CONCRETE
}

\section{SEPTEMBER 1960 \\ NO. 14}
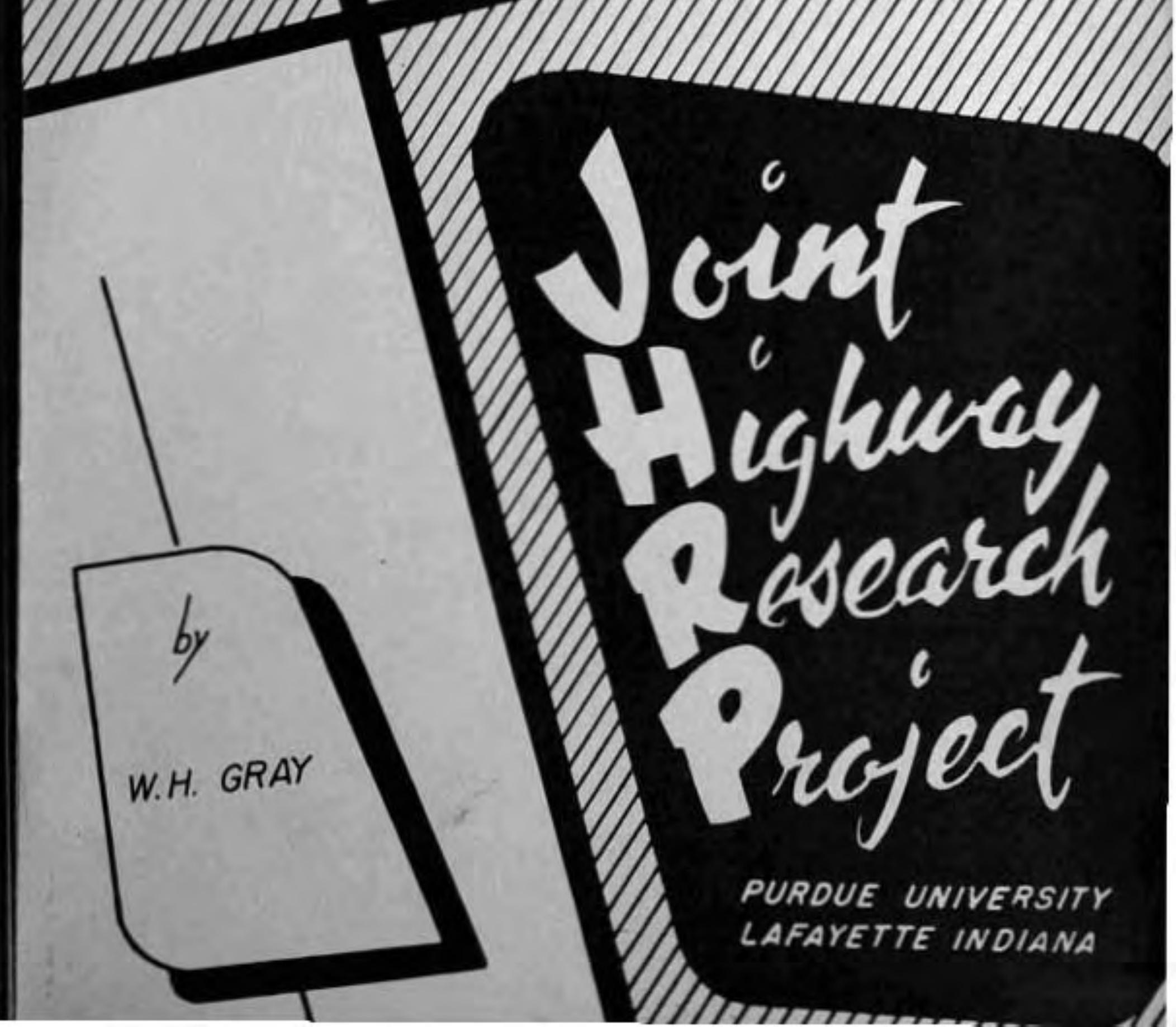
Binal Report

A STUDH OP THS FAFIUUS PROFGRTISS

OP LTOHWEIGH AGGEDATS CONCIBES

TO: X. B. Wooda, Director

Jolnt Hghnay Rasearch Project

Septeribar 13, 1960

Frolls H. L. Michael, Assistant Director Joint Highney Reeearch Project

File: $7-4-7$

Project: $0-36-566$

Attachod is a flnal report entitled, $n_{A}$ Study of the Fatigue Propertiea of IAghtveight Aggregate Conerote". Th1s repost vas prepered by $\mathrm{N} r$. W. H. Gray under the directicn of Professor J. F. Yalaughlin. Hr. Gray also used this report as his thesis for the YSCE degroe.

The roport 18 presented to the Board for the record.

Rospectrully subnitted,

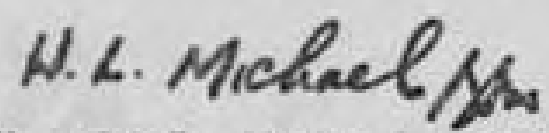

Harold Lo KLchael, Secretary

\section{HLMt JPMsikr}

Attachment

eeI F. L. Aahbaucher

J. R. Coopor

J. P. Molaughlin

W. L. Dolch

R. D. Miles

W. H. Goots

R. B. Mula

G. A. Havldina (U, B. Scott)

C. B. Vogelgeasng

P. P. Havey

G. A. Loonards

J. L. Valing

J. E. W1 son

B. J. Yoder 
Digitized by the Internet Archive in 2011 with funding from

LYRASIS members and Sloan Foundation; Indiana Department of Transportation

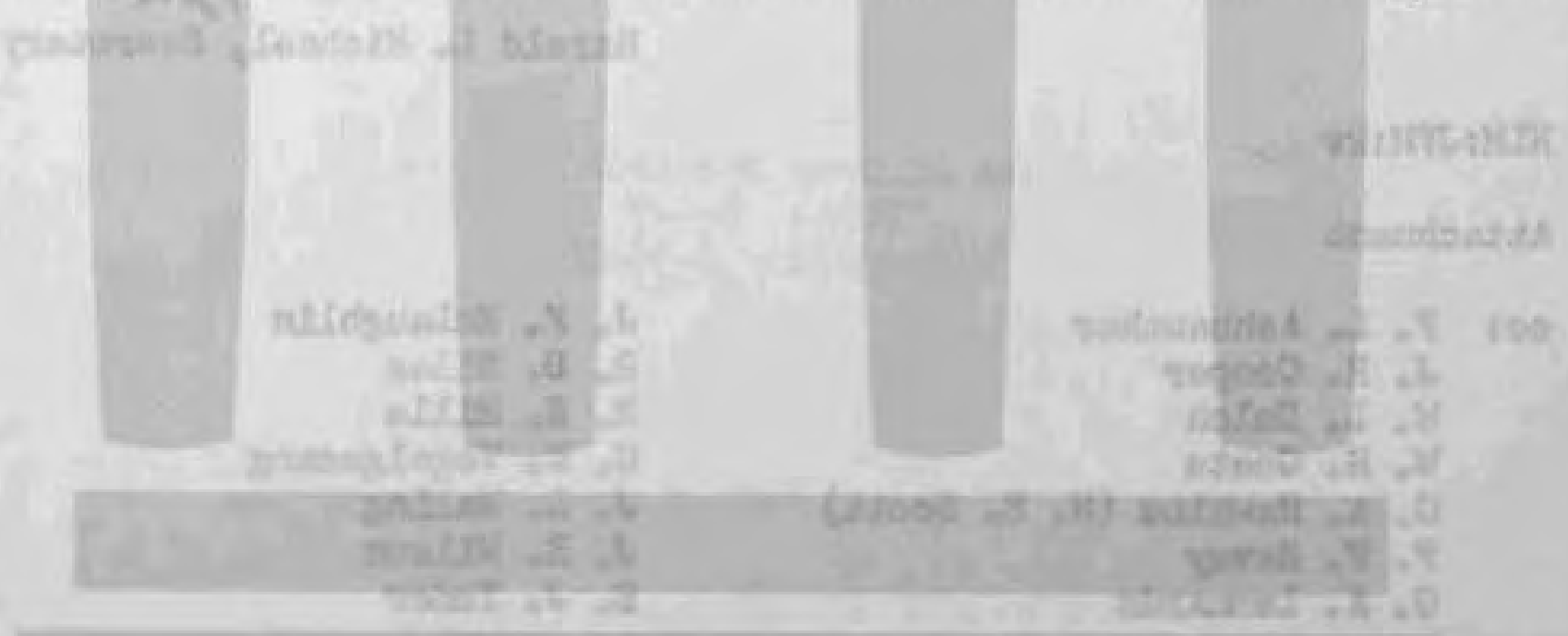


Final Report

A STUDY OP THB FATIGUS PROPERTIES

OP LIGHRIGH AGERGATS CONCRBS

by

Warren H. Gray

Craduate Aseistant

Joint Hifharay Rosearch Projo ot

Files 7-4m-?

Project: $0-36-560$

Purdue Volversdts

Iafayette, Indiana

Septeaber 21, 1960 


\section{ACKONOULEDGNGITS}

This Investigation vas sponsored by the Jolnt Higivay Research Project at Purdue University under the direction of Professor K. B. Woods. The writer is grateful to this organization for providing the necessary financial support.

The vriter vishes to express his sincere sppreciation to Professor J. F. MoLaughlin, Research Engineer, Joint Highvay Research Project, for his helpful suggestions made during the course of the research and the preparation of this thesis.

Thanks are also extended to Professors A.D.M. Levis and I. W. Burr for their assistance during the preparation of this thesis. Professor Levis offered much advice on the operation of the KrousePurdue and Amsler fatigue machines. Professor Burr's suggestions on the statistical ansiysis of the data collected in this study vere sincerely appreciated. 
TABLE G COMEIMS

Page

LIST OF TABLES

LIST OF PIGURES. .......................

v111

ABSTRACT ................................. $1 x$

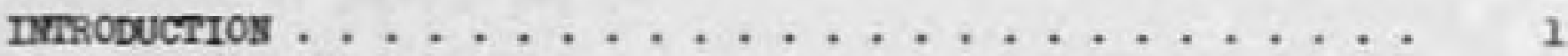

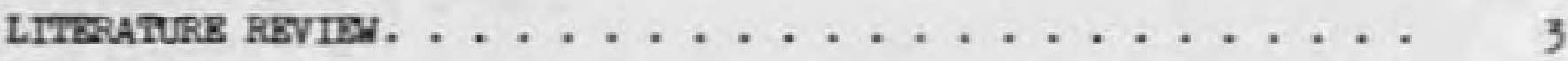

Nomenclsture. . . . . . . . . . . . . . . . 3

Nechanism of Fatigue Failure. . . . . . . . . . . . . . . . . . . 6

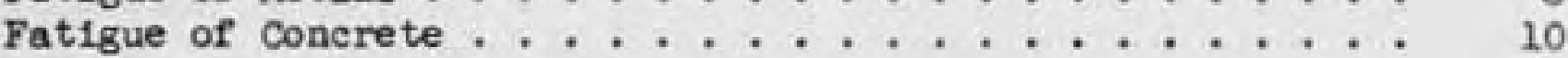

PURPOSE AND SCOPE. . . . . . . . . . . . . . . . 15

TESTIIE PRCGRAM. . . . . . . . . . . . . . . . . 16

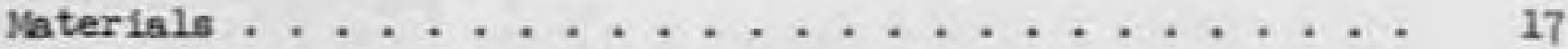

Mix Desiga. . . . . . . . . . . . . . . . . . . . . 17

Mixing Procedure. ....................... 19

Air Determination .................... 21

Molding and Curing of Specimens . . . . . . . . . . . 22

Dryling. . . . . . . . . . . . . . . . . . . . 22

Cappling ........................ . . . . . . 23

Static Compression Tests. . . . . . . . . . . . . 23

Fatigue Tests . . . . . . . . . . . . . . . 25

The Krouse-Purdue Machine. . . . . . . . . . . . . 26

The Amsler Machine . . . . . . . . . . . . . . . 29

Fatigue Testing st Different speeds............ 33

Static Compression Tests to Determine Increase in Strength. . $\quad 33$

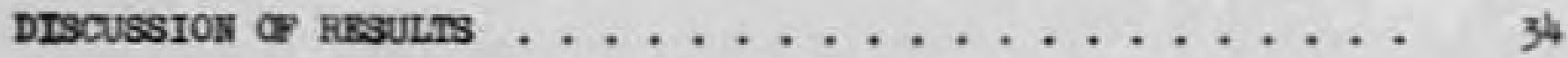

Analyals of Mix Data. . . . . . . . . . . . . . 34

Iov-strength Concrete. ............... 35

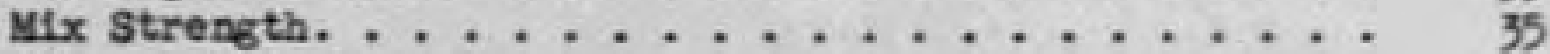

Alr Content and Slump .............. 37

Sumary ..................... 38

High-Strength Concrete ............... 38

Mix strength. . . . . . . . . . . . . . 40

A1r Content and sluap .............. 40

Sumary ................... . . 40 
TABLZ OF COMEMS (continued)

Page

Comparison of Serles .................. 41

Bfrect or Age on Strength. . . . . . . . . . . 43

Fatigue Test Results................. 44

Analysis of Fatigue Test Data. . . . . . . . . 45

The S-N Dlagrams. . . . . . . . . . . . 50

Coraparison of the Two Mixes . . . . . . . . . . . 53

Lnear Regression Analysis. . . . . . . . . . . 53

Comparison of $\mathrm{S}-1 \mathrm{~N}$ Curves. . . . . . . . . . . 56

Type of Fallure. . . . . . . . . . . . . . 60

Other Observations ........................... 60

Speed of Testing Results . . . . . . . . . . . . 62

Sumary of Fatigue Teat Results. . . . . . . . . . 62

Coaperison of Lightveight Concrete with Normal Weight

Concrete .................. 64

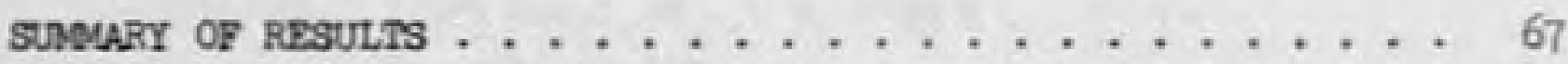

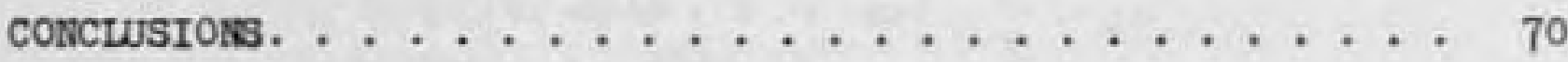

SUGGESTIONS FOR FURTHIR WORK . . . . . . . . . . . . . 71

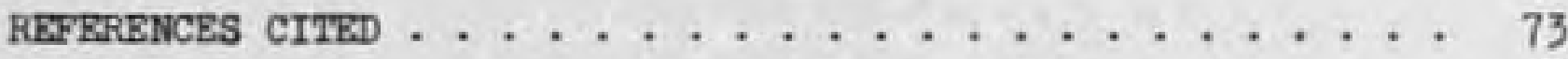

ADDITIONAL RBYERENCBS. .................. 75

APPBIDIX A:

TEST DATA FOR CONCRETE MDCES. . . . . . . . . 77

APPBDDX B:

STATISTICAL ANALYSIS OF STATIC TEST DATA. . . . . . 87 APPBNDIX C:

STATISTICAL ANALYSIS OF FATIGUE TEST DATA . . . . . . . 99 APPBIDIX D:

STATISTICAL CONPARISON OF LIGHTEIGH CONCRETE WITH

NORMAL WEICHT COMRETE. . . . . . . . . . . 114 


\section{LIST GP TABLES}

Table

Page

1 Gradation of Coarse Aggregate ............. 18

2 Gradation or Fine Aggregate ............... 18

3 Physical properties of Conerete: Low-Strength (IL) Mix . . 36

4 Physical Properties of Conerete: High-strength (HL) Mix . . 39

5 Fatigue Test Results: Low-Strength Concrete. . . . . . . 47

6 Fatigue Test Results: High-Strength Concrete ....... 49

7 Ninety-Five Per Cent Predietion Intervals . . . . . . . 59 (Append1x A)

8 Data Sheet for LL Mix - Batch 1.......... 77

9 Data Sheet for L Mix - Batch 2.......... 78

10 Data Sheet for LL Mix - Batch 3.......... 79

11 Data Sheet for IL Mix - Batch 4.......... 80

12 Data Sheet for LI MX - Batch 5........... 81

13 Dats sheet for Hl Mix - Batch 2.......... 82

14 Data Sheet for HL Mix - Batch 3.......... 83

15 Data Sheet for HI M1x - Batch 4............ 84

16 Data Sheet for HIL Mix - Batch 5......... 85

17 Data Sheet for HL M1x - Batch 6............ 86 
LIST OF TABLES (contimued)

Table

Page

(Append1 $\mathrm{B}$ )

18 Bartlett's test for Homogeneity of Varlance for strength

Data: Low-Strength Concrete ............

19 Analysis of Variance for Difference Between Batch Mean

Strengths of Lou-Strength Concrete..........

20 Bartlett's Test for Homogenelty of Variance for strength

Deta: Bigh-Strength Concrete...........

21 Analysis or Varlance for Difference Between Batch Mean

Strength of High-Strength Data. . . . . . . . . .

22 Test for Difference of Mix Strength . . .........

23 Teat for Difference in Batch Strengths Before and After

Fatigue Teating: Batch LL $1 \ldots \ldots$

24 Test for Difference in Batch Strengths Before and After

Fatigue Testing: Batch LL $3 \ldots . . . . . .$.

25 Test for Difference in Batch Strengtha Before and After

Fat1gue Testing: Batch HL $4 \ldots \ldots$

26 Test for Difference in Batch strengtha Before and After

Fatigue Testing: Batch HL $6 \ldots \ldots$

(Append1x C)

27 Calculations for Run Test . . . . . . . . . . .

28 Linear Regression Calculations: Low-Strength Concrete-

All Batches. . . . . . . . . . . . . . 100

29 Linear Regression Calculations: High-Strength Concrete Batches HL 2, HL 3, HL $4 \ldots 102$

30 Linear Regression Calculations: Bigh-Strength Concrete Batches HIL 5 , HL $6 \ldots \ldots$

31 Test for Difference in Correlation Coefficlents .....

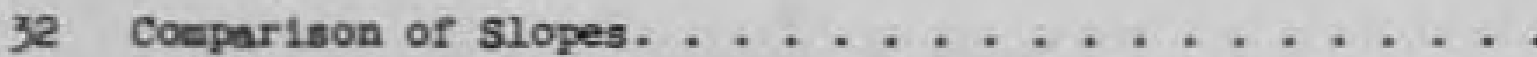

33 Test for D1fference Betveen Intercepts. . . . . . . 110

34 Calculation for Prediction Intervals. . . . . . . . 111 


\section{LIST OF TABLES (cont1nued)}

Table

Page

(Appendix C)

35 Test to Deternine Difference in Fatigue Life When

Testing at Different Speeds. . . . . . . . 113

(Append 1X D)

36 Teat for Difference in Correlation Coefrieients .... 114

37 Comparison of slopes................ 115 


\section{LIST OP PIGURES}

PIgure

Page

1. Typical Fluctuating Cocpressive Stress Encountered Streas Bncountered in Patigue Testing. . . .

2. Maximum Density Curve ............ 20

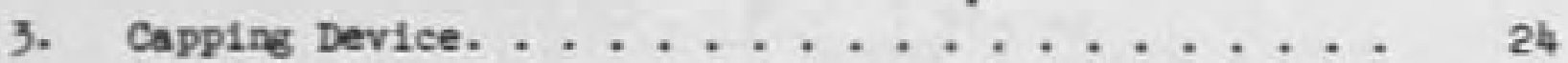

4. Krouse-Purdue Fat1gue Mach1ne ......... 27

5. Hydroulie System of Fatigue Machine ....... 28

6. Specimen Holder ............... 30

7. Pulsator...................... 31

8. Loading Jack. . . . . . . . . . . . 32

9. J-N Diagram for Low-Strength Concrete ....... 51

10. S-N D1agram for High-Strength Concrete ...... 52

11. Typ1cal Fa1lures................... 61 


\section{ABSTRACT}

Gray, Warren H., M.S.C.B., Purdue University, August, 1960. A Study of the Fatigue Properties of Lightweight Aggregate Concrete. Major Professor: John F. Mclaughl1n.

It was the purpose of this study to determine the fatigue properties of IIghtwe1ght aggregate concrete and to investigate the effects of varying the mix proportions and strength of the mix on this property. Fatigue tests were performed on concretes having two mix designs; one being designed for a static compressive strength of 3,500 psi and the other designed for a static compressive strength of 6,000 psi. Five batches of concrete were made using each mix deslgn, and from each batch 30 cylindrical specimens 3 inches in diameter and 6 inches in length were cast. About one-half of these specimens were used in this study. Nearly 70 specimens were tested in static compression to arrive at estimates of the static ultimate compressive strengths of the batches of concrete and nearly 50 others were tested in fatigue. Fatigue tests were conducted at various stress levels at speeds of 1,000 and 500 cycles per minute in two different fatigue testing machines. The Krouse-Purdue machine was used to test at a speed of 1,000 cycles per minute and an Amsler machine was used to test at a speed of 500 cycles per minute.

It was found that within the $11 \mathrm{mits}$ of this investigation the fatigue properties of the lightweight aggregate concrete vere not 
changed by varying the strength of the concrete or aggregate proportions of the concrete. It was also found that the rate of testing used in this testing program had no effect on the fatigue properties of lighweight aggregate concrete. Comparison of the data collected in this study with dats collected in a previous study indicated that the fatigue properties of 11 ghtweight aggregate concrete are not significantly different than the fatigue properties of normal weight concrete. 


\section{INIRODUCTION}

Lightweight aggregate concrete is rapidly becoming a very useful building material. In many instances the additional cost of the lightweight aggregate is more than justified by the savings in total cost of the entire structure. The upper deck of the San Francisco-Dakland Bay Bridge was paved with concrete weighing approximately 104 pef. It is estimated that the savings made possible by the use of lightweight concrete amounted to about $\$ 3,000,000(1)^{*}$. Close examination one year after completion showed that the lightweight concrete was equivalent to heavy concrete in every respect.

One of the first applications of lightweight concrete was its use in the hulls of ships. The successful use of lightweight concrete in the construction of ships brought interest in the material as an economical substance for building construction. Several studies have shown that a substantial savings can be accrued for most types of concrete buildings If lightweight concrete is used $(2,3)$.

Heat insulation is an important attribute of lightweight concrete which makes it even more desirable as a building material. It has been found that concretes can be made that weigh between one-third and two-thirds as much as normal concrete and have thermal conductivities of about onehale to one-fourth that of regular sand-and-gravel concrete (4).

Although lightwelght aggregate concrete has very desirable qualities for structural use, comparatively little is known about the material. Many tests have been carried out to determine the properties

Numbers in parentheses pertain to references listed at the end of this thesis. 
of the various aggregates avallable, but relatively few tests have been made on the properties of the finished concrete. One property that is of vital interest in every structural material is 1 ts resistance to repeated loading.

Many tests have been conducted to determine the resistance of some materials to repeated loading. It has been found for example, that for most steels a definite endurance limit can be found. Below this endurance limit the material can apparently withstand an infinite number of stress applications without falling. A graph of the percentage of ultimate stress versus the $10 \mathrm{~g}$ of the number of stress applications has a negative slope and is referred to as the $\mathrm{S}-\mathrm{N}$ curve. When this curve is plotted for a ferrous metal, the curve levels off and becomes horizontal at the endurance limit. If no endurance limit can be estab11shed, the curve continues to have a negative slope. Concrete is a material in which no leveling off point has been established (5).

Lightweight aggregate concrete has proven itgelf to be a useful structural material and its uses and applications are becoming more numerous as engineers learn more sbout it. Since it proved to be a cost-saving material in the San Francisco-Oakland Bay Bridge and several other major bridges, there is reason to belleve that it w111 continue to be used in these applications. Its properties of light weight and heat insulation make it very desirable as a building material. In bridges and elsewhere, lightwelght aggregate concrete when used as a material must be able to withstand repetition of loading. Hence, more information is needed on the fatigue resistance of this material. The work reported in this thesis had as its major objective, the establishment and comparison of the S-N relstionship of two lightweight aggregate concretes. 


\section{LTTERATURE REVIEW}

Before the testing of this study was begun an extensive survey of literature was conducted on the subjects of lightweight aggregate and fatigue of concrete. Literature on the characteristics of fatigue fallure and the fatigue of metsls was also reviewed. Most of the literature discussing the fatigue properties of metal also describes the phenomenon and theory behind the fallure of materials subjected to repeated loading. Hence the subsequent discussion of mechanics of fatigue vill be based primarily upon the results of fatigue tests conducted on metals. Less is known about the mechanics of failure in concrete but the following discussion will suffice for a background in fatigue fallures.

\section{Nomenclature}

Before presenting the basic mechanics of fatigue failure it was felt that the nomenclature used in this thesis should be defined. In 1949 the American Society for Testing Materials published a standard set of symbols and definitions for use in fatigue testing (6). Before this time there was no standard nomenclature, and terms presented in the early literature were interchanged and confusing. The definitions shown below are taken from the Manual on Fatigue Testing (6). Stress Cycle - A stress cycle is the smallest section of the stress time function which is repested periodically as shown in Figure 1.

Nominal Stress, $\mathbf{S}$ - The stress calculated on the net section by 


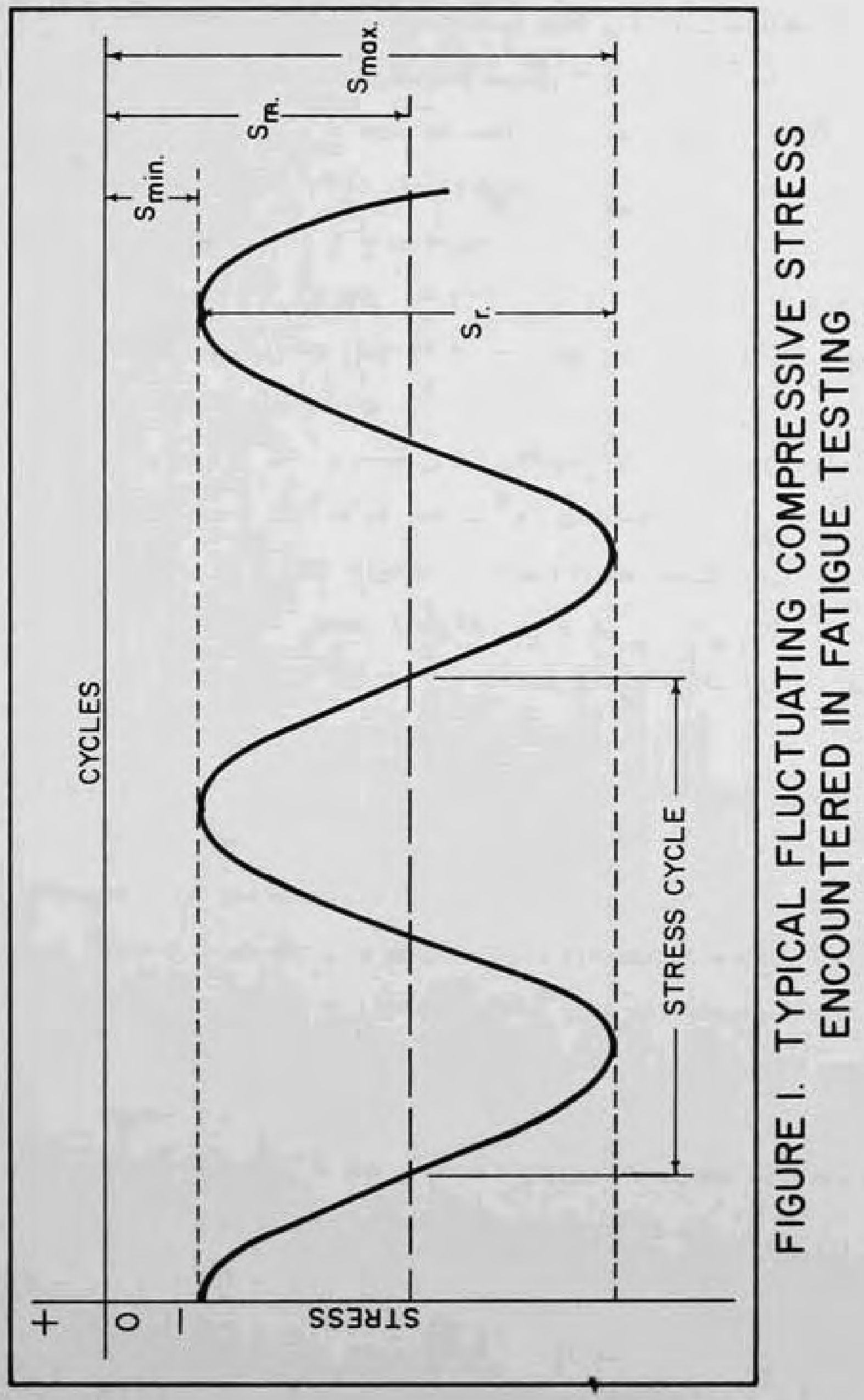


simple theory such as $\mathrm{P} / \mathrm{A}$ without taking into account the variation in stress conditions caused by geonetric discontinuities such as holes, grooves, fillets, and etc.

Maximum Stress, $S_{\max }$ - The highest algebraic value of the stress In the stress cycle, tensile stress being considered positive and compressive stress negative.

Minimum Stress, $\mathrm{S}_{\mathrm{min}}$ - The lowest value of the stress in the stress cycle, tensile stress being considered positive and compressive stress negative.

Stress Range, $\mathrm{s}_{r}$ - The algebraic difference between the maximum and minimum stress in one cycle, that is $S_{r}=S_{\max }-S_{\min }$. Mean Stress, $\mathrm{s}_{\mathrm{m}}$ - The algebraic mean of the maximum and minimum stress in one cycle, that is $\mathrm{s}_{\mathrm{m}}=\left(\mathrm{S}_{\max }+\mathrm{S}_{\min }\right) / 2$.

Fatigue Life, N - The number of stress cycles which can be sustained for a given test condition.

S-N Diagram, - A plot of the stress versus the number of cycles to failure.

Fatigue Limit (or Endurance Limit), $\mathrm{s}_{e}$ - The limiting value of stress below which a material can presumably endure an Infinite number of stress cycles, that is, the stress at which the S-N diagram becomes horizontal and appesrs to rema1n so.

Fatigue Strength, $\mathrm{s}_{\mathrm{n}}$ - The greatest stress which can be sustained for a given number of cycles without fracture. 
Mechanism of Fatigue Failures

Before discussing the mechanism of fatigue fallure, it might be worthwhile to review the method in which a metal falls when subject to loads greater than its ultimate tensile stress. Most metals are made up of a crystalline structure which is not destroyed by the deformations arising from tensile stress. If two adjacent crystals are examined as the tensile stress is increased, it will be found that the bond between the two crystals is not disturbed, but that the yielding will take place along slip planes at a limited number of places within each crystal. Thus if the surface of the two crystals were polished before elongation, they would look like steps after elongation. As the stress is increased the number of slip planes increases unt1l a condition of fallure occurs by tearing of the crystals along the slip planes (7).

There has been much controversy about what actually happens when slip occurs within a crystal. The general feeling is that the molecules along the slip planes are arranged in such a way that the inter-atomic bonds are destroyed between the two faces of slip. As slip takes place, a thin $111 \mathrm{~m}$ of amorphous metal is produced which cements the two faces together. This cementing creates a stronger bond than previously existed and hence the metal has a greater resistance to slip. This greater resistance to slip is called strain hardening $(7,8)$.

Fatigue fallure involves three stages (9):

1. Slip occurs resulting in strain hardening and lattice distort1on.

2. The fatigue crack starts.

3. The crack spreads along the path of least resistance, due to stress concentration. This proceeds until the 
cross-section of the metal is reduced so much that the remaining metal tears or breaks avay suddenly.

It has been observed by many 1nvestigators that a load deformation curve forms a hysteresis loop when a beam is first loaded and then unloaded. This separation of the loading and unloading curves is due to energy absorbed by the metal and is observed even though the metal returns to its original shape. The theory has been advanced that if the hysteresis loop remains at a constant width throughout fatigue testing, regardless of that width, the specimen will not fail. If the width of the hysteresis loop does increase, however, the specimen will eventually fail (7).

It is belleved that fatigue failures start at points of Inhomogeneity within a metal. Most materials in which fatigue would be of concern cannot be made perfectly homogeneous so that they cannot be subdivided indefinitely without changing the properties. Hence the stresses that are computed for a specimen are an average of the total stress across any one section. There is 11 kely to be points throughout a specimen at which the stress is considerably larger than the computed average. The steel used in machines and structursl parts today is quite ductile and can adjust to these stress concentrations if the load is steady. If the load fluctuates, hovever, a crack 1s 11 kely to form at the point of stress concentration and the failure due to fatigue progresses from this $\operatorname{crack}(7)$.

Very little is known about the nature of fatigue cracks during their initial stages. Attempts have been made to observe the cracks in their early stages by microscope, but these have met with little success. There have been several theories suggested as to the cause of cracking under the action of repeated loading. Some believe that cracks are 
atarted at the surface of the metal and are caused by high stress concentrations at exlating 1rregularities (7). It has been reported that the highest real stress concentration 1s less than ten times and probably about nine times as grest as the average stress. Theoretically, a sharp crsck v111 produce an Infinite stress concentration (10). The stress concentration around s circular hole is about three times the average atress (11).

Regardless of where the cracks start, once they have started, they progress along the path of least resistance. Ultimate fallure may or cay not result, depending on the magaltude of the pulating load. As the load is applied, three things may hsppen:

1. The size of the crack is increased.

2. The eurvature at the end of the crack becomes less sharp and thus tends to relleve the atress concentration.

3. Slip and fracture occur at the end of the crack which tend to relleve stress concentration and strengthen the metal by strain hardening.

If the applied load does not exceed a certain limiting value, equilibrium v111 be established in which the reduction of cross-sectional area w111 be counterbalanced by a reduction in concentrated stress and strain hardening. If the applied load exceeds this limiting value the cracking proceeds unt11 fallure.

\section{Fatigue of Metals}

There have been several ilterature revievs of the fatigue of metals. The reault of two of these revievs are discusaed in References (7) and (8). It can be noticed from these revieva that investigators realized In the early pert of the 19 th century that a metal vould fail at a 
stress below the static ultimate stress if that stress vere reapplied repeatedily. It is felt that another reviev of the literature on the fatigue of metals vould yield no further information, but that a summarization of the findings of the early investigators vould be helpful to the underatanding of the basic concepts of fatigue. Such a summarization follows:

1. A definite fatigue 1 inlt can be establiabed for ferrous metala and ferrous alloya. At this fatigue limit an elbow is apparent in the $\mathrm{S}-\mathrm{N}$ diagram.

2. Most non-ferrous materials do not have a definite fatigue 1imit. There is no elbow in the S-N diagram and the curve continues to slope downward.

3. Flaws on the surface and discontinuities in the interfor of a material have a detrimental effect upon the fatigue strength of the materisl.

4. Speed of testing and teaperature have no effect upon the fatigue strength unlese the temperature is high. If the stress is applied at such a rate that the heat gain due to hysteresis cannot be dissipated, the rate of testing could effect the fatigue strength.

5. If a metal is repeatedly atressed below its fatigue 1 fmit, strain hardening will occur and the fatigue life of the material w111 be increased.

6. As the mean stress incresses, the range of atress which will endure a given number of cyclea decreases.

7. If fatigue teating is atopped and the specinen alloved to rest 
for a while, partial recovery will take place and the fatigue life w1ll be increased.

The fatigue strength of metals is best correlated with the ultimate tensile strength. Several investigators have attempted to establish relationships between fatigue strength and other properties of steel but these have not led to very satisfactory results $(8)$.

\section{Fatigue of Concrete}

In recent years several investigators have completed several extensive literature reviews on the fatigue of concrete. In 1927 Moore and Konmers published their text on The Fatigue of Metals which contained a chapter on the fatigue of cement and concrete (7). This chapter presented the tests and results of many investigators before that time. In 1958 Nordby published a paper summarizing the most important literature on the fatigue of concrete (5). In his litersture search, Nordby reviewed more than 100 publications including many in foreign literature.

The work reported in this thesis is part of a series of fatigue testing programs to be conducted at Purdue University. Previous to this study one was conducted by Antrim at Purdue University to determine the effect of entrained air on the fatigue properties of concrete $(12,13)$. Antrim included an extensive literature review in the write-up of his work (13). Since the available literature has been reviewed and summarized at least twice in the past few years, it is felt that the inclusion of another complete summary in this thesis would not be warranted. Instead, the conclusions dravn from the previous reviews will be presented along with a review of the literature which has been published since these reviews vere completed. 
The conclusions drawn by Antrim (13) in his review of literature are quoted below:

1. The early investigations indicate that there is a defiaite stress that is approximately 50 to 55 per cent of the ultimate static stress below which concrete can undergo fatiguing action indefinitely, and above which the number of cycles to fallure decreases as the stress increases.

2. There appears to be little variation in this linit that 1s due to type of testing (compression, flexure, and tension) and speed of testing.

3. Permanent set occurs during the earlier stages of the fatigue action. If the maximum stress is below the fatigue limit, the perasnent set reaches and malntalna a constant value. Stresses above the fatigue $11 \mathrm{l}$ t cause progressive deformation.

4. When the applied stress is below the fatigue limit, the modulus of elasticity reaches and maintains a constant value.

5. The repetition of a stress which is below the fatigue ind appears to increase the strength of concrete.

Nordby (5) goes further in summarizing the results of these same investigations and his conclusions are quoted below:

1. Under repetitive load the modulus of elasticity changes in various vays depending upon the intensity of load. The secant modulus decreases with repeated load; the slope of the stress-strain curve may decrease in the lower part of the curve and increase slightly in the upper portion to become concave upward.

2. Age and curing has a decisive effect on the fatigue strength. Inadequately aged and cured concrete is less resistant to fatigue than vell-aged and cured. concrete.

3. Rest periods seen to increase the endurance of concrete although test results are very scant.

4. Fatigue strength decreasea slightly vith leaner alxea and higher water cenent ratiou (dnta not exteno1ve). 
5. As the range of stress is decressed the upper limit of the stress (fatigue strength) is increased substantially. This phenomenon can be represented by the Modified Goodman Dlagram.

A summary of the results of the literature on the fatigue of reinforced concrete, taken from Nordby's paper is as follows:

1. Most fallures of reinforced beams were due to failure of the reinforeing steel. The fallures seemed to be connected with severe cracking and the possible stress concentration and/or abrasion connected these cracks. Beams critical in longitudinal reinforcement seemed to have an endurance limit of 60 to 70 per cent of the static ultimate strengths for one milition cycles.

2. Often times it was pointed out that the concrete in the compression zone behaves much the same way as axislly loaded compression specimens. There is certainly no assurance of this, since it is not true for static tests and of course there $1 \mathrm{~s}$ a strain gradient in the beam which does not exist in compression specimens. No fatigue compression failures were noted in any of the besms reported except those of LeCamus.

3. On occasion beams failed in diagonal tension fatigue but the real cause of fallure was obscured by bond and shear combination fallures. Tests have been reported in which beams have failed in shear in repested laads as low as 50 per cent of the ultimate strength. Data are very scarce on this phase.

4. Beams accumulate residual deflections under extensive fatigue loading much the same as plain concrete specimens; but recover somewhat during rest periods.

In sdaition to the conclusions quoted above on fatigue properties of plain and reinforced concrete, Nordby also drew conclusions on the fatigue properties of prestressed concrete which are as follows:

1. In none of the tests did concrete fall by fatigue. The current working stresses seem to give adequate protection in this regard.

2. Fatigue fallure of stressing wires or strands was the cause of all fallures reported. These fallures seem to be related to the extent and severity of the cracks. 
3. Bond fallures were rare and found only under unususl circumstances, 1.e., short beams, short shear span.

4. The ultimate strength of prestressed beams for static loads vas unaffected by repetitive loading if they did not fail by fatigue.

5. Safety factors seemed to be approximately "two" against fatigue fallure for most of the beams tested.

6. Prestressed beams seemed to be superfor to conventions 1 beams for resisting fatigue losding. In fact, in a recent paper, Eckberg and Walther anslytically verified this by relating the modified Goodman diagram of both the concrete and prestressing steel to the theoretical stresses in both types of beams.

Several papers have been written on the fatigue properties of concrete since these extensive literature reviews were completed. Antrim and Mclaughiln found that intentionally entrained air in a concrete did not affect the fatigue properties of the concrete (12). It was apparent from their tests, however, that more consistent fatigue results could be obtained with alr-entrained concrete than with non-airentrained concrete. These findings were the results of fatigue tests on 65 plain concrete cylinders 3 inches in diameter and 6 inches in length.

In 1958 McCall sttempted to show a correlation between the $8-\mathbb{N}$ curve and the probability of fallure (14). McCall conducted fatigue tests on $3 \times 3 \times 14-1 / 2$ inch plain air-entrained concrete beams. The beams were tested unt1l they had failed or endured 20 million repet1tions of load. He concluded that the $S-\mathbb{N}$ curve for concrete did not level off in the neighborhood of 20 million cycles and that the probability of fatigue fallure at 20 million cycles is slightly less than $1 / 2$. A graphical relationship between the $8-N$ curve and the probability of failure is shown. 
Assimacopoulos, Warner, and Eckberg have reported results of tests on 34 plain concrete cylinders (15). Twenty-five 2 inch by 4 inch cylinders were tested in direct compression at a speed of 9,000 cycles per minute. Nine other cylinders of the same size were tested at a rate of 500 cycles per minute. Specimens were tested at different minimum and maximum stress levels st each speed and the tempersture changes of the specimens were recorded as the tests progressed. No appreciable temperature change was measured in the cylinders tested at 500 cycles per minute but an increase in temperature of nearly $100^{\circ} \mathrm{F}$ was measured in the specimens tested at 9,000 cycles per minute. The tempersture Increase was generally in direct proportion to the range of stress variation but no adverse effect of this temperature increase could be seen in the test results. The authors concluded that, although the amount of data vas quite small, no difference in the fatigue properties could be detected for the rates of loading used.

Several recent tests have been made to determine the fatigue action of reinforced concrete beams. Chang and Kesler tested 25 beams having a $4 \times 6$ inch cross-section and contalning 1.02 per cent reinforcing steel (16). The beams were loaded at the third points of a 60 Inch span at a rate of 440 cycles per minute. The beams of this study displayed four different modes of fallure lavolving relnforcement, diagonal cracking, and shear-compreasion.

Stelson and Cernica tested eleven over-reinforced beams (17). They determined that the fatigue limit of these beams was between 60 and 65 per cent of the static ultimate load. The beams failed in diagonal tension. 


\section{PURPOSE AND SCOPE}

The purpose of this study was to determine the fatigue characteristics of lightreight aggregate concrete and, further, to investigate the effects of varying the strength and aggregate proportions on this property. Finally, 1t was the purpbse of this study to determine the fatigue limit of lightweight aggregate concrete if the data indicated that one existed.

Specimens were made from concrete of two different proportions. One was designed for a high strength and relatively high percentage of fine material. The other mix vas designed for a lower strength and was designed for a high percentage of coarse material. Both mixes were designed for the same slump and same percentage of total air. Batches were made periodically so that specimens were tested at nearly the same age. Specimens were tested from each batch at stress levels of $40,50,60,70$, and 80 per cent of the static ultimate compressive strength of the respective batch. 


\section{TESTING PROGRAM}

The testing program was divided 1nto two parts. In the first part tests were conducted on concrete designed to have a static compressive streagth of 3,500 psi. This concrete was called the low-strength concrete and will be referred to as the IL series. The second part consisted of conducting tests on concrete designed to have a static compressive strength of 6,000 ps 1 . This concrete was called the highstrength concrete and will be referred to as the HL series. Bach series was made up of five batches of concrete and from esch batch 30 cylinders 3 inches in diameter and 6 inches in length were cast.

All of the cylinders from any batch were cured for 28 days, after which, about one-half of them were placed in an oven at $105^{\circ} \mathrm{C}$ for about four days to prevent further hydration. The remaining cylinders were placed in storage at room conditions so that they could be tested at a future date. The object of the future testing 18 to determine whether or not drying of the specimen in an oven will affect the fatigue properties.

After the drying was completed the specimens were removed from the oven and capped. Five specimens were then chosen at random and tested in static compression so that an estimate of the batch strength could be made. Fatigue tests were conducted on about five of the remaining cylinders at various stress levels. If any specimens from a batch remained after the fatigue testing was completed, they were tested in static compression to determine whether any change in the batch strength 
occurred during the fatigue testing.

Tests were also conducted on one batch from the Hl. serles to deternine if the rate of load application had any effect on the fatigue properties of lightweight concrete.

\section{Materials}

The aggregate used in this study was an expanded shale produced In a rotary $\mathrm{kiln}$. It was shipped fron the producer in central Indiana to Purdue University in bags containing ageregate of two sizes. The gradations of these two aggregate sizes are shova in Tables 1 and 2.

Since the physical properties of expanded shale, such as specific gravity and absorption characteristics, are extremoly variable, the use of these properties in the design of the concrete was not practical and these properties were not determined.

Type I portland cement manufactured in central Indlana was used in both mix designs. All of the cement used in this study came from one clinker batch (1aboratory designation 315) and 1t was assumed that its characteristics did not vary significantly.

Darex was added to the mixing water of all batches as an airentraining agent.

\section{Mix Design}

The mixes were designed in accordance with the ACI "Proposed Reccmended Practice for Selecting Proportions for Structural Lightweight Concrete," (18) except that the specifle gravity factor was not coaputed.

The coabination of fine and coarse aggregate that would yleld the maximu density (mininum voids) vas deternined by plotting the unit 
Table 1

GRADATION OF COARSE AGGREGATE

\section{Sleve S1ze}

3/8 1nch

No. 4

No. 8

No. 16

No. 30

No. 50

No. 100

No. 200

\section{$\underline{\text { Per Cent Passing }}$}

$$
\begin{array}{r}
100.0 \\
30.1 \\
2.9 \\
1.9 \\
1.8 \\
1.7 \\
1.6 \\
1.4
\end{array}
$$

Table 2

\section{GRADATION OF FINE AGGRBGATE}

Sieve Size

No. 4

No. 8

No. 16

No. 30

No. 50

No. 100

No. 200
Per Cent Passing

$$
100.0
$$

93.3

71.7

48.2

27.1

13.2

7.2 
veight against the percentage of fines. This plot is shown in Figure 2. It was decided that 60 per cent of the aggregate should consist of the finer fraction in the LL series and 65 per cent of the aggregate should consist of the finer fraction in the HL series.

Trial mixes were used to determine the required amount of water and the proper cement factor. The amount of Darex needed to produce the design air content was also determined from the trial mixes.

The low-strength concrete was designed for a strength of 3,500 psi, a slump of three 1nches, and an sir content of seven per cent. A cement factor of 5.8 bags per eubic yard was required to produce the design strength.

The high-strength concrete was designed for a strength of 6,000 psi, a slump of three inches, and a total air content of seven per cent. A cement factor of 9.6 bags per cubic yard was required to produce the design strength.

\section{Mixing Procedure}

Both the fine and coarse aggregates vere stored in covered barrels in the laboratory. The aggregate was sleved so that it could be stored in four main size groups for better control of gradation. The coarse aggregate was stored in two barrels, one containing material retained on the No. 4 sieve and the other containing material passing the No. 4 sieve and retained on the №. 8 sieve. The fine aggregate was stored in two barrels, one containing material retained on the No. 16 sieve and the other containing material passing the No. 16 sieve.

It has been found by several investigators that the moisture content of lightwelght aggregate immediately prior to mixing has little 


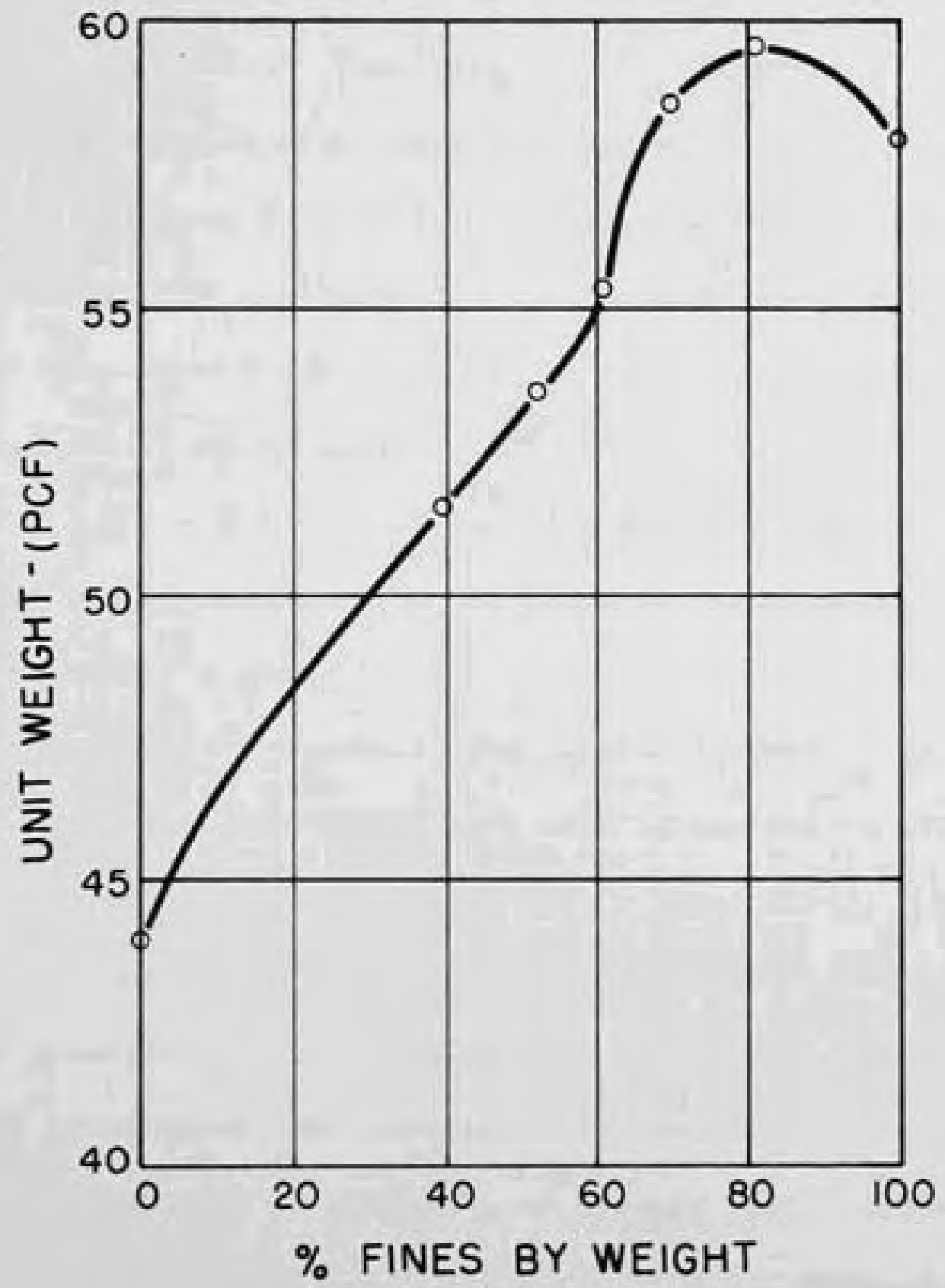

FIGURE 2. MAXIMUM DENSITY CURVE 
effect on the compressive strength of the concrete (18). For this reason no effort was made to saturate the aggregate or determine its water content before mixing.

The mixing was done in a 1-1/2 cublc foot capacity, Lancaster, tub type, counter current mixer. Two-thirds of the mixing water was placed In the mixer slong with the fine and coarse aggregate and allowed to mix for five minutes. It was felt that this mixing period would satisfy the initial absorption of the aggregate and thus produce more uniform results. The cement was then added and allowed to mix for one minute with the moistened aggregate. Finally the rensinder of the mixing water and the Darex were added and the batch was mixed for an additionsl two minutes. The mixing water was adjusted during the final two'minutes so that the slump would be about 3 inches.

Three measurements were made on the plastic concrete. Slump, unit weight, and air content measurements were made in accordance with ASTM Designations: C 143-58, C 138-44, and C 173-58 respectively. The concrete used for these tests was discarded so that no chance of contaminating the material left in the mixer would result. In the case of the unit weight messurement, the one cubic-foot measure was replaced by a measure having a capacity of one-tenth of a cublc foot because the size of the batch was suall. Modifications of the air content measurements are described in the following section.

\section{Air Determination}

The alr content of the low-strength concrete was determined by the gravinetric method as described in ASTM Designation: C 173-58. When this method is used a given amount of plastic concrete is placed in a 
device called a Rollameter. The Rollameter is then filled vith water and rolled until the air in the concrete is displaced by the added water. The laboratory vas not equipped with a Rollameter st the time this study was in progress but a PCA type meter was avallable which vas similar to the Rollameter in every vay except size.

A borroved Rollameter vas used to deternine the alr content of the LL series. A1r content vas also determined for the LL series by rolling the PCA type seter in a fashion simlar to that used for the Rollameter.

The PCA type aeter was callbrated with the Rollaneter fron air content deterninations made on the LL series and several trisi mixes. Air content determinations on the high-atrength concrete vere made with the calibrated PCA type meter.

\section{Molding and Curing of Specimens}

Thirty specimens, 3 inches in diameter and 6 inches in length, were cast from each batch of concrete in accordance with ASTM Designation: C 192-57. Since small molds were used, 1t was necessary to replace the 5/8-1nch diameter rod by a 3/8-inch diameter rod.

Inmediately after casting, the specimens vere covered vith metal pans and moistened rags to prevent evaporation while they vere stored at room temperature in the molds for 24 hours. The specinens vere then renoved from their molds and stored for 27 days in a satursted lime solution at a temperature of about $70^{\circ} \mathrm{F}$.

\section{Drying}

At an age of 26 days, all of the specimens vere resoved fron the esturated line solution. Approximately one-balf of the cylinders froa each batch vere placed in an electric oven and alloved to dry at $105^{\circ} \mathrm{C}$ 
until they reached constant weight. The remaining specimens from esch batch were placed on shelves in the laboratory to dry at room temperature. Oven drying usually required four days.

\section{Capping}

After the specimens were removed from the drying oven, they were allowed to cool for 24 hours before capping. Caps were then placed on each end of all cylinders in the device shown in Figure 3. A sulfurcarbon compound (trade named Vitrobond) was used for the capping material. The capping material was heated to approximately $275^{\circ} \mathrm{C}$ before being poured into the molds. The caps had a thickness that varied from $1 / 16$ of an fnch to $3 / 16$ of an fnch, depending upon the end conditions of the specimens.

An attempt was made to arrange the testing prograni so that fatigue tests could be started within four or five days after oven drying. Several power failures and machine break-downs interrupted the testing program, however, so that a time lag of from two days to two weeks occurred between capping and fatigue testing. It is assumed that this time lag had no effect on the fatigue properties of the concrete.

\section{$\underline{\text { Static Compression Tests }}$}

Static compression tests were conducted on five randomly chosen specimens from esch batch to estimate the ultimate strength of the batch. These tests were performed in a Riehle screw-type testing machine with a Graham variable speed drive. The machine had a capacity of 50,000 lbs. snd the no-load head speed was set at 0.05 inches per minute as prescribed in ASTM Designation: c 39-56T. 


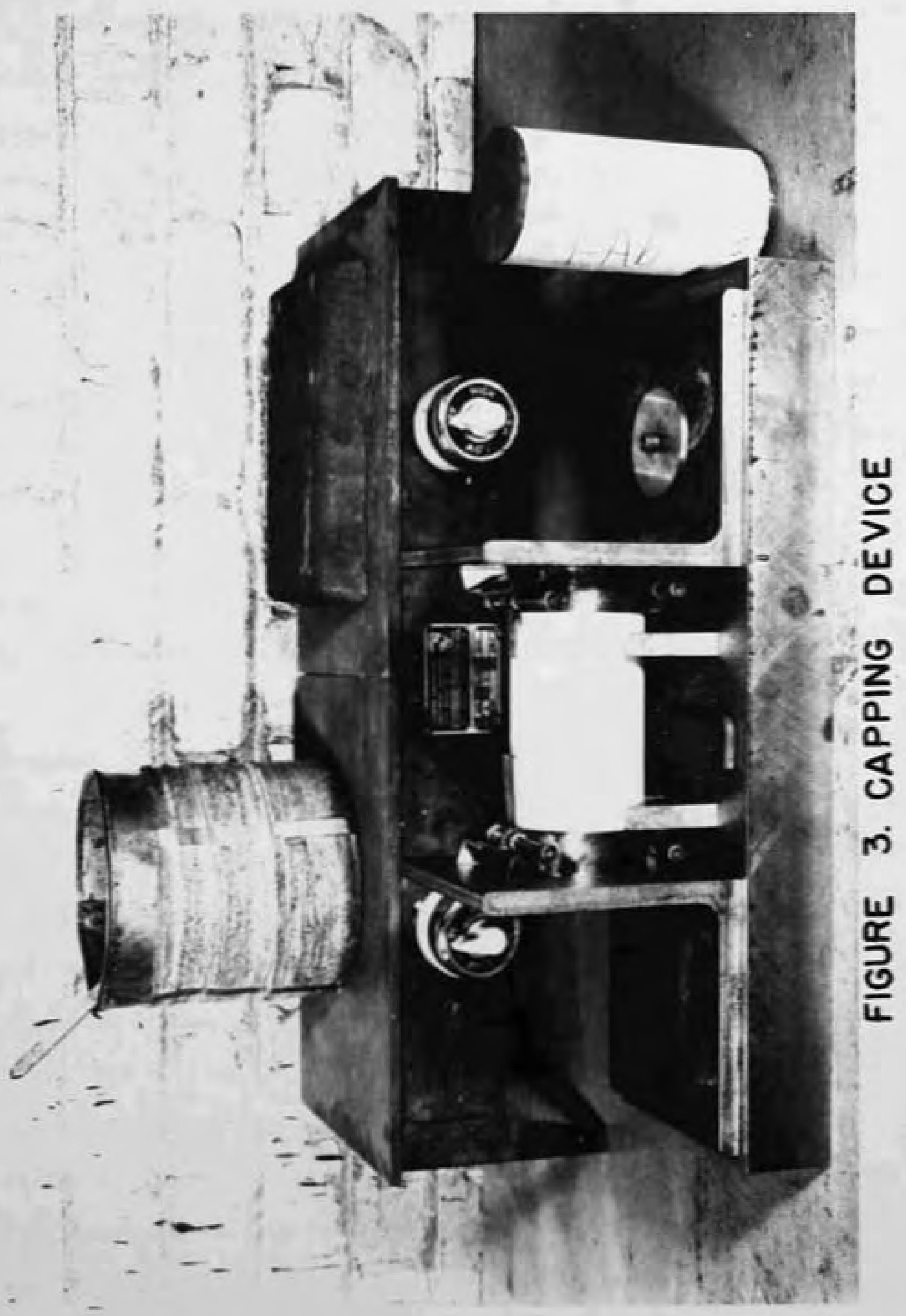


It was originally planned to teat the static compression specimens one day after cappling. After several power fallures delayed the fatigue teating progran, however, it vas decided that the static coupression tests should be delayed until fatigue testing vas sbout to begin. Thus the age at which static tests on the specinens vere conducted varied considerably as shown in Tables 8 through 17 of Appendix A.

\section{Patigue Tests}

sight specimens vere chosen at randon from each batch to be tested under a pulasting load. These teats vere conducted at 40, 50,60,70, and 80 per cent of the estimated static conpressive strength of the batch. Specimens were tested in direct compression only and a minimum stress of between 70 and $170 \mathrm{ps} 1$ was malntained on all specimens to eliminate any possibility of Impact. The maintaining of a constant or near constant minimum load required the range of stress to vary between stress levels. Th1s variable vas not considered, hovever.

In soue cases, vhere pover fallures or testing achine break-downs vere frequent, it vas not possible to test specimens froe each batch at all stress levels. In the BL seriea, no specimens vere tested at the 40 per cent stress level after the firat two batches had been tested and it vas found that at 40 snd 50 per cent of the static ultimate strength specimens endured more than ten aillion cycles of load. On this basis it vas felt that further testing of specimens at the 40 per cent atress level vould yleld no additional information. Ten million cycles was selected at the beginning of the study as the maximum number of cycles any specimen would be permitted to endure. The data at the 40, 50, and 60 per cent stress levels are not complete (fewer than f1ve specinens vere tested to fallure) because some or all of the specimens endured ten million cycles. 
Other causes of incoraplete data were power failures and machine break-downs which ruined all of the remaining specimens in a batch. Once the testing of a specimen had stopped, the specimen was discarded and a new specimen was tested. No sttempt was made to test at the 90 per cent stress level because it was found in a previous investigation that, with the equipment avallable, the specimen would fall before the load could be established (13).

\section{The Krouse-Purdue Machine}

At the beginning of this study only the Krouse-Purdue fatigue testing machine was available. This machine is of the constant deflection type which derives its force from hydraulic pressures acting on a piston. The Krouse-Purdue machine is shown in F1gure 4.

Two components of load are applied by the Krouse-Purdue Mach1ne. The first is an average prelosd which is proportional to the difference in average pressures existing at opposite ends of a hydraulic cylinder. This load is automatically controlled by a hydraulic make-up pump. The pulsating losd is controlled by varying the throw of an eccentric crank. This causes a loading which is alternately larger and smaller than the preload. Both loads can be adjusted while the machine is in operation. A simplified line disgram of the Krouse-Purdue machine is shown in Figure 5 .

The apecimen is held in place by an adjustable load screw which extends through the upper head of the machine. A reversible motor is used to adjust the load screw and provide the required testing space. When the required testing space has been eatablished, a locking nut is 


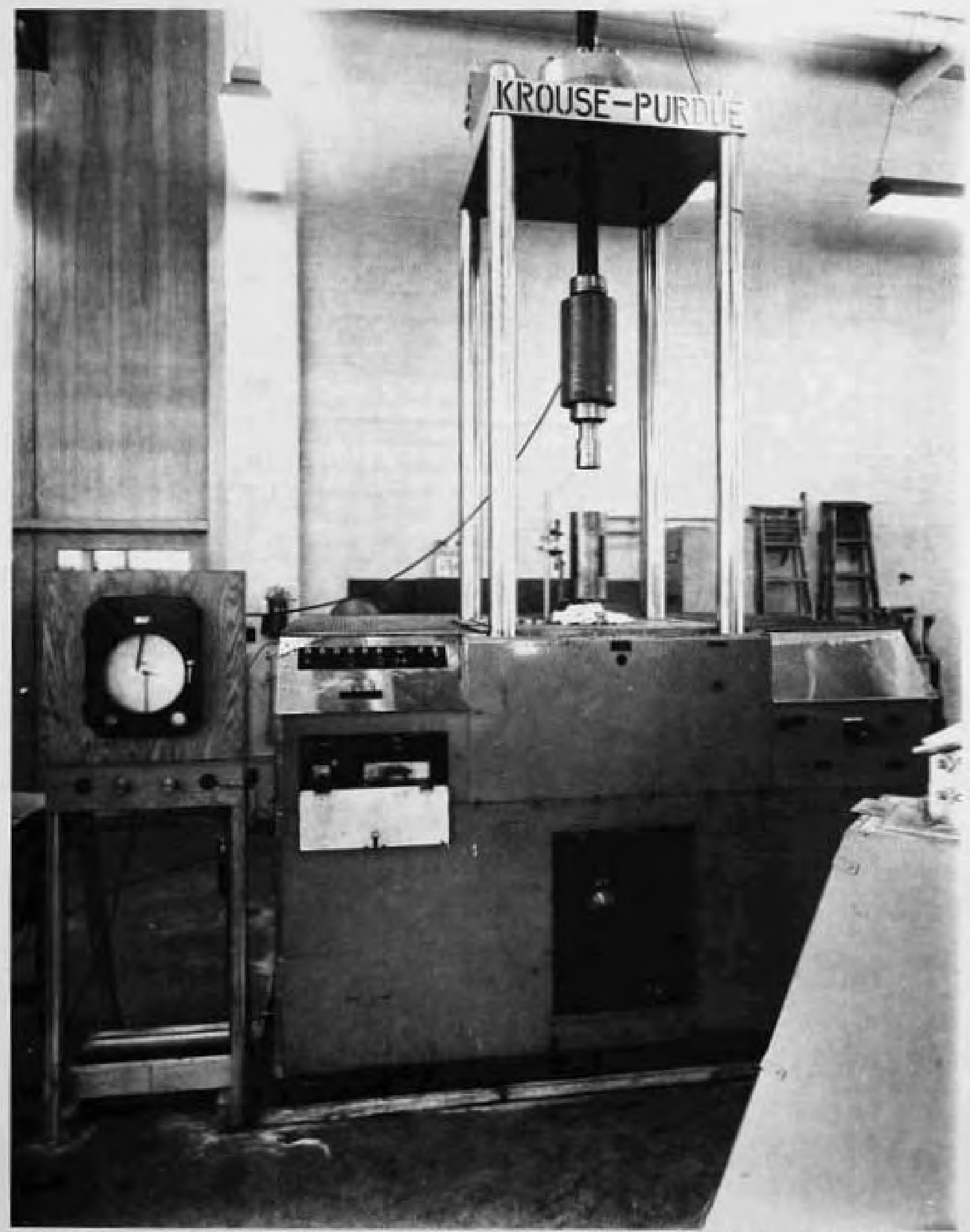

FIGURE 4. KROUSE-PURDUE FATIGUE MACHINE 


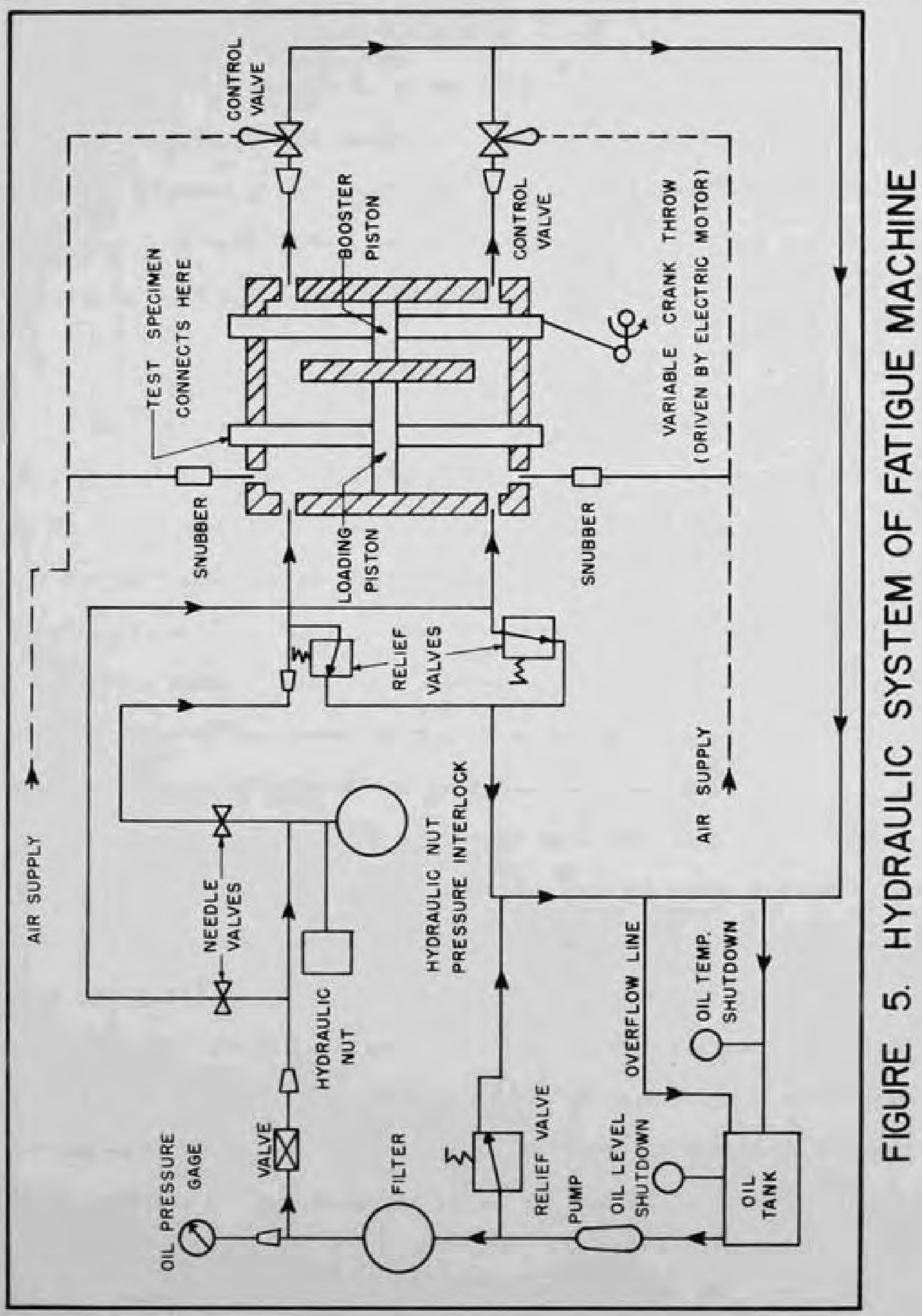


closed on the screw by means of a hydraulic cyllnder. A close-up of the specimen holder and automatic shut-down device is shown in Figure 6.

The Krouse-Purdue machine has a capacity of $\pm 60,000$ 1bs. and operates at 1,000 cycles per minute. Loads are measured by an electronic system which is actuated by a Baldwin-Lima-Hamilton type U-1, SR-4 load cell. The load cell is an integral part of the loading screw. Loads can be messured to within \pm 100 lbs.

\section{The Amsler Machine}

At about the mid-point of the fatigue testing program an Amsler fatigue testing rachine was installed in the materials testing laboratory at Purdue University. This machine is based on the same principle as the Krouse-Purdue machine except that the loading Jacks are sepsrated from the pulsator. Tubing connects the pulsator and the loading Jack. The preload of the Amsler machine is the minimum load to be applied and the pulsator increases the load from this minimum to the desired maximum. Loads are transmitted by hydraulic pressure through the tubing to the load jack which is mounted on a specially built frame. The jack develops its force by pushing against the frame and the concrete specimen which is placed on a bearing plate on the floor. The pulsator Is shown in Figure 7 and the loading jack is shown in Figure 8.

This machine has a capacity of $110,000 \mathrm{lbs}$. and can operate at speeds of either 250 cycles per minute or 500 cycles per minute. Losds are measured by two gauges mounted in the hydraulic systerl of the machine. It 1 s possible to read these gauges to the nearest $100 \mathrm{lbs}$. 


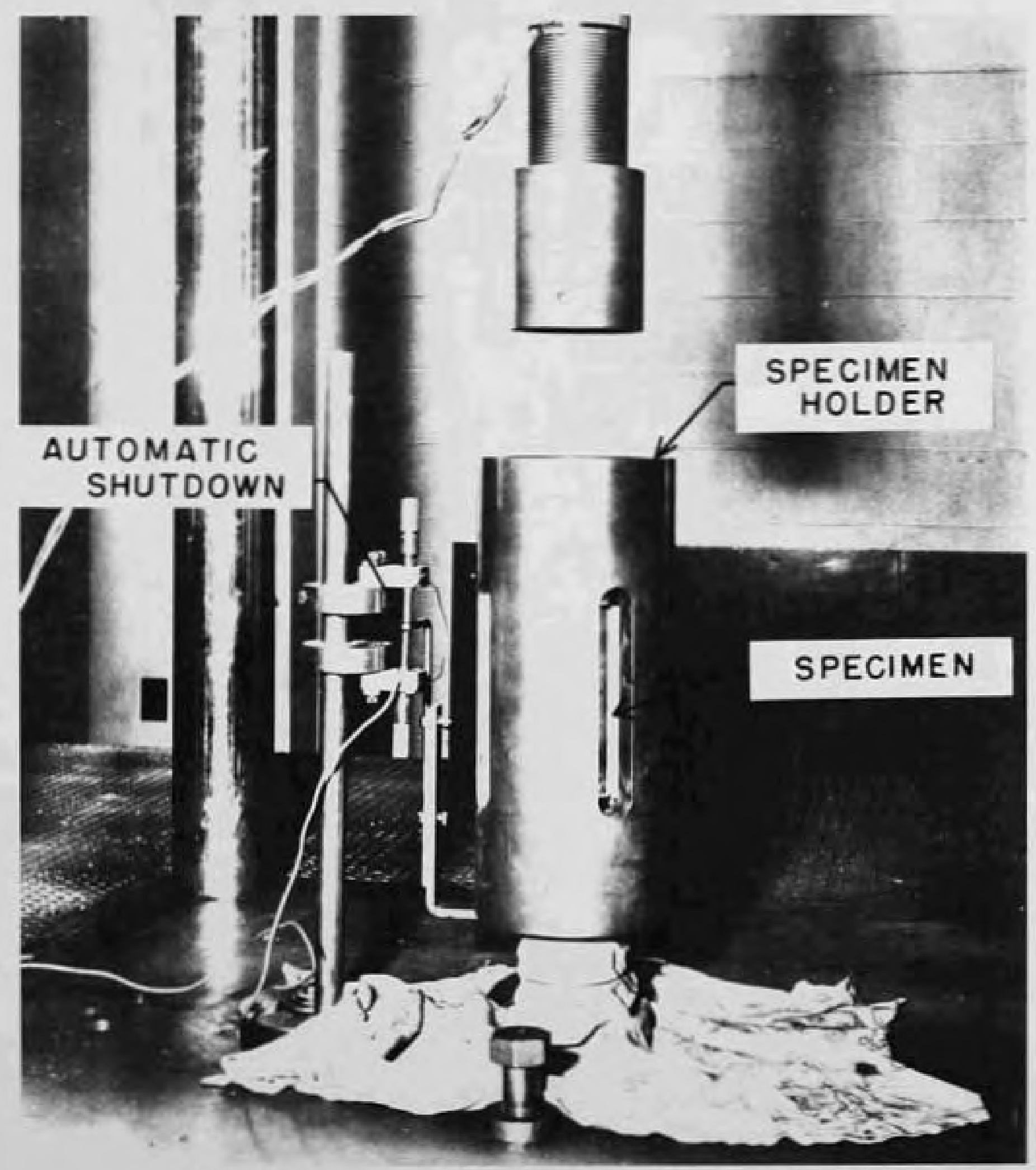

FIGURE 6. SPECIMEN HOLDER 


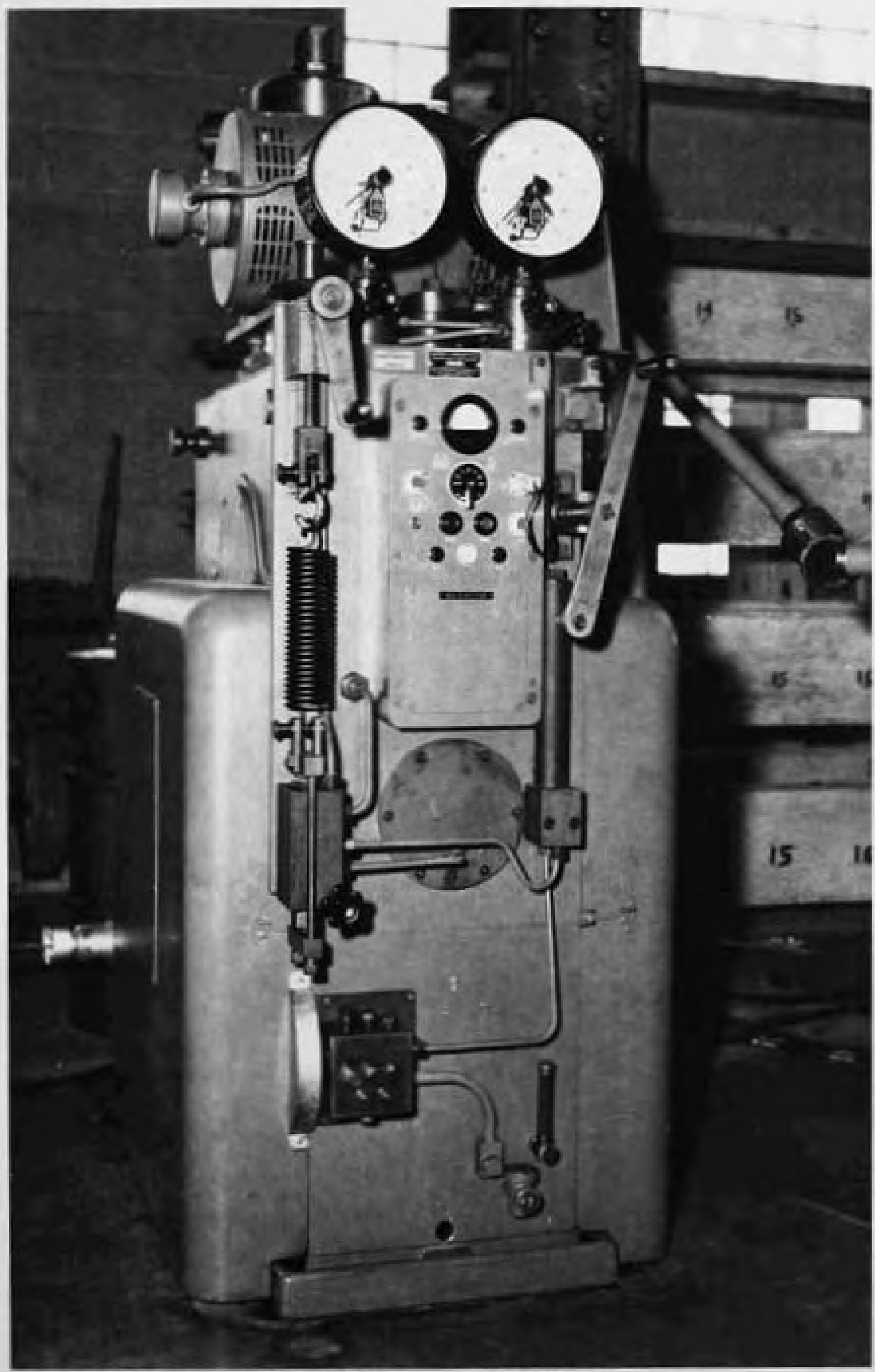

FIGURE 7. PULSATOR 


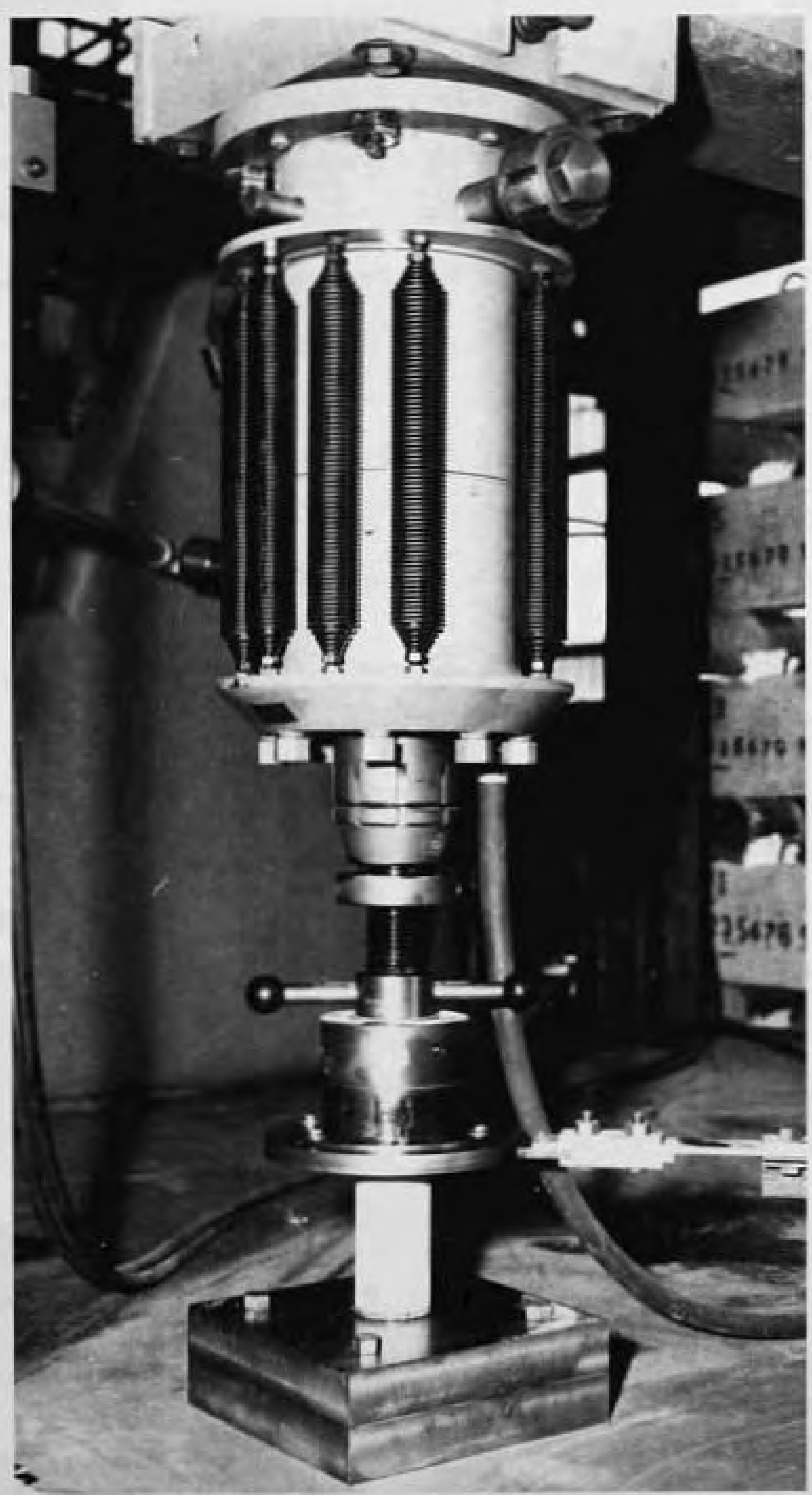

FIGURE 8. LOADING JACK 


\section{Fat1gue Testing at Different Speeds}

Since the Krouse-Purdue machline tested at a rate of 1,000 cycles per minute and the Amsler machine vas used at the maximum speed of 500 cycles per minute, it was felt that a test should be carried out to see if this varistion would affect the fatigue test results. Batch HL 1 vas selected for this purpose and it vas decided to test as many cylinders as possible in each machine. All of the specimens from batch HL 1 were, therefore, oven-dried. Fatigue tests were conducted on these specimens, at the 80 per cent stress level only, in the same way as they were in all other batches except that one-half of the specimens were tested in each machine.

\section{Static Compression Tests to Determine Increase in Strength}

A period of at least two weeks was required to complete the fatigue testing on any one batch. It, therefore, seemed reasonable to determine the increase in strength which took place over this period. After fatigue testing had been completed the remaining specimens in the batch were tested in direct compression if enough specimens remained to make a reasonable estimate of the batch strength. The procedure used was identical to that used when the first estimate of batch strength was made. 


\section{DISCUSSION OF RESULTS}

The discussion of the results of this study has been divided into three parts. The first part is concerned with physical properties of the plastic concrete and the static tests on the hardened concrete. The discussion of the fatigue testing data is presented in the second part and the third part is concerned with the comparison of the results of this study with the results of a previous study.

\section{Anslysis of Mix Dats}

Since each series consisted of a group of five separately mixed betches, it was necessary to estimate the properties of each series from the properties of the individual batches. The purpose of this study was to compare the fatigue properties of the two classes of concrete but before this could be done, it was necessary to show that other properties of the two concretes were different and that each batch within a series was not different than the other batches within the series.

A statistical procedure known as the analysis of variance was used to test for any significant difference between the aversge bstch strengths (19). When using this procedure, two estimates are made of the total variance in individusl specimen strengths, these being the sum of the Individual variance within each batch and the variance between batches. It is known that the ratio of two variances follows an F-distribution. If the calculated ratio of these two variances is less than the theoretical F-value at some significance level there is no statistically significant 
difference between the individual batch averages and the apparent difference can be attributed to chance. If the calculated F-value is larger than the theoretical F-value at some significance level then there is a statistically significant difference between the batch means.

The analysis of varlance is valid only if the individual values follow a normal distribution and if the batch variances are equal. It is assumed in this analysis that the individual strength meesurements are normally distributed. When this assumption is not satisfied the consequences are not great (20). Bartlett's test was used to test for a significant difference in batch varlances (19). This test assumes that the value of $\mathrm{M} / \mathrm{C}$ computed in Tables 18 and 20 of Appendix B follows a chi-squared distribution.

\section{Low-Strength Concrete}

The data for the low-strength concrete are shown in Tables 8 through 12 in Appendix A and summarized in Table 3. These data are discussed first in terms of homogeneity of variance and then in terms of strength, slump, and air content.

Mix strength. Bartlett's test for homogeneity of variance showed that there is no significant difference between the variances of the five batches. It can be seen from Table 18 of Appendix B that the calculated value of $\mathrm{M} / \mathrm{C}$ of 1.58 was much lower than the theoretical value of 9.49 .

On the assumption of normality and equal variances, a one-way analysis of variance was made on the mean batch strengths. The calculated value of F from this analysis was 6.44 which is much larger than the theoret1cal value of 2.87 as shown in Table 19 of Appendix B. Therefore, 
Table 3

PHYSICAL PROPERTIES OF CONCRETE

LON-STRENGTH (LL) MIX

\begin{tabular}{|c|c|c|c|c|}
\hline $\begin{array}{c}\text { Batch } \\
\text { Designation }\end{array}$ & $\begin{array}{c}\text { A1r } \\
\text { Content } \\
\text { Percent }\end{array}$ & $\begin{array}{l}\text { Slump } \\
\text { Inches }\end{array}$ & $\begin{array}{l}\text { Average U1 } \\
\text { After Oven } \\
\text { Dry1ng } \\
\\
\text { p81 }\end{array}$ & $\begin{array}{c}\text { 1mate Strength } \\
\text { After Fatigue } \\
\text { Testing } \\
\text { ps1 }\end{array}$ \\
\hline LI 1 & 6.5 & $2-5 / 8$ & 3500 & 3280 \\
\hline LI 2 & 6.1 & $2-3 / 8$ & 3820 & None tested *** \\
\hline LL 3 & 7.6 & $3-1 / 4$ & 4060 & 3900 \\
\hline LL 4 & $7 \cdot 5$ & 3 & 3880 & None tested \\
\hline LL 5 & 6.2 & $1-1 / 2$ & 3530 & None tested \\
\hline
\end{tabular}

* Specimen age when tested was 34 days

* Specimen age ranged from 51 to 58 days

*** All specimens were used in fatigue testing 
there is reason to belleve that the batch strengths of the LL series are not equal. In an effort to determine which batch means were different, a Neman-Kuels sequential range test was applied to the data. This test compares the difference in means with a significant range. If the difference in means is larger than the significant range it can be inferred that the means are significantly different. The Newman-Kuels test indicates that the mesn of batch LL 3 is significantly different from the means of batches LL 1 and LL 5 as shown in Table 19 of Appendix B. No satisfactory explanation can be offered to account for this difference.

The average strength of the 10w-strength concrete was estimated to be 3,760 psi as shown in Table 22 of Appendix B. This value is the average of all of the specimens tested statically before fatigue testing in the LL series.

Air Content and Slump. Since an effort was made to control the slump and air content of the individual batch mixes, these properties are not likely to be normally distributed. For this reason only the mean, standard deviation, and the coefficient of variation have been calculated for the plastic characteristics of the mix. The coeficient of variation is the standard deviation expressed as a percentage of the mean. It is designated as $C$ in the following table.

\begin{tabular}{lcccr}
\hline Property & $\begin{array}{c}\text { Number } \\
\text { of } \\
\text { Batches }\end{array}$ & $\bar{y}$ & s & c \\
\hline Slump & 5 & $2.51 \mathrm{n}$. & 0.61 & $24 \%$ \\
Air Content & 5 & $6.8 \%$ & 0.64 & $9 \%$ \\
\hline
\end{tabular}


Summary. Most of the preceding analyses vere based on the assumption that the data followed a normal distribution when actually the shape of the distribution was not known. It is felt, however, that the lack of normallty, If any exists, will affect the results only slightly and that the following conclusions may be drawn:

1. The variance of the batches of low-strength concrete were not significsntly different.

2. The average strength of batch LL 3 is significantly different than batches LL 1 and LL 5 .

3. The best est1mate of the average strength of the low-strength series is 3760 ps1. with a standard error of $294 \mathrm{ps} 1$.

4. The average slump of the low-strength series was 2.5 inches and the coefficlent of variation is 24 per cent. This coefficient is much larger than the desirable value of 5 per cent usually strived for in laboratory work.

5. The average air content of the low-strength series is 6.8 per cent with a coefficient of variation of 9 per cent.

\section{High-Strength Concrete}

The data for the high-strength concrete are shown in Tables 13 through 17 of Append1x A and are sumarized in Table 4. Table 4 includes the properties of batch HL 1 which are not shown in Appendix A. This batch was used to determine the effect of the rate of load application on the fatigue properties of the concrete, and will not be included in the subsequent analyses. The low-strength series was first tested for homogenelty of variance of the batch strengths and then for difference in batch mean strengths. Properties of the plastic concrete 
Table 4

PHYSICAL PROPERTIES OF CONCRETE

HIGH-STRENGTH (HL) MIX

\begin{tabular}{ccccc}
\hline $\begin{array}{c}\text { Batch } \\
\text { Designation }\end{array}$ & $\begin{array}{c}\text { Air } \\
\text { Content } \\
\text { Percent }\end{array}$ & $\begin{array}{l}\text { Slump } \\
\text { Inches }\end{array}$ & $\begin{array}{c}\text { Average Ultimate Strength } \\
\text { After Oven } \\
\text { Drying }\end{array}$ & $\begin{array}{c}\text { After Fstigue } \\
\text { Testing } \\
\text { psi }\end{array}$ \\
\hline HL 1 & 6.8 & $2-3 / 8$ & 5130 & None tested *** \\
HL 2 & 6.6 & $2-1 / 8$ & 6310 & None tested \\
HL 3 & 6.5 & $2-3 / 8$ & 6360 & None tested \\
HL 4 & 6.3 & $1-7 / 8$ & 6360 & 6180 \\
HL 5 & 6.8 & 3 & 6260 & None tested \\
HL 6 & 7.0 & $2-3 / 4$ & 6010 & 5790 \\
\hline
\end{tabular}

- Specimen age ranged from 44 to 69 days

* Specimen age ranged from 84 to 94 days

** All specimens were used in fatigue testing 
are also discussed.

Mix Strength. Bartlett's test for homogeneity of variance indicates that there is no significant difference between the variance of the individual batches. The calculated value of $\mathrm{M} / \mathrm{C}$ was 1.39 which is much smaller than the theoretical value of 9.49 . Table 20 of Appendix B shows the calculations used in this test.

The one-way analysis of variance indicated that, for the highstrength concrete, no significant difference existed between the individual batch means. The calculated $F$ value of 1.02 was considerably lower than the theoretical value of 2.87 as shown in Table 21 of Appendix B.

The average strength of the high-strength concrete was estimated to be $6,260 \mathrm{ps} 1$ as shown in Table 22 of Appendix B. This value is the average of all specimens tested before fatigue testing of the HL serfes.

A1r Content and Slump. As in the case of the low-strength concrete only an estimate of the mean, standard deviation, and coefficient of variation have been calculated for the slump and alr content. The results of these calculations are shown in the following table.

\begin{tabular}{lcccc}
\hline Property & $\begin{array}{c}\text { Number } \\
\text { of } \\
\text { Batches }\end{array}$ & $\bar{y}$ & S & C \\
\hline Slump & 5 & 2.4 & 0.41 & $17 \%$ \\
Air Content & 5 & 6.5 & 0.35 & $5 \%$ \\
\hline
\end{tabular}

Summary. The following conclusions can be drawn from the above analysis of the high-strength concrete data, assuming that the data 
follow a normal or nearly normal distribution:

1. The variances of the individual batches of high-strength concrete were not significantly different.

2. The average strength of the individual batches of high-strength concrete were not significantly different.

3. The best estimate of the average strength of the high-strength series is 6,260 ps1. with a standard error of 329 psi.

4. The average slunp of the high-strength series was 2.4 inches with a coefficient of variation of 17 per cent. This coeffic1ent is much larger than the desirable value of 5 per cent usually strived for in laboratory work.

5. The average a1r content of the high-strength series was 6.5 per cent with a coefficient of variation of 5 per cent.

\section{Comparison of Series}

The two mix designs were compared statistically to see if they did represent two different populations as planned. The variance of each series is given along with the series mean and the number of observations in Table 22 of Appendix B. The variances shown in this table are the total sum of squares divided by the corresponding degrees of freedom show in Tables 19 and 21 of Appendix B multiplied by 100 . The ratio of these two variances was calculsted to be 1.25 which is less than the theoretical F-value of 1.98 . Hence, at the 5 per cent significance level there is no resson to belleve that the series variances are different.

The theoretical F-value at the 25 per cent significance level is 1.32 which 18 st111 larger than 1.25. It 1s, therefore, reasonable 
to assume that the variances are equal for the purpose of the $t$-test between series mesn strengths. As shown in Table 22 of Append1x B, the calculated $t$-value was 28.299 which is much larger than the theoret1cal value of 2.064 . The results of this analysis indicates that the two series represent two different populations, but the populations have the same varlance.

By inspection it can be seen that the magnitudes of slump and air content are about the same for each series. The variation of these properties is larger in the low-strength series. The concrete in both series experienced some bleeding immediately after it was placed in the molds. It was noticed that in the high-strength series there was less bleeding than in the low-strength series. This can be expected because the low-atrength concrete contalned a larger proportion of coarse aggregate and was a harsher $\mathrm{mix}$. Since it was planned to test concretes representing two different populations, these differences in plastic characteristics are assumed to have no significant effect on the results. Conclusions which can be drawn from the analysis of mix data are as follows:

1. The variances of the batch strengths were not significantly different in either the high-strength or low-strength concrete.

2. The batch means were signiflcantly different in the low-strength series but vere not signiflcantly different in the high-strength series.

3. The total variance of the low-strength series was not significantly different than the total varlance of the high-strength ser1es. 
4. The average strength of the high-strength concrete was significantly different than the sverage strength of the low-strength concrete.

5. The slump and air content of the concrete appear to be about the same for both series. The variation of these properties between batches was greater in the LL series.

6. Concrete in both the HL series and the LL series experienced bleeding when placed in the molds. The bleeding was more severe in the LL series.

\section{Erfect of Age on Strength}

Since the strength of concrete may increase with age, it seened necessary to check for any gain in strength that may have occurred during the time required for fatigue testing. Even though all specimens were oven-dried to preclude this strength gain, it was felt that addtional information should be collected.

Two batches from each series contained an adequate number of specimens renaining after fatigue testing to give a statistically sound estimate of the average batch strength. The batches used for this test were LL 1 and LL 3 in the low-gtrength series and HL 4 and HL 6 in the high-strength series. The second estimate of the average batch strength was made and compared to the original batch strengths in Tables 23 through 26 of Appendix B.

The variances of the individual batch strengths were first tested, and in no case did the analysis show any significant difference between the two batch variances. The estimates of the average batch 
strength were then compared by a t-test. The calculated $t$-value for batch LL 1 was 2.373 wh1ch was larger than the theoret1cal value of 2.306. Hence, there is a significant difference between the estimates. Observation of the dats in Table 23 of Appendix B indicates that the mean strength of batch LL 1 decreased w1th age rather than increased. The t-tests on the other three batches indicated that there was no $81 \mathrm{~g}$ nificant difference in the strength of the concrete before fatigue testing and the strength of the concrete after fatigue testing.

Since three of the four batches tested showed no significant increase in strength during the time of fatigue testing and the other showed a decrease of only 218 ps1 it seems obvious that the concrete specimens did not gain strength during the period of fatigue testing. The small difference observed in the opposite direction for a single batch is not considered large enough to give rise to significant differences in the fatigue test results.

\section{Fatigue Test Results}

Fatigue dats are best represented by a plot of the stress level, expressed as a percentage of the static ultimate strength, versus the number of cycles to failure. If a curve can be fitted to this plot It is called an S-N curve. It is often difficult to fit a curve to a plot of this type because of the great amount of scatter resulting from fatigue testing.

The large amount of scatter can be explained by the very nature of fatigue. In order to obtain an estimate of the strength of any batch a number of cylinders must be tested to fallure. Because of the physical variation from piece to piece, and even within pieces, the 
ultimate strength of any specimen 1 s unlikely to be the same as the batch estinste. Since the static test specimens cannot be used for fatigue testing, only a crude estimate of the strength of the specinen to be tested in ratigue can be made.

It is necessary to conduct fatigue testing programs over a long period of time, during which changes in atwospheric conditions take place. Some of the scatter in a plot of stress level versus cycles to fallure is undoubtedly due to errors in messuring and loading caused by these atmospheric changes.

The amount of time required to conduct a fatigue testing program also affects the amount of data which can be collected. It is impractical, from the standpoint of required time, to collect a large amount of data at the lover stress levels. To establish the existence of a fatigue IIn1t, hovever, much data would be needed at the lover stress levels. Generally if a specimen endures a predetermined number of cycles vithout falling, it is resoved frce the testing machine and the pext specimen is tested. In this stuily the maximum number of cycles which a specisen vas alloved to endure vas ten m11lion.

\section{Analysis of Fatigue Test Data}

The analysis of the fatigue data is limited by the characteristics of the data which were discussed in the previous section. When analyzing the data it was necessary to assume that each specimen had the properties defined by the static tests on the corresponding batch. Other difficulties developed as the data was collected which made interpretation of the results more inderinite.

In the case of the lou-strength concrete, all of the specinens at the 40 per cent stress level endured ten $=1111$ on repetitions of loading 
without fallure, as shown in Table 5, and vere removed from the testing machine. Thus $1 \mathrm{t}$ was impossible to determine the true fatigue life of 11ghtweight concrete at the 40 per cent stress level from the data collected in this study. All of the specimens tested at the 50 per cent stress level failed before enduring ten million cycles except one. Spec1men number two of batch IL 3 had endured 9.2 million when a power fallure stopped the machine. Since this specimen endured nearly twice as many cycles as the other specimens of the LL series which were tested at the 50 per cent stress level, it was felt that if the power fallure had not occurred the specimen would have endured the maximum of ten million cycles without fallure.

If the sssumption that specimen two of batch LL 3 endured ten milion cycles without failure is accepted, the data at the 50 per cent stress level is incomplete. Using only the four specimens which failed at the 50 per cent stress level, when actually five were tested, would introduce a bias into the statistical interpretation of the fatigue data. For this reason a better approximation can be made of the S-N relationship if only the data at the 60,70 , and 80 per cent stress levels are included in the calculations.

In the case of the high-strength concrete, the first two specimens tested at the 40 per cent stress level endured the maximum of ten million cycles of loading without failure. Since all of the specimens of the LL series tested at the 40 per cent stress level endured ten million repetitions of loading, it was felt that no further information could be gained from testing the remaining scheduled specimens of the HI series at the 40 per cent stress level. At the 50 per cent stress level only two specimens falled before they had endured ten million 
Table 5

FATIGUE TEST RESULTS

LOW-STRENGTH CONCRETE

\begin{tabular}{|c|c|c|c|c|}
\hline $\begin{array}{c}\text { Batch } \\
\text { Designation }\end{array}$ & $\begin{array}{c}\text { Specimen } \\
\text { Number }\end{array}$ & $\begin{array}{c}\text { Maximum } \\
\text { Fatigue Load } \\
\end{array}$ & $\begin{array}{c}\text { Minimum } \\
\text { Fat1gue Load } \\
\end{array}$ & $\begin{array}{l}\text { Number of } \\
\text { Stress Cycles } \\
\text { Endured }\end{array}$ \\
\hline LL 1 & $\begin{array}{l}1 \\
2 \\
3 \\
4 \\
5\end{array}$ & $\begin{array}{r}9,900(40) * \\
12,400(50) \\
14,800(60) \\
17,300(70) \\
19,800(80)\end{array}$ & $\begin{array}{l}900(3.6)^{*} \\
800(3.2) \\
700(2.8) \\
900(3.6) \\
800(3.2)\end{array}$ & $\begin{array}{c}10,304,600 \\
3,147,600 \\
688,700 \\
43,000 \\
19,100\end{array}$ \\
\hline LL 2 & $\begin{array}{l}1 \\
2 \\
3 \\
4 \\
5\end{array}$ & $\begin{array}{l}10,800(40) \\
13,500(50) \\
16,200(60) \\
18,900(70) \\
21,600(80)\end{array}$ & $\begin{array}{l}900(3.3) \\
800(3.0) \\
500(1.9) \\
800(3.0) \\
800(3.0)\end{array}$ & $\begin{array}{r}10,005,400 \\
4,926,400 \\
396,600 \\
52,800 \\
3,500\end{array}$ \\
\hline LL 3 & $\begin{array}{l}1 \\
2 \\
3 \\
4 \\
5\end{array}$ & $\begin{array}{l}11,500(40) \\
14,300(50) \\
17,200(60) \\
20,100(70) \\
23,000(80)\end{array}$ & $\begin{array}{l}700(2.4) \\
500(1.7) \\
900(3.1) \\
800(2.7) \\
500(1.7)\end{array}$ & $\begin{array}{r}10,464,100 \\
9,204,100- \\
1,610,000 \\
51,400 \\
1,600\end{array}$ \\
\hline LL 4 & $\begin{array}{l}1 \\
2 \\
3 \\
4 \\
5\end{array}$ & $\begin{array}{l}11,000(40) \\
13,700(50) \\
16,500(60) \\
19,200(70) \\
22,000(80)\end{array}$ & $\begin{array}{r}1,000(3.6) \\
1,100(4.0) \\
900(3.3) \\
800(2.9) \\
900(3.3)\end{array}$ & $\begin{array}{r}10,418,100 \\
5,673,300 \\
1,217,000 \\
105,100 \\
8,600\end{array}$ \\
\hline LL 5 & $\begin{array}{l}1 \\
2 \\
3 \\
4 \\
5\end{array}$ & $\begin{array}{l}10,000(40) \\
12,500(50) \\
15,000(60) \\
17,500(70) \\
19,900(80)\end{array}$ & $\begin{array}{r}1,000(4.0) \\
1,000(4.0) \\
1,000(4.0) \\
900(3.6) \\
1,100(4.3)\end{array}$ & $\begin{array}{r}11,723,300- \\
4,628,100 \\
2,262,500 \\
26,300 \\
1,900\end{array}$ \\
\hline
\end{tabular}

* Figure in parentheses is the dynamic load expressed as a percentage of the sverage ultimate strength of the batch. was stopped.

** $\rightarrow$ indicates that the specimen had not failed when the test 
cycles of loading as shown in Table 6. Furthermore, these two specimens come from the same batch. Therefore the data collected at the 50 per cent level could not be used to interpret the S-N relationship of the HL series. At the 60 per cent stress level all but one specinen failed before enduring the ten million limit. This specimen, specimen 3 of batch HL 3 , endured about 9.7 million before it was stopped by a power failure.

If the test on this specimen had not been stopped by a power failure, the limiting number of stress cycles would probably have been reached.

Two alternatives existed for analyzing the fatigue data of the highstrength concrete. The first was to neglect the data collected st the 60 per cent stress level because of the bias introduced into the $s-N$ relationship by considering only four test specimens when actually five were tested. If this were done, the S-N relstionsh1p would be defined from data collected at the 70 and 80 per cent stress levels. The second alternative was to include the data taken at the 60 per cent stress level knowing that a bias was being introduced. It was felt that the use of three sets of data which included a small bias in one set would give a better estimate of the true $\mathrm{S}-\mathrm{N}$ relationshlp than two sets of data which included no bias. Therefore, the second alternative was selected.

At the 70 per cent stress level, only four specimens were tested from the HL series. This is a result of a faulty automatic shut-down on the Amsler machine which stopped the testing several times before failure had occurred. Thus the data at this stress level is incomplete but no bias is introduced here because all specimens which were tested falled. 
Table 6

FATIGUB TEST RESULTS

HIOH-STFEIOTH CONCRETE

\begin{tabular}{|c|c|c|c|c|}
\hline $\begin{array}{c}\text { Batch } \\
\text { Designation }\end{array}$ & $\begin{array}{c}\text { Specimen } \\
\text { Thumber }\end{array}$ & $\begin{array}{l}\text { Kaximum } \\
\text { Patigue Load }\end{array}$ & $\begin{array}{l}\text { Minimum } \\
\text { Petigue Lond }\end{array}$ & $\begin{array}{c}\text { Rumber of } \\
\text { Stress Cycles } \\
\text { Bndured }\end{array}$ \\
\hline BIL 2 & $\begin{array}{l}1 \\
2 \\
3 \\
4 \\
5\end{array}$ & 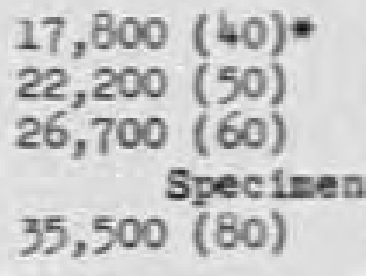 & $\begin{array}{l}1,000(2.2) * \\
1,200(2.7) \\
1,100(2.5) \\
\text { not tested } \\
1,200(2.7)\end{array}$ & $\begin{array}{c}10,458,700 \rightarrow \\
10,620,300- \\
720,500 \\
6,100\end{array}$ \\
\hline HL 3 & $\begin{array}{l}1 \\
2 \\
3 \\
4 \\
5\end{array}$ & $\begin{array}{l}18,000(40) \\
22,500(50) \\
27,000(60) \\
31,500(70) \\
36,000(80)\end{array}$ & $\begin{array}{r}1,100(2.4) \\
900(2.0) \\
1,000(2.2) \\
1,000(2.2) \\
1,000(2.2)\end{array}$ & $\begin{array}{c}10,216,500 \rightarrow \\
10,474,400- \\
9,673,500 \rightarrow \\
150,900 \\
6,600\end{array}$ \\
\hline HI 4 & $\begin{array}{l}1 \\
2 \\
3 \\
4 \\
5 \\
6\end{array}$ & $\begin{array}{l}\text { Specimen } \\
22,500(50) \\
22,500(50) \\
27,000(60) \\
31,000(70) \\
36,000(80)\end{array}$ & $\begin{array}{l}\text { not tested } \\
1,000(2.2) \\
1,200(2.7) \\
1,000(2.2) \\
1,000(2.2) \\
1,000(2.2)\end{array}$ & $\begin{array}{r}4,751,300 \\
5,957,200 \\
736,400 \\
166,100 \\
5,400\end{array}$ \\
\hline HL 5 & $\begin{array}{l}1 \\
2 \\
3 \\
4 \\
5\end{array}$ & $\begin{array}{l}\text { Spec1men } \\
22,200(50) \\
26,600(60) \\
31,000(70) \\
35,400(80)\end{array}$ & $\begin{array}{l}\text { not tested } \\
1,300(2.9) \\
1,100(2.5) \\
1,100(2.5) \\
1,100(2.5)\end{array}$ & $\begin{array}{c}10,499,400 \rightarrow \\
6,737,500 \\
611,900 \\
110,000\end{array}$ \\
\hline BIL 6 & $\begin{array}{l}1 \\
2 \\
3 \\
4 \\
5\end{array}$ & $\begin{array}{l}\text { Specimen } \\
21,200(50) \\
25,400(60) \\
29,700(70) \\
33,900(80)\end{array}$ & $\begin{array}{l}\text { not teated } \\
1,200(2.8) \\
1,100(2.6) \\
1,100(2.6) \\
1,100(2.6)\end{array}$ & $\begin{array}{c}10,196,100 \rightarrow \\
4,116,700 \\
753,600 \\
86,300\end{array}$ \\
\hline
\end{tabular}

Plgure in parentbeses is the dymmic load expressed as a percentage of the average ultimate strength of the batch.

vas stopped.

Indicates that the specimen had not failed when the test 
The S-N Diagrams. A seml-log coordinate system was used to plot the S-N relstionship because this system presented the data in a form which is easier to view and easier to interpret than either a $\log -\log$ plot or an arithmetic plot. The data collected from the LL series are plotted in Figure 9 and the data collected from the HL series are plotted in Figure 10.

When the data from the HL series were plotted there appeared to be two separate and distinct relationships. The concrete of batches HL 5 and HL 6 seemed to have different fatigue properties than the concrete of batches HL 2, HL 3, and HL 4. The reason for this separation of data is unknown. Referring to Table 4 it is seen that the slump and the air content of batches HL 5 and HL 6 are larger than the same properties of batches HL 2, HL 3, and HL 4. A correlation between slump and air content can be expected but it seems unlikely that the fatigue properties would be altered by such stall variations in the slump and alr content. The scatter of data within the two apparent sets of data 18 not great enough to substantiate any correlation between fatigue properties and plastic properties of the high-strength concrete. The only conclusion that can be drawn from the data collected in this study is that the fatigue properties of the high-strength concrete are somewhst influenced by the slump, the air content, or both.

The S-N disgrams indicate that no fatigue limit was reached at ten million cycles of repeated loading for the concrete tested in this study. None of the S-N curves appear to become horizontal nor even start to level out in the neighborhood of ten million cycles. 


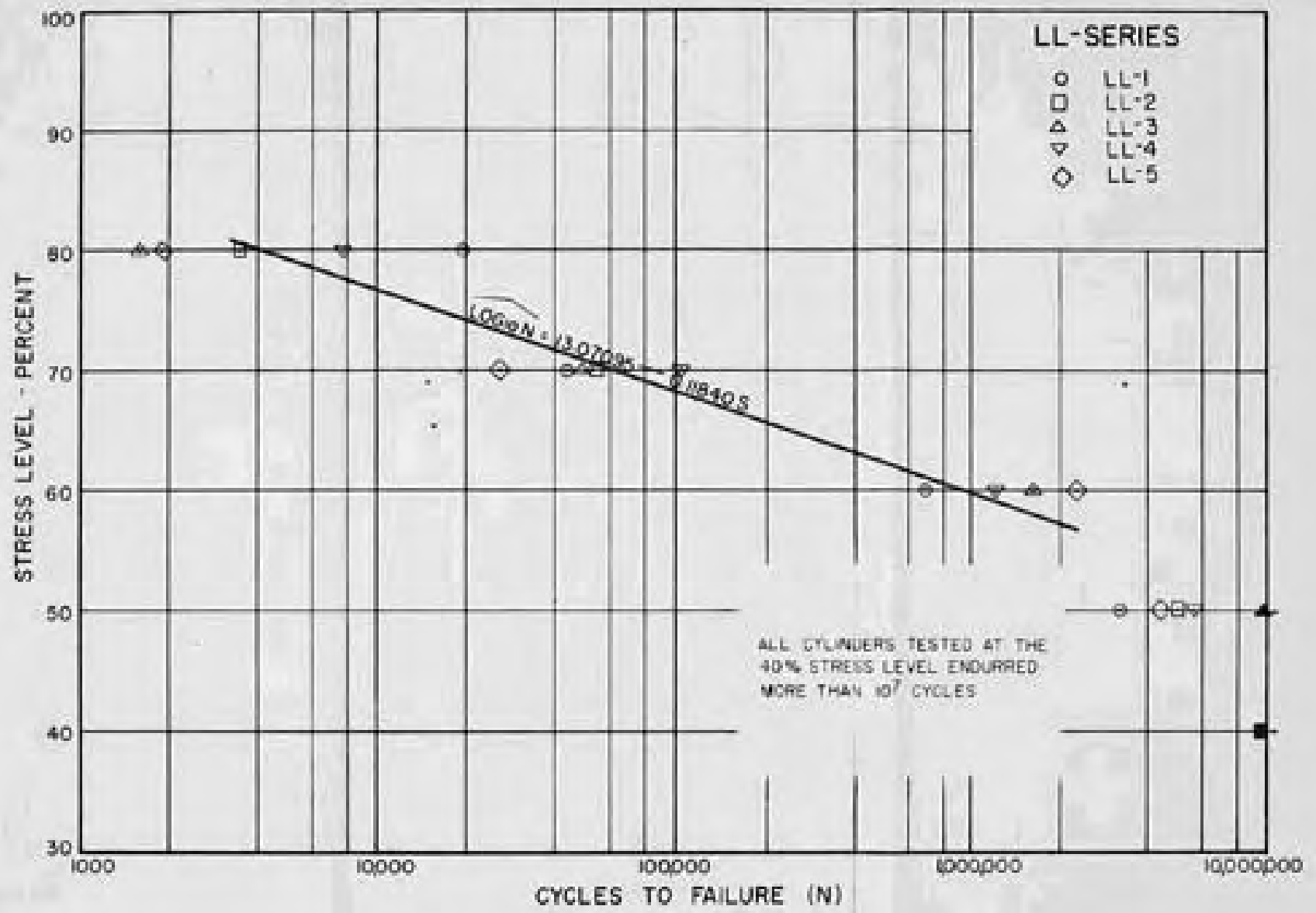

FIGURE 9. S-N DIAGRAM FOR LOW STRENGTH CONCRETE 


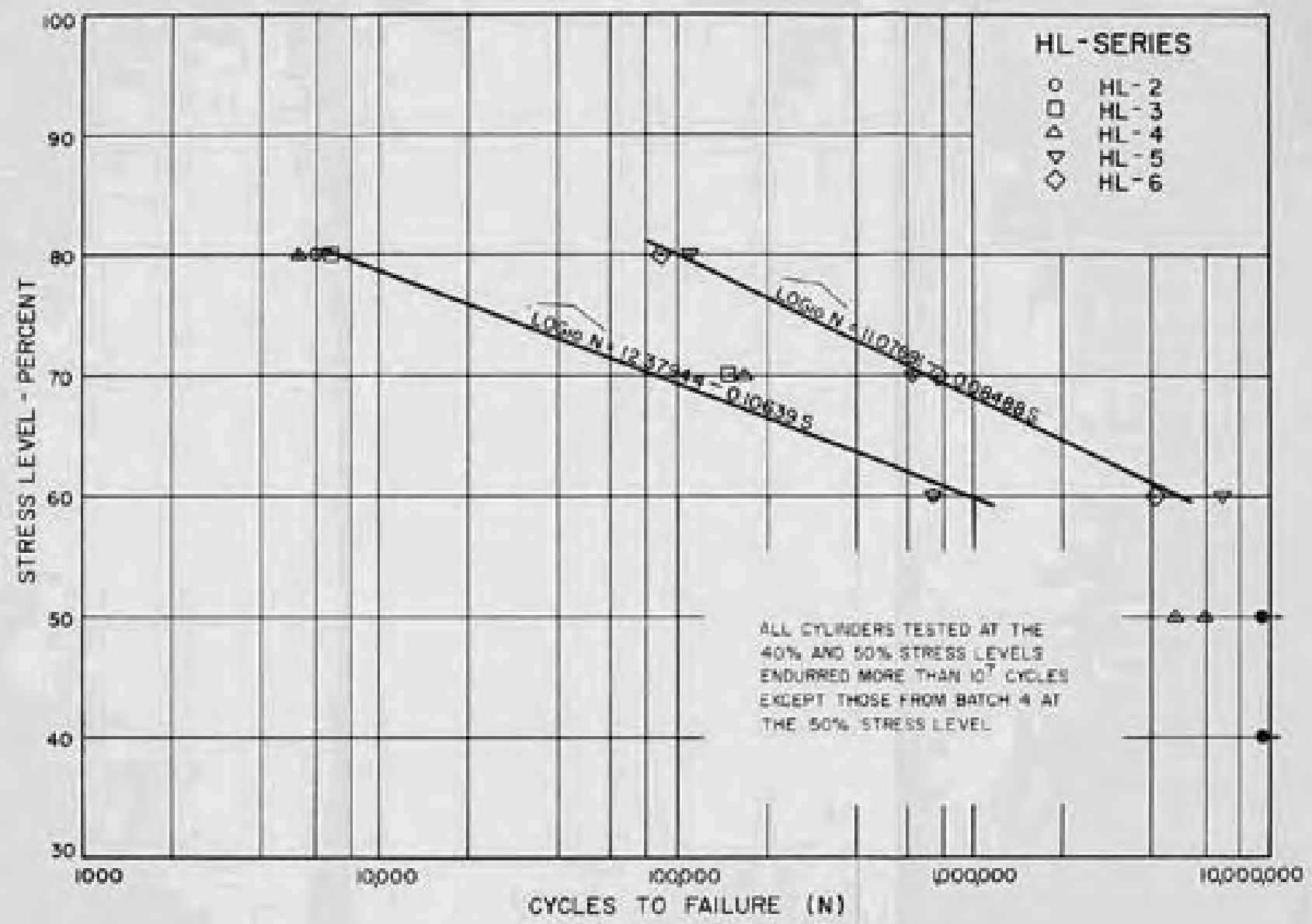

FIGURE IO. S-N DIAGRAM FOR HIGH STRENGTH CONCRETE 
Comparison of the Two Mixes. Since the form of the distribution of fatigue data was unknown, it was felt that sone test should be employed to determine whether or not the two sets of data represent populstions having the same frequency distribution. A method called "Runs" was chosen for this purpose (21). When using this test one can infer that if there are no more or no fewer runs in the data than would be expected by chance, the populations have the same frequency distribution. The run test was applied to the data of each stress level and the calculations are shown in Table 27 of Append $1 x$ C.

At the 60,70 , and 80 per cent stress levels, the run test shows that there is no reason to believe the two populations have different frequency distributions. Tests could not be made at the 40 and 50 per cent stress level because many of the specimens endured ten million cycles of loading and were removed from the testing machine before fallure. Hence, there is no way of estimating the number of cycles these specimens would have endured if the tests had been contimued. A similar condition existed at the 60 per cent stress level, but it was felt that the run test could be applied to those specimens which failed at fewer than ten million cycles.

Linear Regression. The simplest type of regression is a linear regression. If the data to be analyzed does not follow a linear relationship, they can often be transformed by extracting the square root, squaring, or taking the logarithm of the individual values. By taking the logarithm of the individual values of the cycles to failure, the data of this study appeared to have a linear $\mathrm{S}-\mathbb{N}$ relationship (Figures 9 and 10). Linear regression calculations were based on the assumption 
that the $8-\mathbb{S}$ relationship vas 1 inear and that the transforned data were normally distributed.

Three curves vere fitted to the fatigue test data, one for the LL series and two for the HL series. For purposes of calculation, the IL series vill be referred to as sample I. Batches HL 2, HL 3, and HL 4 vill be referred to as sample II and batches HIL 5 and HL 6 vill be referred to as sample III. Curves vere fitted to each set of dats by the method of least squares. An anslysis of variance vas also included in the least squares conputations to determine whether or not the S-BI relationship vas actually linear. The linear regression calculations are shown in Tablea 28,29 , and 30 of Appendix C.

The least squares linear regression equation obtained from the data of sample I 1s:

$$
\widehat{\log N}=13.077-0.118 \mathrm{~s}
$$

where $\mathrm{N}$ is the number of cycles to failure and $\mathrm{S}$ is the stress expressed as a percentage of the static ultimate stress. This equation can be used to eatimate $N$ only when the value $S 11$ es between 60 and 80 per cent because this is the range of $\mathrm{S}$ used in the calculations. The calculsted $P$ In the test for linearity was 0.51 which is less than the theoretical value of 4.75. Therefore, there is no reason to belleve that the $8-15$ relationship is aot 11 near.

The least squares linear regression equation obtained fron the data of sample II 1s:

$$
\widehat{\log x}=12.379-0.1068
$$

The uae of this equation 1 s also 1 falted to values of $\mathrm{s}$ between 60 and 80 
per cent. The calculated $F$ value in the test for linearity was 169.95 which is much larger than the theoretical value of 7.71 . There is, therefore, a significant reason to belleve that the $5-8$ relationship of these dats is not linear. By visually iaspecting the data of sample II In Figure 10, it can be seen that a curve passing through the means of the three stress levels vould be concave dowivard. Additional dats vould be needed to better define this curve.

The lesst squares linear regression equation obtained from the data of sample III is:

$$
\widehat{\log I 7}=11.077-0.0858
$$

The use of this equation is limited to values of $S$ between 60 and 80 per cent. The calculated $F$ in the teat for 11nearity was 22.0 as compared with the theoretical value of 10.1 . Thus there is reason to believe that the $\mathrm{s}-\mathrm{N}$ relationship of these data is not linear. By visually inspecting the dats of sample III, Figure 10, it can be seen that a curve passing through the means of the three stress levels would be concave upvards. This indicates that posaibly a fatigue limit is being approsched.

Additional dats would be needed to better define this curve.

Calculations for correlstion coefricients vere also included in the linear regression anglyses. In all three samples 1 t vas found that there is a very high degree of association between cyeles to fallure and the 
stress level. The correlation coefficients were found to be -0.952 , -0.982 , and -0.956 for samples I, II, and III respectively. Table 31 of Appendix $C$ shows the calculations for a test to determine whether the correlation coefficients are significantly different and the procedure is outlined in reference (22). The test showed that there is no reason to believe that the correlation coefficients sre different. Hence, the degree of association between the stress level and the number of cycles to fallure can be assumed to be the same for all three samples.

Comparison of $8-N$ Curves. In the comparison of the three $\mathrm{S}-\mathrm{N}$ curves it is necessary to first consider the data of the HL series. These data appear to be separated into two separate and distinctive S-II relationships for no apparent reason. If there is a specific reason for this separation it was not planned in the design of the concrete tested and, therefore, a correction to the usual statistical methods must be made.

It is necessary to determine the number of ways in which the five batches of concrete could have been divided 1nto two main groups. There are ten ways in which the five batches could have been divided so that one group contained two batches and the other contained three batches. There are also five ways in which the batches could have been divided so that one group contalned four batches and the other group contained only one batch. Hence, there $1 \mathrm{~s}$ a total of 15 vays in which the data of the HL series could have been placed Into two separate groupings.

If the characteristics of these two groups were to be compared by using an F, or any other statistic, at the 5 per cent significance level by the usual statistical procedures, the actual statistical significance level vould be 15 times 5 per cent or 75 per cent. It is evident, 
therefore, that if it is desired to compare these two curves at any given significance level, the given significance level must be divided by 15 to produce reliable results.

Since it is desired to compare the two curves of the HL series with the curve of the LI series a factor other than 1/15 must be applied to the desired signiffeance level because the five batches of the LL serles have not been separated into two groups. At the present time, there is no method avallable to determine the exact reduction factor which should be used. It is felt, however, that the proper reduction factor for the three sets of data under consideration is probably between $1 / 10$ and $1 / 15$. The following tests on slopes and intercepts were conducted at the apparent significance level of $1 / 2$ per cent on the assumption that the reduction factor of $1 / 10$ would yield sufficiently accurate results for the purposes of this calculation. The fact that the degrees of freedom used in these tests are relatively large, tends to verify this conclusion because the difference between test statistics decreases as the degrees of freedom increase.

An analysis of covariance was used to deternine whether the slopes of the three regression curves were significantly different. The computations for this anslysis are shown in Table 32 of Appendix C and are described in reference (19). The results of this test indicate that there is no reason to believe that the slopes of the three regression equations are different. The analysis does show reason to believe that the slopes of the three regression equations are not the same as a common over-all slope. It is slso apparent that the slopes within samples do not differ significantly from the slope between samples. 
A two-way analysis of variance test was conducted on the combined data of all three samples to see if there was any difference in the intercepts of the regression equation. This anslysis is shown in Table 33 of Appendix C and indicates that there is a significant difference between intercepts. A Newman-Kuels sequential range test showed that the intercept of sample III was different than the intercepts of the other two samples.

Since the slope is the property which best defines

the S-N relationship, it seems reasonable to conclude

that the fatigue properties of the three sets of data

are the same.

In an effort to strengthen this conclusion the prediction intervals for each sample were calculated. The calculations are shown in Table 34 of Appendix $C$ and summarized in Table 7 . It was felt that if the prediction intervals overlapped, it could be definitely concluded that the fatigue properties of all three samples were the same.

Referring to Table 7 it 1 s clear that the linear regression equation for sample I lies within the prediction intervals calculated for sample II. It is also evident that the linear regression equation of sample II lies within the prediction 1ntervals of sample I. Therefore, there is no reason to believe that the fatigue properties of sample I and sample II are different. On the basis of the prediction interval concept, the data of sample III appears to be separated from that of the other two sanples.

The relationship between the stress level and the number of cycles 


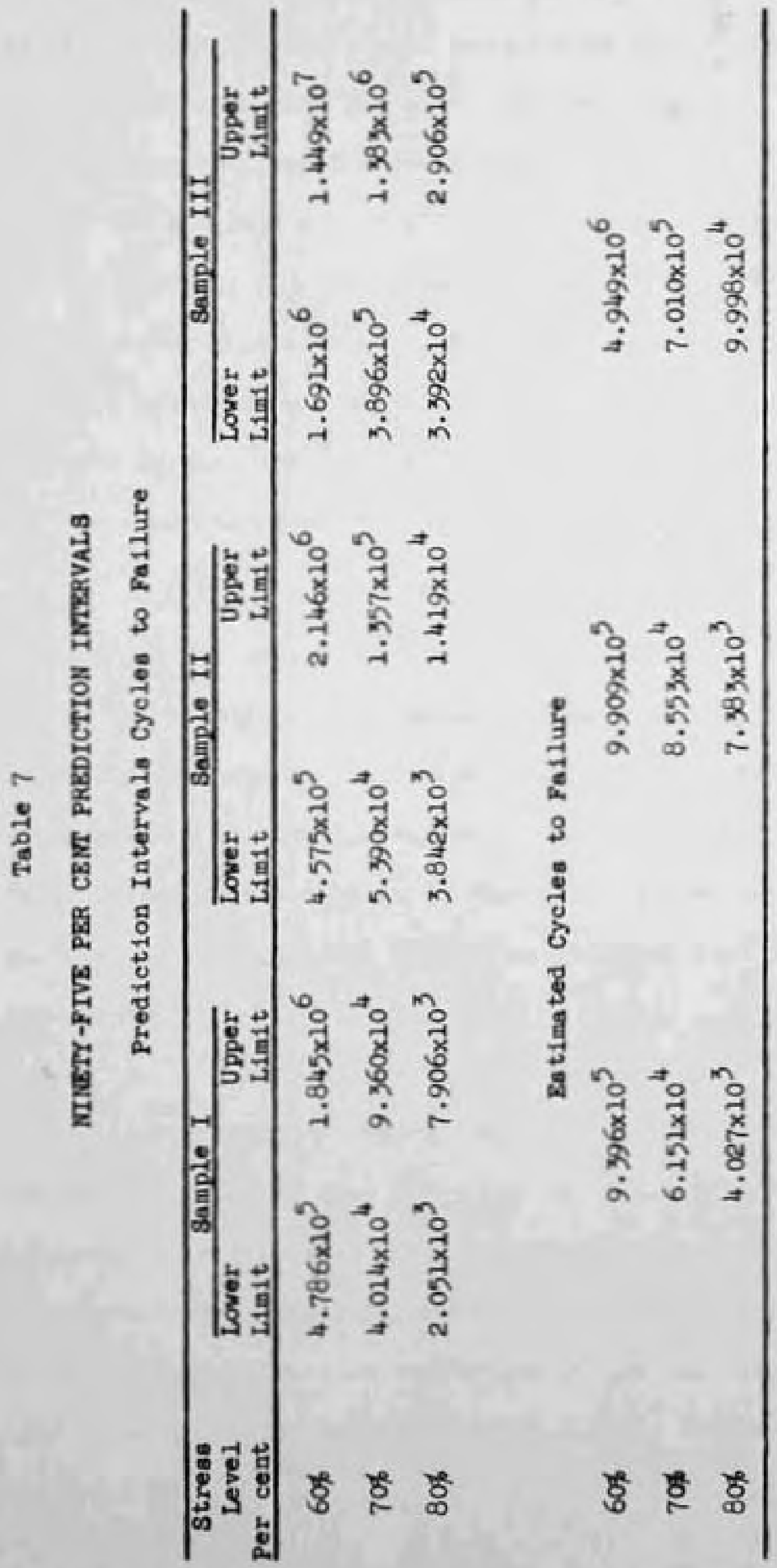


to fallure is represented most clearly by the slope of the linear regression equation. The results of the analysis of slopes suggest that the data of all three samples have the same slope and therefore suggest that all three samples have the same $S-N$ relationship. The prediction Intervals tend to weaken the conclusion that all three samples have the same $\mathrm{S}-\mathrm{N}$ relationship but this test is not as strong as the analys is of slopes because individual errors rather than a total combined error is used. It is, therefore, felt that the strongest and most likely conclusion that can be drawn from this analysis is that the fatigue properties of all concrete tested in this study are the same regardless of differences in the static properties.

\section{Type of Fallure}

It was not possible to observe the process of fatigue failure because all of the speclmens that falled, did so extremely rapidly and without warning. The appearnace of specimens that falled in fatigue was not unlike the appearance of those which falled statically. Typical fallures of static and fatigue specimens are shown in Figure 11. Automatic shut-down devices were employed on both machines so that no crushing load was applied to the failed specimens.

\section{Other Observations}

It was noticed that a change in load occurred on most fatigue specimens during the last few thousand cycles before failure. This change consisted of a decrease in maximum load and an increase in minimum load. This Indicates that as the specimen nears the falling point, a change takes place in the stress-deformation properties of the concrete which is reflected back into the characteristics of the fatigue machine and its recording device. 


\section{w

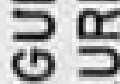 \\ $\frac{1}{4}=$ \\ 나 4}

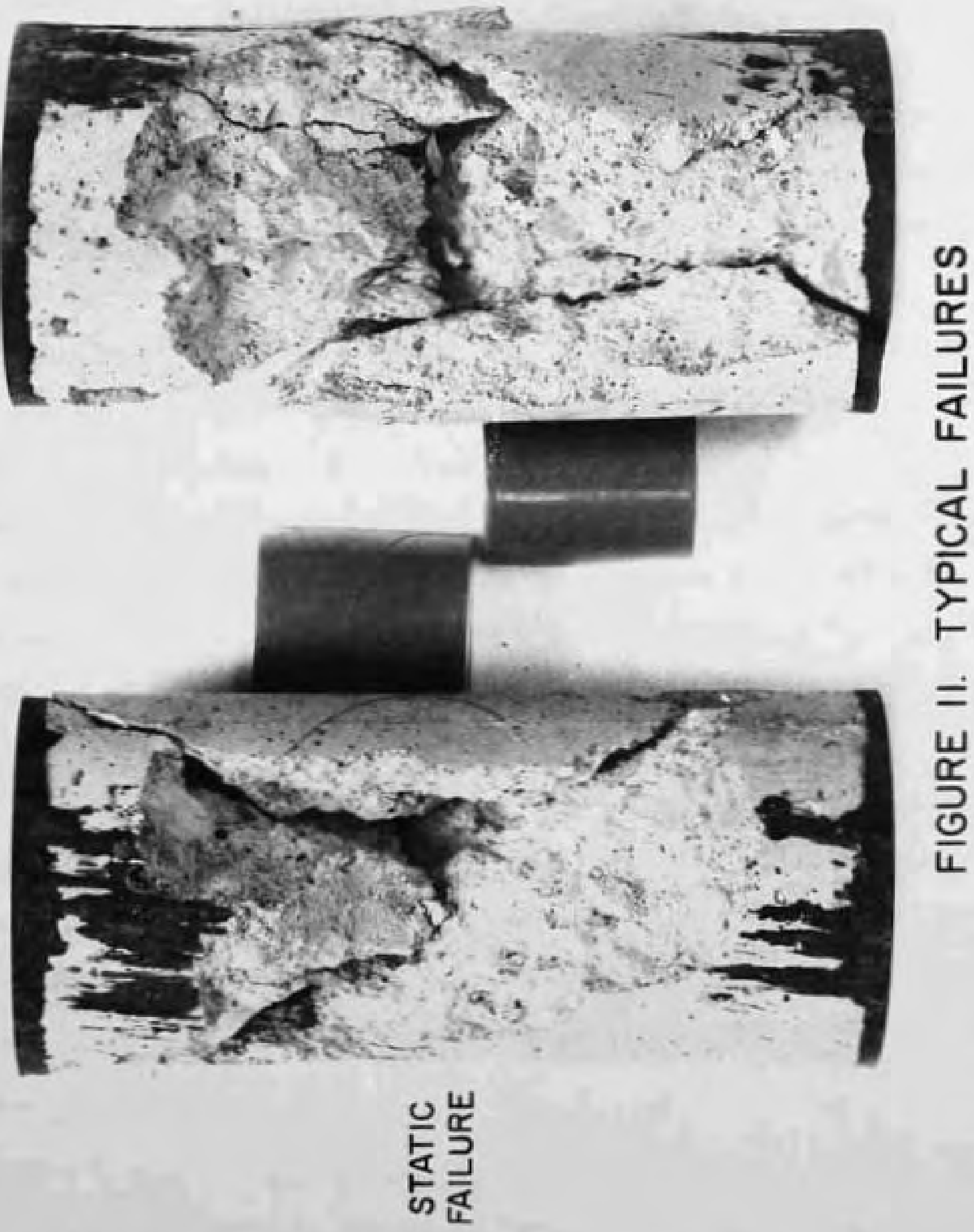




\section{Speed of Testing Results}

Since two machines were used that applied loads at different rates, It was felt that some testing should be done to determine if the different rate of load application had any effect on the fatigue properties of the concrete. Batch IL 1 was used for this purpose.

Nine specimens were tested in each machine at the 80 per cent stress level and a $t$-test was made on the means obtained. Specimens tested in the Krouse-Puraue machine vere tested at a rate of 1,000 cycles per minute and those tested in the Amsler machine were teated at a rate of 500 cycles per minute.

An F-test was used to compare the variance of the number of cycles to failure for each machine. As shown in Table 35 of Appendix C the calculated $F$ was 2.015 and the theoretical $F$ was 3.44 . Therefore, there is no reason to believe that the variances of the two sets of dsta were different. The $t$-test was then conducted and the calculated $t$ value of 0.264 was compared with the theoretical value of 2.12 . Since $2.12>0.264$ there 1 s no reason to belleve that the two means are different.

It seems reasonable to conclude that the speed of test did not affect the fatigue properties of lightweight aggregate concrete when the speed of testing was between 500 and 1,000 cycles per minute. This conclusion is in accordance with the statements expressed in the avallable 11terature on the rate of testing of concrete fatigue specimens $(15,23)$.

\section{Summary of Fatigue Test Results}

Throughout this study care was taken to minimize the differences 
between batches. An attempt was made to make all of the concrete of each series as nearly the same as possible with respect to strength, air content, and consistency. All specimens were prepared for testing in an identical manner. Even with this attempt to control the physical properties of the concrete and the test procedures, the fatigue test data showed a large amount of scatter. Some of this scatter was undoubtedly due to variations in atmospheric conditions because the fatigue tests were begun In sumer and continued through most of the winter. The largest part of the scatter is accounted for, however, by the observed variations in physical properties between batches and within individual specimens. The results obtained from the analysis of fatigue test data may be summarized as follows:

1. The linear regression equation of the $8-N$ relationships for the low-strength concrete for values of $\mathrm{s}$ between 60 and 80 per cent is:

$$
\widehat{\log N}=13.077-0.118 \mathrm{~s}
$$

2. The data of the high-strength series appeared to form two separate S-N relationships. The linear regression equations of these two S-N relationships for values of s between 60 and 80 per cent are:

$$
\widehat{\log N}=12.379-0.106 \mathrm{~s}
$$

and

$$
\widehat{\log N}=11.077-0.085 \mathrm{~s}
$$

3. There is no reason to believe that a difference exists between the fatigue properties of low-strength and the 
high-strength concrete. Hence there is no reason to belleve that the gradations used in this study have any effect on the fatigue properties of 11ghtveight abgregate concrete.

4. The $8-18$ diagrams appear to shov no fatigue limit for Ifghtwelght sggregate in the nelghborhood of ten allifon repetitions of loading.

5. There is no reason to belleve, fron the results obtained on the 18 specimens tested, that the rate of load application has an effect on the fatigue properties of lightvelight aggregate concrete when the rate of load application 11 es between the values of 500 and 1,000 cycles per minute.

\section{Comparison of Lightweight Concrete}

With Normal Welght Concrete

In July of 1958, the results of a study comparing the fatigue properties of alr-entrained concrete with the fatigue properties of non-air-entrained concrete was reported (13). That study vas made in the same laboratory as the present study. The testing programs vere nearly identios l except for the materials used. The aggregate utilized In the 1958 study was a crushed Iimestone from Ceatral Indiana. The cesent used in both studies vas from one clinker batch (Iaboratory desigration 315) and is assumed to have the same properties.

It vas felt that since the conditions under which tiese two studies 
were conducted vere similar, a comparison could be made to determine whether the fatigue properties of lightweight concrete are different than the fatigue properties of normal weight concrete. A comparison of correlation coefficients is shown in Table 36 of Appendix D and a signif1cance test for difference between slopes is shown in Table 37 of Appendix D. The values used for these tests can be found in Appendix C of Reference (13). No attempt was made to compare the difference between 1ntercepts because the values of stress level in the study on normal weight concrete varied so greatly that only one reading ws recorded at some stress levels. When a cell contains only one reading a poor estimate of the error variance results and it was felt that such a test would not yield accurate results.

A reduction factor must be applied to the significance level in the test for differences in slopes. In this case a comparison of three sets of data with the two of the HL series would require a smaller reduction factor than $1 / 15$. The actual reduction factor should be slightly less than the one used in the section on Comparison of the S-N Data. It was felt that the actual reduction factor should be about $1 / 10$ and that this value would yield sufficiently accurate results. The tests were, therefore, conducted at the $1 / 2$ per cent significance level to detect any difference in slopes at the 5 per cent significance level. The test indicated that at the 5 per cent significance level there is no reason to belleve that the slopes are different. Since the slope is the property which best defines the S-N relationship, it seems reasonable to conclude that the fatigue properties of the concrete used in the present study do not differ from the fatigue properties of normal concrete. Hence a reduction in dead load 
can be attained for all types of construction using lightweight aggregate concrete, and the design strength vould not need to be Incressed above that required for normal concrete to account for repetitive loading. This result should be of particular importance to agencies engaged in the design and construction of bridges because experience has shown that substantial saviags can be accrued by the uge of 11ghtvelght aggregate concrete as a paving naterlal for highway bridgea.

The test for difference in correlation coefficients indicated that there is a significant difference between the correlation coefficients or the five S-N relationships tested. By comparing these coefficlents visually it can be seen that the correlation coefficient of the nonair-entrained series reported in Reference (13) is about 30 per cent lower than the other four values compared. This comparison indicates that the degree of association between stress level and number of cycles to fallure is much higher for concrete containing entrained air.

Antrim'a findings indicate that air-entrained concrete yields more conglatent fatigue data than non-air-entra1ned concrete (13). The comparian of the correlation coefficients found in this study with those found by Antrim tend to strengthen this conclusion. Hence if air-entrained concrete (11ghtweight or normal) is used where fatigue action is anticipated, the relationship between cycles to fallure and stress level can be estinated with more confidence and, therefore, a lover factor of safety could be employed. Thus the entrainment of air can be benefleial to the resistance of repetitive loading as vell as durab111ty and vorkab111ty. 


\section{SUMMARY OF RESULTS}

In this section, the significant results discussed in the foregoing sections are restated in the order in which they were considered;

1. The average strength of the low-strength concrete was 3,760 ps 1 and the average strength of the high-strength concrete vas $6,260 \mathrm{ps} 1$. The variance of the batch strengths within each of these series was not significantly different but the average of each series did differ significantly.

2. The average slump of the low-strength series was 2.5 Inches with a coefficient of variation of 24 per cent. The average slump of the high-strength series was 2.4 inches with a coefficient of variation of 17 per cent.

3. The air contents of the low and high strength concretes vere 6.8 and 6.5 per cent respectively. The coefficients of variation were 9 and 5 per cent respectively.

4. Both mix designs experienced bleeding at the time of casting. The bleeding of the low-strength concrete was more noticeable than that of the high-strength concrete.

5. There was no significant change in the ultimate compressive strength of the concrete during the time of fatigue testing. 
6. The $s-N$ relationship of the low-strength concrete between stress levels of 60 and 80 per cent, as determined by a linear regression analysis was:

$$
\widehat{\log N}=13.077-0.118 \mathrm{~s}
$$

7. The fatigue data of the high-strength concrete sppeared to have two separate and distinct $\mathrm{S}-\mathrm{N}$ relationships. The linear regression equations for these two relationsh1ps between the stress levels of 60 and 80 per cent were:

$$
\widehat{\log N}=12.379-0.106 \mathrm{~s}
$$

and

$$
\widehat{\log \mathrm{N}}=11.077-0.085 \mathrm{~s} .
$$

8. The degree of association between the number of cycles to fallure and the stress level was the same for the three S-N relationships investigated in this study. It was found that the slopes of the three S-N curves had the same slope but that the intercepts of one of the high-strength concrete relationships differed from the other two intercepts. Prediction intervals also indicated that the $8-N$ curve with the different intercept was separsted from the other two relationships. Since the slope of the S-N curve best describes the relationship between stress level and cycles to failure, it was concluded that the $S-\mathbb{N}$ relationsh1p was the same for both the low-strength and high-strength concrete.

9. The fatigue data collected in this study indicated that in general the S-N relationship did not tend to level out and, 
therefore, there is no fatigue 11m1t for 11ghtweight aggregate concrete in the neighborhood of ten million repetitions of loading.

10. Tests on 19 specinens indicated that there is no difference in the fatigue properties when the rate of load application varies betveen 1,000 and 500 cycles per minute.

11. Coaparison of the results of this study and the results of a previous study, which compared the fatigue properties of air-entrained and non-air-entralned concrete, indicated that there is no difference between the fatigue properties of 11ghtweight aggregate concrete and normal weight concrete. 
COMCLUSIONS

The folloving conclusions can be drava from the fatigue data collected in this study. These conclusions are based on the fatigue testing of forty-seven 3 inch by 6 inch lightwelght aggregate concrete specinens tested in direct conpression at a rate of loading which varied from 1,000 to 500 cycles per minute.

1. The fatigue properties of lightveight aggregate concrete are not changed significantly by varying the proportions of fine and coarse aggregate in the $m i x$ design.

2. The fatigue properties of lightweight aggregate concrete are not significantly different than the fatigue properties of normal weight concrete. 
SUGGESTIONS FOR FURTHER WORK

This study has been concerned only with the fatigue properties of lightweight concrete having two different strengths. The amount of time required to collect data limited the range of stress level over which fatigue data could be collected. Unfortunately many studies on the fatigue of concrete will probably be hampered by the time factor unless the investigators have several years in which to investigate the fatigue of concrete.

The results of this study indicate that every precaution must be taken to minimize the number of variables which may be acting during an investigation. Care should be taken to test specimens at, as nearly as possible, the same age and any other control that would eliminate the batch-to-batch differences should be employed.

Following is a list of suggestions for further research:

1. More information is needed to supplement the results of this thesis. Tests should be conducted at lower stress levels to more fully investigate the existence of fatigue limit for lightweight aggregate concrete.

2. The literature has indicated that the moisture content of lightweight aggregate immediately prior to mixing has no effect on the strength of the concrete. The molsture content may, however, have sn effect on the fatigue properties of the concrete and this variable should be investigated. 
3. More tests are needed to determine the effect of the rate of fatigue load application on the fatigue properties. If it can be definitely concluded that the rate of laad application has no effect on the fatigue of concrete, more rapid testing would enable future investigators to more completely determine the effects of the variables which they are concerned with. Temperature measurements should also be included in this type of testing.

4. Tests should be conducted to determine the mechanism in which fatigue failures take place in concrete. This would shed more light on previous investigations and also aid future experimenters. 
RRFIERIBHCES 


\section{REFEREMCES CTTED}

1. Woodruff, Glen B., "L1ght Weight Concrete Pavement on the San Franc1sco-Oakland Bay Bridge," Proceedings, American Concrete Institute, Vol. 34, pp. 225-238, 1938.

2. Stephens, A. W., "The Bconomic Possibilities of Lightweight Aggregate in Buildings," proceedings, American Concrete Institute, Vol. 16, pp. $152-155,1920$.

3. Rands 11, Frank G., "Economics of Light Weight Conerete in Bullaings," Proceedings, American Concrete Institute, Vol. 27, pp. 925-939, $1930-31$.

4. Kluge, Ralph W., Sparks, Morris M., and Tums, Edward C., "Lightweight Aggregate Concrete, " Proceedings, Americsn Concrete Institute, vol. 45, pp. 625-692, 1949.

5. Nordby, Gene M., "Fatigue of Concrete - A Review of Research," Journal, American Concrete Institute, Vol. 30, №. 2, pp. 191-221, August 1958.

6. Manual on Fatigue Testing, Special Technical Publication No. 91, American Society for Testing Materisls, 1949.

7. Moore, H. F., and Kommers, J. B., The Fatigue of Metals, lst ed., New York, MoGraw-H111 Book Co., Inc., 1927.

8. Cazaud, R., Fatigue of Metals, translated by A. F. Fenner, New York Philosophical Library, Inc., 1953.

9. Boas, W., Physics of Metsls and Alloys, New York, John Willey and Sons, Inc., 1947 .

10. Gillett, H. W., The Behavior of Engineering Metals, New York, John Wiley and Sons, Inc., 1951 .

11. Singer, Ferdinand L., Strength of Mater1als, New York, Harper Brothers, 1951.

12. Antrim, John de C., and McLaughlin, John F., "Fatigue Study of A1r-Bntrained Concrete," Journal, American Concrete Institute, Vo1. 30, No. 11, pp. 1173-1182, May 1959.

13. Antrim, John de C., "A Study of the Fatigue Properties of A1rEntrained Concrete," A Thesis submitted to Purdue University for the degree of Master of Science in Civil Engineering, July 1958. 
14. MeCall, John F., "Probability of Fatigue Failure of Plain Concrete," Journal, American Concrete Institute, Vol. 30, No. 2, pp. 233-244, August 1958.

15. Assimacopoulos, Basil M., Warner, Robert F., and Ekberg, Carl B. Jr., "H1gh Speed Fatigue Tests on Small Specimens of Plaln Concrete," Journal, Prestressed Concrete Inst1 tute, Vol. 4, No. 2, September 1959.

16. Chang, Tien S., and Kesler, Clyde E., "Fatigue Behavior of Reinforced Concrete Beams," Journal, American Concrete Institute, vol. 30 , No. 2, August $1955^{\circ}$.

17. Stelson, Thomas E., and Cernica, John N., "Fatigue Properties of Concrete Beams," Journal, American Concrete Institute, Vol. 30 , No. 2, August 1958 .

18. "Proposed Recommended Practice for Selecting Proportions for Structural Light Weight Concrete," Proceedings, American Concrete Inst1 tute, Vol. 55, pp. 305-314, September 1958.

19. Duncsn, Acheson J., Quality Control and Industrial Statistics Homewood, Illinois, Rlchard D. Irwin, Inc., 1959.

20. Cochran, W. G., "Some Consequences When the Assumptions for the Analysis of Varlance Are Not Sat1sfied," Biometrics, Vol. 3, No. 1 , p. $22,1947$.

21. Dixon, W. J., and Massey, F. J., Jr., Introduction to Stat1stical Analysis, New York, MoGraw-H1il Book Company, Inc., 1951.

22. Ostle, B., Statiatics 1n Research, Ames: The Iowa State College Press, 1954.

23. Kesler, C. B., "Bffect of Speed of Test1ng of Flexural Fatigue Strength of Plain Concrete," Proceedings, Highway Research Bosrd, vol. 32, pp. 251-258, 1953. 
ADDITIONAL REFBRENCES

ASTM Standards, Part 4, American Society for Testing Materisls, 1958.

Clemser, H. F., "Fatigue of Concrete," Proceedings, American Society for Testing Materials, Vol. 22, Pt. 2, pp. 406-419, 1922.

Crepps, R. B., "Fatigue of Mortar," Proceedings, American Society for Testing Naterials, Vol. 23, Pt. 2, pp. 329-340, 1923.

Bxpended Shale Institute, "The Report of an Investigation on the Condition an Physical Properties of Exponded Shale Reinforced Concrete After 34 Exposure to Sea Water."

"Fatigue of Conerete," Bulletin 110. 24, Purdue Uni versity Bngineering Bxperiment station, vol. 9, 150. I1, pp. 44-55, November 1925.

"Fatigue of Mortar and Concrete," Bulletin No. 34, Purdue University, Engineering Experinent Station, Vo1. 12, No. 7, pp. 34-55, Hovenber 1928.

Franke1, Jacob Porter, Principles of the Properties of Materials, INev York, MoGrav-H1111 Book Compary, Inc., 1957.

Hist, И. K., Tatigue of Concrete," Proceedings, H1ghwsy Research Board, vol. 4 , pp. $47-60,1924$.

Batt, W. K., "Wote on Fatigue of Mortar," Proceedings, American Concrete Inst1 tute, Vol. 18, Pp. 167-173, 1922.

Kluge, Ralph V., "Structural Lightweight Aggregate Concrete," Proceedings, American Concrete Institute, Vol. 53, pp. 383-401, October 1956.

Mavis, F. J., and Stevart, J. J., Purther Teats of Dynamically Loaded Beans," Jourmal, Aserlcan Concrete Institute, vol. 30, No. 11, May 1959.

Mills, R. E., and Davson, R. F., "Tatigue of Concrete," Proceedings, Highvay Research Board, Vo1. 7, Pt. 2, pp. 160-172, 1927.

Murdock, John W., and Kesler, Clyde E., 'Brfect of Range of Stress on Fatigue Strength of Main Concrete Beams," Journal, American Conerete Inst1tute, Vol. 30, No. 2, pp. 221-233, August 1958.

Prevention of the Pollure of Metals Under Repeated Stress, Nev York: John Wiley and Sons, Inc., 1941. 
Sinnott, Maurice J., The Sol1d State For Engineers, New York, John Wiley and Sons, Inc., 1958.

Symposium on Fatigue v1th Emphasis on Stat1stical Approach - II, Special Technics I Publication, \$o. 137, American Society for Testing Naterials, 1952.

Symposium on Statistical Aspects of Fatigue, Special Technical Publication No. 121, American Society for Testing Materials, 1951.

Van Ornum, J. L., "The Fatigue of Cement Products," Transactions, American Society of Civil Engineers, Vol. 51, pp. 4h-451, 1903.

Van Ornum, J. L., "The Fatigue of Concrete," Transsctions, American Society of Civil Englneers, Vol. 58, pp. 294-320, 1907.

Van Vlack, Lavrence H., Elements of Materlals Science, Reading, Massschusetts, Addison-wesley Publishing Co., Inc., 1959.

Williams, B. A., "Fatigue Tests of Light Weight Aggregate Concrete Beans," Proceedings, American Concrete Institute, Vol. 39, pp. $441-447,1943$. 
APPBNDIX A

TBST DATA FOR CONCRETE MIOES 
Trble 8

DATA SHISET FOR LL MIX - Batch 1

Plastic Properties

$$
\begin{aligned}
& \text { slump }=2-5 / 8 \text { inches } \\
& \text { air content }=6.5 \text { per cent }
\end{aligned}
$$

Curing

1 day in molds

27 days in saturated lime solution

Drying

$$
\begin{aligned}
& \text { age at start }=28 \text { days } \\
& \text { age at finish }=32 \text { days }
\end{aligned}
$$

\section{Copping}

$$
\text { at age of } 33 \text { days }
$$

Static compression test

$$
\begin{array}{lcc}
\text { age when tested (days) } & \underline{34} & \underline{58} \\
\text { breaking stress (ps1) } & 3,500 & 3,270 \\
& 3,570 & 3,250 \\
& 3,110 & 3,470 \\
& 3,560 & 3,400 \\
& 3,750 & 3,020
\end{array}
$$

Fatigue tests

$$
\begin{array}{ccc}
\text { age of specimens: } & \text { at start }=34 \text { days } \\
\text { at flnish } & =55 \text { days } \\
\text { Maximum } & \text { Per cent of Static } \\
\text { Load } & \text { Stress Cycles Endured } & \begin{array}{c}
\text { Pltimate Strength } \\
\text { Ult }
\end{array} \\
9,900 & 10,304,600 & 40 \\
12,400 & 3,147,600 \text { falled } & 50 \\
14,800 & 688,700 \text { falled } & 60 \\
17,300 & 43,000 \text { Pailed } & 70 \\
19,800 & 19,100 \text { Palled } & 80
\end{array}
$$

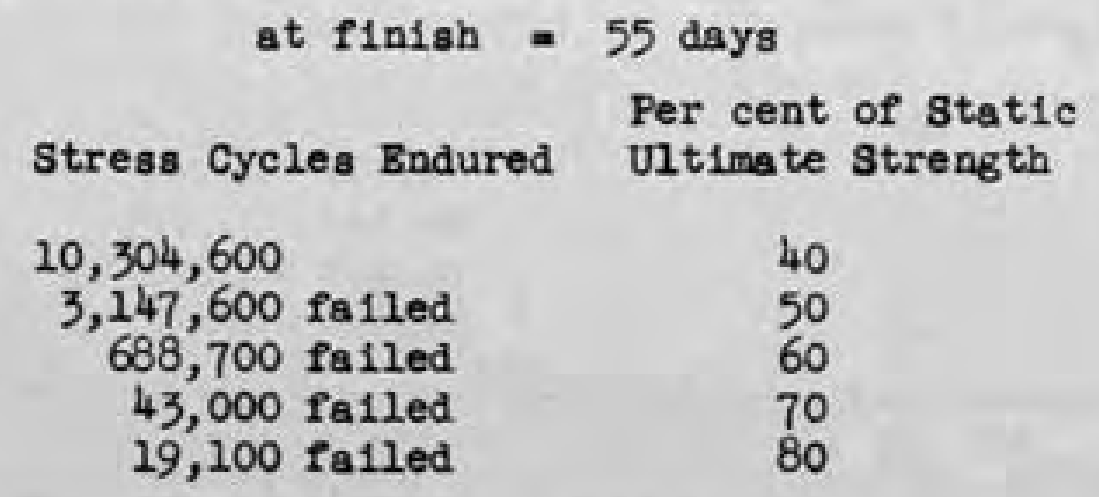

Minimum

Load

(1b)

900

800

700

900

800 
Table 9

DATA SHISET FOR LL MIX - Batch 2

Plastic Properties

$$
\begin{aligned}
& \text { slump }=2-3 / 8 \text { inches } \\
& \text { sir coutent }=6.1 \text { per cent }
\end{aligned}
$$

Curing

1 day in molds

27 days in saturated lise solution

Drying

$$
\begin{aligned}
& \text { age at start }=28 \text { days } \\
& \text { age at finish }=32 \text { days }
\end{aligned}
$$

Capping

$$
\text { at age of } 33 \text { days }
$$

\begin{tabular}{|c|c|c|c|}
\hline $\begin{array}{l}\text { Minimum } \\
\text { Load } \\
\text { (1b) }\end{array}$ & $\begin{array}{l}\text { Maximun } \\
\text { Losd } \\
\text { (1b) }\end{array}$ & Stress Cycles Bndured & $\begin{array}{l}\text { Per cent of Static } \\
\text { Ultinate Strength }\end{array}$ \\
\hline 900 & 10,800 & $10,005,400$ & 40 \\
\hline 800 & 13,500 & $4,926,400$ falled & 50 \\
\hline 500 & 16,200 & 396,600 falled & 60 \\
\hline 800 & 18,900 & 52,800 ralled & 70 \\
\hline 800 & 21,600 & 3,500 falled & 80 \\
\hline
\end{tabular}

Stat1c compression test

$$
\begin{array}{lc}
\text { age when tested (dsys) } & \text { 迅 } \\
\text { break1ng strength (ps1) } & 3,800 \\
& 3,450 \\
& 3,880 \\
4,210 \\
\\
& 3,760
\end{array}
$$

Fat1gue tests

$$
\begin{aligned}
\text { age of specimen: } & \text { at start }=34 \text { days } \\
& \text { st rinish }=45 \text { days }
\end{aligned}
$$


Table 10

DATA SHRBT POR LL MDX - Batch 3

Plast1c Properties

$$
\begin{aligned}
& \text { slump }=3-1 / 4 \text { inches } \\
& \text { air content }=7.6 \text { per cent }
\end{aligned}
$$

Curing

1 day in molds

27 days in saturated lime solution

Dry1ng

$$
\begin{aligned}
& \text { age at start }=28 \text { days } \\
& \text { age at } \mathrm{f} \text { inish }=32 \text { days }
\end{aligned}
$$

Capping

$$
\text { at age of } 33 \text { days }
$$

Stat1c Compression Test

Patigue Tests

$$
\begin{array}{lrr}
\text { age when tested (days) } & \text { 点 } & \text { 21 } \\
\text { breaking strength (psi) } & 3,920 & 3,970 \\
& 4,060 & 4,060 \\
& 4,240 & 3,810 \\
& 4,200 & 3,850 \\
& 3,890 & 3,800
\end{array}
$$

$$
\begin{aligned}
\text { age of specimen: } & \text { at start }=36 \text { days } \\
\text { at finish } & =51 \text { days }
\end{aligned}
$$

$\begin{array}{cccc}\begin{array}{c}\text { Minimum } \\ \text { Load }\end{array} & \begin{array}{c}\text { Maximum } \\ \text { Load } \\ \text { (1b) }\end{array} & \text { Stress Cycles Bndured } & \begin{array}{c}\text { Per cent of } \\ \text { Ultimate } 8 t r\end{array} \\ 700 & 11,500 & 10,464,100 & 40 \\ 500 & 14,300 & 9,204,100 & 50 \\ 900 & 17,200 & 1,610,000 \text { failed } & 60 \\ 800 & 20,100 & 51,400 \text { failed } & 70 \\ 500 & 23,000 & 1,600 \text { failed } & 80\end{array}$


Table 11

DATA SHEST FCR LL MIX - Batch 4

Plast1c Propert1es

sluap = 3 inches

air content $=7.5$ per cent

Curing

1 day in molda

27 days in saturated lime solution

Dry1ng

$$
\begin{aligned}
& \text { age at start }=28 \text { days } \\
& \text { age ot finish }=32 \text { days }
\end{aligned}
$$

Capping

$$
\text { at age of } 33 \text { days }
$$

Stat1c Compression Test

sge when teated (days)

breaking strength ( $p s 1$ )

3,720

3,640

4,160

4, 080

3,850

Pat1gue Test

$$
\begin{aligned}
\text { age of specimen: at start } & =34 \text { days } \\
\text { at finish } & =47 \text { days }
\end{aligned}
$$

\begin{tabular}{cc}
$\begin{array}{c}\text { Minimum } \\
\text { Load }\end{array}$ & $\begin{array}{c}\text { Maximum } \\
\text { Load }\end{array}$ \\
$(1 \mathrm{~b})$ & $(1 \mathrm{~b})$ \\
1000 & 11,000 \\
1100 & 13,700 \\
900 & 16,500 \\
800 & 19,200 \\
900 & 22,000 \\
\hline
\end{tabular}

Stress cycles endured

$$
\begin{array}{r}
10,418,100 \\
5,673,300 \text { failed } \\
1,217,000 \text { failed } \\
105,100 \text { failed } \\
8,600 \text { falled }
\end{array}
$$

Per cent of Static U1timate strength

40

50

60

70 
Table 12

DATA SHEET FOR LL MIX - Batch 5

\section{Plast1c Propert1es}

$$
\begin{aligned}
& \text { slump }=1-1 / 2 \text { inches } \\
& \text { alr content }=6.2 \text { per cent }
\end{aligned}
$$

\section{Curing}

\section{1 day in molds}

27 days in saturated lime solution

Drying

$$
\begin{aligned}
& \text { age at start }=28 \text { days } \\
& \text { age at finish }=32 \text { days }
\end{aligned}
$$

Capping

$$
\text { at age of } 33 \text { days }
$$

$\underline{\text { Static Conpression Test }}$

$$
\begin{array}{lr}
\text { age vhen tested (dnys) } & 34 \\
\text { breaking strength (pai) } & 3,500 \\
& 3,310 \\
3,600 \\
3,510 \\
3,710
\end{array}
$$

Patigue Test

$$
\begin{aligned}
\text { age of speciven: at start } & =34 \text { days } \\
\text { at rinish } & =54 \text { days }
\end{aligned}
$$

\section{Minimum}

Load

(1b)

$\begin{array}{rr}1000 & 10,000 \\ 1000 & 12,500 \\ 1000 & 15,000 \\ 900 & 17,500 \\ 1100 & 19,900\end{array}$

Load

(1b)
Maximus:

Stress cyeles endured

$11,723,300$

$4,628,100$ falled

$2,262,500$ Palled

26,300 falled

1,900 falled
Per Cent of Static Ultimate strength

40

50

60

70

80 
Table 13

DATA SHEET FOR HL MDX - Batch 2

Plast 1c Properties

$$
\begin{aligned}
& \text { slunp }=2-1 / 8 \text { Inches } \\
& \text { air content }=6.6 \text { per cent }
\end{aligned}
$$

Curing

$$
1 \text { day in molds }
$$

27 dsys in saturated 11me solution

Drying

$$
\begin{aligned}
& \text { age at start }=28 \text { days } \\
& \text { age at } \mathrm{fInish}=32 \text { days }
\end{aligned}
$$

\section{Capping}

$$
\text { at age of } 33 \text { dsys }
$$

\begin{tabular}{|c|c|c|c|}
\hline $\begin{array}{l}\text { Minimum } \\
\text { Load } \\
\text { (1b) }\end{array}$ & $\begin{array}{l}\text { Maximum } \\
\text { Load } \\
\text { (1b) }\end{array}$ & Stress cycles endured & $\begin{array}{l}\text { Per cent of Static } \\
\text { U1timate Strength }\end{array}$ \\
\hline 1000 & 17,800 & $10,458,700$ & 40 \\
\hline 1200 & 22,200 & $10,620,300$ & 50 \\
\hline 1100 & 26,700 & 720,500 falled & 60 \\
\hline Specimen & not tested & & 70 \\
\hline 1200 & 35.500 & 6,100 falled & 80 \\
\hline
\end{tabular}

Stat1c Compression Test

$$
\begin{array}{cc}
\text { sge vhen tested (days) } & \\
& \\
\text { breaking stress (pei) } & 5,960 \\
& 6,650 \\
& 6,290 \\
& 6,480 \\
& 6,140
\end{array}
$$

\section{Pat1gue Test}

$$
\begin{aligned}
\text { age of specimen: } & \text { at start }=58 \text { days } \\
\text { at finish } & =72 \text { days }
\end{aligned}
$$


Table 14

DATA SHEET FCR HL NDX - Batch 3

Plast1c Properties

$$
\begin{aligned}
& \text { slump }=2-3 / 8 \text { loches } \\
& \text { air content }=6.5 \text { per cent }
\end{aligned}
$$

Curing

1 day in molds

27 days in saturated lime solution

Drying

$$
\begin{aligned}
& \text { age at start }=28 \text { days } \\
& \text { age st finish }=32 \text { days }
\end{aligned}
$$

Capping

$$
\text { at age of } 33 \text { days }
$$

Stat10 Conpression Test

$$
\begin{aligned}
& \text { age when tested (dsys) } \\
& \text { breaking stress (psi) }
\end{aligned}
$$

Patigue Test

\begin{tabular}{cccc}
$\begin{array}{c}\text { Minimum } \\
\text { Load }\end{array}$ & $\begin{array}{c}\text { Maximum } \\
\text { Load }\end{array}$ & Stress cycles endured & $\begin{array}{c}\text { Per cent of static } \\
\text { U1timate Strength }\end{array}$ \\
$11 \mathrm{~b})$ & $(1 \mathrm{~b})$ & $10,216,500$ & 40 \\
1100 & 18,000 & $10,474,400$ & 50 \\
900 & 22,500 & $9,673,500$ & 60 \\
1000 & 27,000 & 150,900 fa1led & 70 \\
1000 & 31,500 & 6,600 fsiled & 80 \\
1000 & 36,000 & & \\
\hline
\end{tabular}


Table 15

DATA SHEET POR HL MTX - Batch 4

Plastic Properties

$$
\begin{aligned}
& \text { slump }=1-7 / 8 \text { Inches } \\
& \text { a1r content }=6.3 \text { per cent }
\end{aligned}
$$

Guring

1 day in molds

27 days in saturated lime solution

Drying

$$
\begin{aligned}
& \text { age at start }=28 \text { days } \\
& \text { age at } f 1 n 1 s h=32 \text { days }
\end{aligned}
$$

Capping

$$
\text { at age of } 33 \text { days }
$$

\begin{tabular}{|c|c|c|c|}
\hline $\begin{array}{l}\text { Minimum } \\
\text { Loed } \\
\text { (1b) }\end{array}$ & $\begin{array}{l}\text { Maximum } \\
\text { Load } \\
\text { (1b) }\end{array}$ & Stress cycles endured & $\begin{array}{l}\text { Per cent of Static } \\
\text { Ultimate strength }\end{array}$ \\
\hline & imen not & & \\
\hline 1000 & 22,500 & $4,751,300$ failed & 40 \\
\hline 1200 & 22,500 & $5,957,200$ falled & 50 \\
\hline 1000 & 27,000 & 736,400 falled & 60 \\
\hline 1000 & 31,000 & 166,100 failed & 70 \\
\hline 1000 & 36,000 & 5,400 falled & 80 \\
\hline
\end{tabular}

Static Compression Test

$$
\begin{array}{lcr}
\text { sge when tested (days) } & 69 & 24 \\
\text { breaking stress (pu1) } & 6,260 & 5,830 \\
& 6,250 & 6,310 \\
& 6,770 & 6,340 \\
& 6,250 & 6,280 \\
& 6,250 &
\end{array}
$$

Fatigue Teat

$$
\begin{array}{ll}
\text { age of specimen: } & \text { at start }=70 \text { days } \\
\text { at finish } & =92 \text { days }
\end{array}
$$


Table 16

DATA SHEES FOR HL MDX - Batch 5

Plastic Properties

$$
\begin{aligned}
& \text { slump }=3 \text { Inches } \\
& \text { a1r content }=6.8 \text { per cent }
\end{aligned}
$$

Curing

1 day in molds

27 days in saturated line solution

Drying

$$
\begin{aligned}
& \text { age at start }=28 \text { days } \\
& \text { age at finioh }=32 \text { days }
\end{aligned}
$$

Capping

$$
\text { at age of } 33 \text { days }
$$

Static Coepression Teat

$$
\begin{array}{cc}
\text { age when tested (days) } & 44 \\
\text { breaking stress (psi) } & 6,430 \\
& 6,490 \\
& 6,060 \\
& 6,560 \\
& 5,770
\end{array}
$$

\section{Patigue Test}

$$
\begin{aligned}
\text { age of speciven: at start } & =45 \text { days } \\
\text { at finish } & =89 \text { days }
\end{aligned}
$$

\begin{tabular}{cccc}
$\begin{array}{c}\text { Minimum } \\
\text { Load }\end{array}$ & $\begin{array}{c}\text { Maximum } \\
\text { Load }\end{array}$ & Per cent of Static \\
(1b) & $(1 \mathrm{~b})$ & Stress cycles endured & U1timate Strength \\
1300 & 22,200 & $10,499,400$ & 50 \\
1100 & 26,600 & $6,737,500$ failed & 60 \\
1100 & 31,000 & 611,900 failed & 70 \\
1100 & 35,400 & 111,000 fa1led & 80 \\
\hline
\end{tabular}


Table 17

DATA SHBXI POR HL MDX - Batch 6

\section{Plast1c Properties}

$$
\begin{aligned}
& \text { slump }=2-3 / 41 \text { nches } \\
& \text { air content }=7 \text { per cent }
\end{aligned}
$$

Curing

$$
1 \text { day in molds }
$$

27 days in ssturated lise solution

\section{Drying}

$$
\begin{aligned}
& \text { age at start }=28 \text { days } \\
& \text { age st finish }=32 \text { days }
\end{aligned}
$$

Capping

$$
\text { at age of } 33 \text { days }
$$

Stat1c Compreasion Test

$$
\begin{array}{lcc}
\text { age when tested (dsys) } & 69 & \text { 84 } \\
\text { breaking stress (ps1) } & 6,000 & 5,720 \\
& 6,270 & 6,100 \\
& 6,260 & 6,040 \\
& 5,440 & 5,280 \\
& 6,260 & 5,640
\end{array}
$$

Pat1gue Test

$$
\begin{aligned}
& \text { age of specimen: st start = } 71 \text { days } \\
& \text { at finish }=82 \text { days } \\
& 10,196,100 \\
& 4,116,700 \text { fsilled } \\
& 753,600 \text { falled } \\
& 86,300 \text { falled }
\end{aligned}
$$

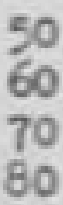

$\begin{array}{cc}\begin{array}{c}\text { Minfmum } \\ \text { Load }\end{array} & \begin{array}{c}\text { Maxinum } \\ \text { Load } \\ \text { (1b) }\end{array} \\ \begin{array}{c}\text { (1b) } \\ 1200\end{array} & 21,200 \\ 1100 & 25,400 \\ 1100 & 29,700 \\ 1100 & 33,900\end{array}$


APPBIDIX B

STATISTICAL ANALYSIS OP STATIC TBST DATA 
Table 18

BARTLETT'S TEST FOR BOMOGENBITY OF VARIANCE

POR STREKGTH DATA LON-STREIOTH CONCRETE

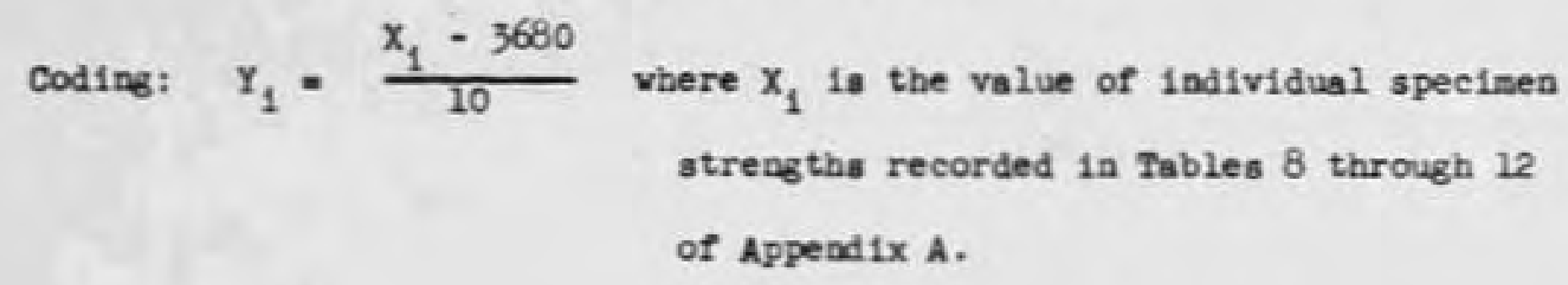

Batch Designation

$\begin{array}{lllll}\text { LL 1 L L 2 } & \text { LL 3 } & \text { LL 4 } & \text { LL 5 } \\ -18 & +12 & +24 & +4 & -17 \\ -11 & -23 & +38 & -4 & -37 \\ -57 & +20 & +56 & +48 & -8 \\ -12 & +53 & +52 & +40 & -17 \\ +7 & +8 & +21 & +17 & +3\end{array}$

\begin{tabular}{|c|c|c|c|c|c|}
\hline $\mathbb{B}_{\mathrm{j}}$ & 5 & 5 & 5 & 5 & 5 \\
\hline$\sum_{1}^{\sum} Y_{1 j}$ & -91 & +70 & +191 & +105 & -76 \\
\hline$\sum_{1} Y_{1 j}^{2}$ & 3887 & 3946 & 8301 & 4225 & 2020 \\
\hline 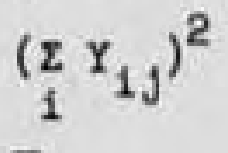 & 8281 & 4900 & 26481 & 11025 & 5776 \\
\hline$\overline{\mathbf{Y}}_{\mathrm{J}}$ & -18.2 & +14.0 & +38.2 & +21.0 & -15.2 \\
\hline$s_{j}^{2}$ & 4444.70 & 4687.50 & 8552.20 & 4730.00 & 2236.20 \\
\hline
\end{tabular}

vhere

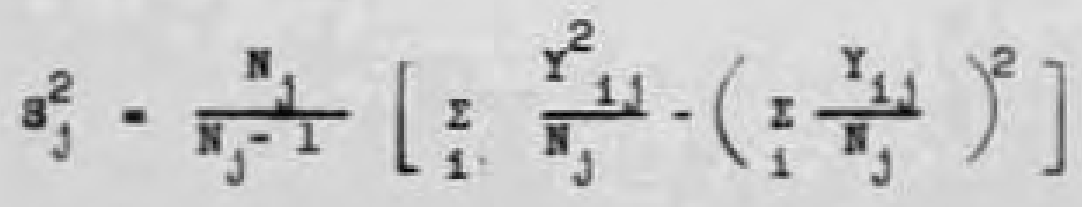

$z_{1} s_{j} \log s_{j}^{2}$

$=73.10092$

$\left[\begin{array}{ll}z \mathrm{~s}_{j} \\ 1\end{array}\right]\left[\log \frac{z_{j} \mathrm{x}_{j} s_{j}^{2}}{z \mathrm{~s}_{j}}\right]=73.85720$ 
Table 18 (continued)

$\begin{aligned} M & =2.30259\left[\left(\sum n_{j}\right)\left(\log \frac{\sum \mathrm{N}_{j} s_{j}^{2}}{\sum_{j} N_{j}}\right)-\sum_{j} N_{j} 108 s_{j}^{2}\right] \\ & =1.7410\end{aligned}$

$c=1+\frac{1}{3(j-1)}\left[\sum_{j} \frac{1}{x_{j}}-\frac{1}{\sum_{j} \mathbb{B}_{j}}\right]=1.10000$

$\mathrm{M} / \mathrm{C}=1.58$

$x^{2} \cdot 05^{(4)}=9.49>M / C$

At the 56 significance level there is no reason to believe that the varlance of the five batch strengths are different. 
Table 19

ANALYSIS OF VARIANCE FOR DIFTERENCE BETWEEN

BATCH VEAN STRENOTHS OF LOW-BTREINTH CONCRETE

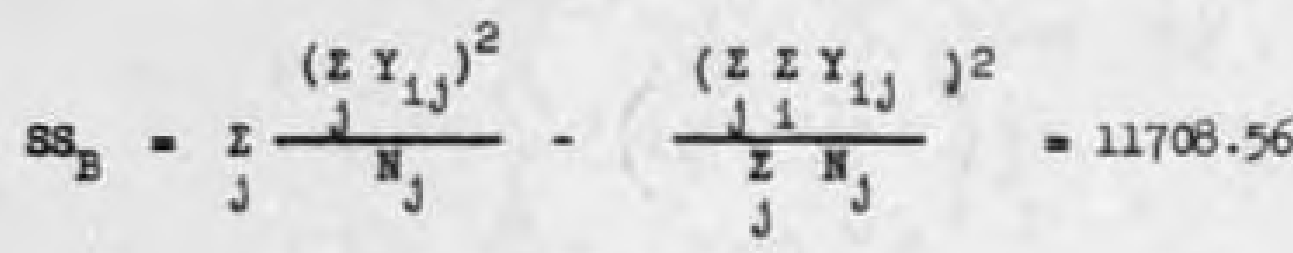

$s s_{e}=\sum_{j} \sum Y_{1 j}^{2}-z_{j} \frac{\left(\sum Y_{1 j}\right)^{2}}{n_{J}} \quad=9086.40$

$s s_{t}=\sum_{j I} z Y_{1 J}^{2}-\frac{\left(\sum \Sigma Y_{1 J}\right)_{2}}{z s_{J}}=20794.96$

ANOVA TABLE

Source

If Sum of Squares Nean Square

F ratio

batch

error

$4 \quad 11,708.56$

$2,927.14$

6.44

Total

20 9,066.40 454.32

$24 \quad 20,794.96$

$$
{ }^{P} .05(4,20)=2.87<6.44
$$

At the 5 olgnificance level there is reason to belleve that the five average bateh strengthe are different.

\section{Comparison of Difference}

$s_{e}^{2}=454.32$

$s \bar{y}=\sqrt{454 \cdot 32 / 4}$

.10 .66

$R_{5}=4.23 \times 10.66=45.0$

$\mathrm{R}_{4}=3.96 \times 10.66=42.2$

$R_{3}=3.58 \times 10.66=38.2$

$R_{2}=2.92 \times 10.66=31.1$ 
Table 19 (cont1nued)

\begin{tabular}{ccccc}
\hline Batch & 1 & 5 & 2 & 4 \\
\hline 3 & 56.4 & 53.4 & 24.2 & 17.2 \\
4 & 39.2 & 36.2 & 7.0 & \\
2 & 32.2 & 29.2 & & \\
5 & 3.0 & & & \\
\hline
\end{tabular}

At the of significance level there is reason to belleve that the average strength of batch LL 3 is different than the average batch strengths of batches LL 1 and LL 5 . 
Table 20

\section{BARTLETT'S TEST FOR HOMOOENEITY OF VARIARCE}

FOR STREICTH DATA HIGH-STREIXTH CONCRETE

$$
\begin{gathered}
\text { Coding: } Y_{1}=\frac{\frac{X_{1}-6000}{10} \text { where } X_{1} \text { is the value of the individual }}{\text { specimen strengths recorded in Tables } 13} \\
\text { through } 17 \text { of Appendix A. }
\end{gathered}
$$

\begin{tabular}{|c|c|c|c|c|}
\hline 프 2 & 프 3 & BL 4 & HEL 5 & HL 6 \\
\hline $\begin{array}{l}-2 \\
+65 \\
+29 \\
+48 \\
+14\end{array}$ & $\begin{array}{r}-5 \\
+86 \\
+67 \\
+27 \\
+5\end{array}$ & $\begin{array}{l}+26 \\
+25 \\
+78 \\
+25 \\
+25\end{array}$ & $\begin{array}{l}+43 \\
+49 \\
+6 \\
+56 \\
-23\end{array}$ & $\begin{array}{l}-1 \\
+27 \\
+27 \\
-65 \\
+13\end{array}$ \\
\hline 5 & 5 & 5 & 5 & 5 \\
\hline 154 & 180 & 179 & 131 & 1 \\
\hline 7570 & 12664 & 8635 & 7951 & 5853 \\
\hline 3716 & 32400 & 32041 & 17161 & 1 \\
\hline 30.80 & 36.00 & 35.80 & 26.20 & 0.20 \\
\hline & 1546.0 & 556.7 & 1129.7 & 1463.2 \\
\hline
\end{tabular}

\section{Batch Designation}

where

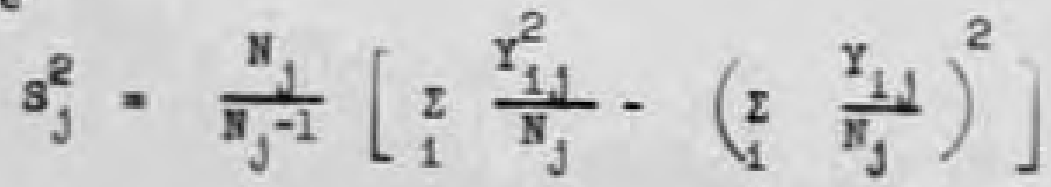

$$
\begin{aligned}
& z_{j} N_{j} \log s_{j}^{2}=60.00932 \\
& {\left[\begin{array}{ll}
z & s_{j}
\end{array}\right]\left[\log \frac{\frac{2}{z} s_{j} s_{j}^{2}}{\frac{3}{3} s_{j}}\right]=60.67240}
\end{aligned}
$$


Table 20 (continued)

$M=2.30259\left[\left(\sum_{j} \mathbb{N}_{j}\right)\left(\log \frac{\sum \mathbb{N}_{j} s_{j}^{2}}{\sum \mathbb{N}_{j}}\right)-\sum_{j} \mathbb{N}_{j} \log s_{j}^{2}\right]$

$=1.52680$

$C=1+\frac{1}{3(j-1)}\left[\sum_{j} \frac{1}{B_{j}}-\frac{1}{\sum \pi_{j}}\right]=1.10000$

$\mathrm{M} / \mathrm{C}=1.39$

$x^{2} .05(4)=9.49>x / c$

At the 56 aignificance level there is no reason to belleve that the varlance of the five batch strength is different. 
Table 21

AKALYSIS $O F$ VARIAKCE FOR DIFFERBSCE BSTMEEN

BATCH MEAN STRBITTAS OP HIGH-STRBNGT COKCRER

$s_{B}=\sum_{j} \frac{\left(\sum Y_{1 j}\right)^{2}}{N_{j}}-\frac{\left(\sum \sum Y_{1 j}\right)_{2}}{\sum_{j} N_{j}}=4422.80$

$s s_{e}=\sum_{j i} \sum_{i j}^{2}-\sum_{j} \frac{\left(\sum Y_{i j}\right)_{2}}{\mathbb{B}_{j}}=21609.20$

$s s_{t}=\sum_{j i} \sum Y_{1 j}^{2}-\frac{\left(\sum \sum Y_{1 j}\right)_{2}}{\sum_{j} N_{j}}=26032.00$

ANOVA TABLB

Bource

df Sum of Squares Nean Square

Pratio

batch

$4 \quad 4422.80$

$1105 \cdot 70$

1.02

error

$\underline{20} \quad \underline{21609.20} \quad \underline{1080.46}$

Total

$24 \quad 26032.00$

$$
F_{.05}(4,20)=2.87>1.02
$$

At the 56 significance level there is no reason to belleve that the five average batch strengths are different. 
Table 22

TEST FOR DIFFERENCE OF MIX STRENGTHS
LI Mix
$\mathrm{N}=25$
$\bar{Y}=3760$
$s^{2}=866.45666$
HIL Mix
$\mathbb{N}=25$
$\bar{Y}=6260$
$s^{2}=1084.66666$

Difference in variance

$$
\begin{aligned}
& F=\frac{1084.66666}{866.45666}=1.25 \\
& F_{.05}(24,24)=1.98
\end{aligned}
$$

At the $5 \%$ significance level there is no reason to believe that there is any difference in the variance of the two mix designs.

\section{Difference in means}

$$
\begin{aligned}
& t=\frac{\bar{Y}_{1}-\bar{Y}_{2}}{\sqrt{\left[\frac{\left(N_{1}-1\right) s_{1}^{2}+\left(N_{2}-1\right) s_{2}^{2}}{N_{1}+N_{2}-2}\right]\left[\frac{1}{N_{1}}+\frac{1}{N_{2}}\right]}} \\
& t=56.60 \\
& t_{.10}^{(48)}=2.68<56.60
\end{aligned}
$$

At the $5 \%$ significance level there is reason to believe that the mean of the $\mathrm{BL}$ mix is significantly larger than the mean of the LL mix. 
Table 23

TEST FOR DIFFERENCB IN BATCH STRENGTHS

BEFORE AND AFTER FATIGUE TESTINE - BATCH LL 1

Raw strength

$$
\mathrm{Y}_{1}=\mathrm{X}_{1}
$$

\section{Before \\ Fatigue \\ Testing}

3500

3580

3110

3560

3570
After

Fat1gue

Test1ng

3270

3250

3470

3400

3020
Coded Strength

$$
Y_{1}=\frac{x_{1}-3200}{10}
$$

\section{Before \\ Fatigue \\ Testing}

After

Fatigue

Testing

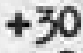

$+38$

$-9$

$+36$

$+55$

$+7$

$+5$

$+27$

$+20$

$-18$

$F=\frac{561.50}{336.75}=1.67$

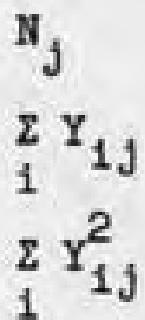

5

5

41

1527

6746

30.0

8.2

561.50

$F_{.025}(4,4)=9.60>1.67$

$\begin{array}{ccc}\bar{y}_{j} & 30.0 & 8.2 \\ s_{j}^{2} & 561.50 & 336.75\end{array}$

At the $5 \%$ significance level there is no reason to believe that the two variances are not equal.

$$
\begin{aligned}
& t=\frac{\bar{Y}_{1}-\bar{y}_{2}}{\sqrt{\left[\frac{\left(\mathbb{N}_{1}-1\right) s_{1}^{2}+\left(N_{2}-1\right) s_{2}^{2}}{N_{1}+N_{2}-2}\right]\left[\frac{1}{N_{1}}+\frac{1}{N_{2}}\right]}} \\
& t=2.373 \\
& t_{.05}(8)=2.306<2.373 .
\end{aligned}
$$

At the $5 \%$ significance level there is reason to belleve that the two means are different. The data indicate that the strength decreases after fatigue testing. 
Table 24

TEST FOR DIFFERENCE IN BATCH STRENGTHS

BEFORE AND AFTER FATIGUE TESTING

Batch LI 3

Raw Strength

$$
\mathrm{Y}_{1}=\mathrm{x}_{1}
$$

\section{After}

Patigue

Testing

3970

4060

3810

3850

3800
Before

Fatigue

Testing

12

26

44

40

9

5

131

4437

26.2

251.20
Coded strength

$$
Y_{1}=\frac{x_{1}-3800}{10}
$$

$\mathrm{N}_{3}$

$Y_{1} Y_{1 J}$

$\sum Y_{1 j}^{2}$

$\overline{\mathbf{Y}}_{\mathrm{J}}$

$\mathrm{s}^{2}$
After

Patigue Testing

17

26

1

5

5

49

991

9.8

127.70

At the $5 \%$ significance level there is no reason to believe that

the two variances differ.

$$
\begin{aligned}
& t=\frac{\overline{\mathrm{Y}}_{1}-\overline{\mathrm{Y}}_{2}}{\sqrt{\left[\frac{\left(\mathrm{N}_{1}-1\right) \mathrm{s}_{1}^{2}+\left(\mathrm{N}_{2}-1\right) \mathrm{s}_{2}^{2}}{\mathrm{~N}_{1}+\mathrm{N}_{2}}\right]\left[\frac{1}{\mathrm{~N}_{1}}+\frac{1}{N_{2}}\right]}} \\
& t_{.05}=1.88 \\
& t_{.02}=2.306>1.88
\end{aligned}
$$

At the $5 \%$ significance level there is no reason to belleve that the means are different. 
Table 25

TEST FCR DIFFERENCE IN BATCH STREICTHS

BEYORE AND AFTER FATIGUE TESTINC

Batch BII 4

Rav strength

$$
\mathrm{x}_{1}=\mathrm{x}_{1}
$$

\section{Before \\ Fatigue \\ Testing}

$\begin{array}{ll}6260 & 5830 \\ 6250 & 6310 \\ 6770 & 6340 \\ 6250 & 6280\end{array}$

6250

$\mathbf{F}=\frac{260.0}{535.8}=1.79$

$F_{.025}(3,4)=9.98$
After

Patigue

Testing

5830

6340

6280

Coded Strength

$$
y_{1}=\frac{x_{1}-6250}{10}
$$

\section{Before \\ Fatigue \\ Testing}

$+1$

0

$+52$

0

0
After

Fatigue

Testing

$-42$

$+6$

$+9$

$+3$

4

$-24$

3024

$\sum \mathrm{Y}_{13}^{2} 2705$

10.6

$-6.0$

960.0

At the 5 significance level there is no reason to believe that the two variances differ.

$$
\begin{aligned}
& t=\frac{\bar{y}_{2}-\bar{y}_{1}}{\sqrt{\left[\frac{\left(N_{1}-1\right) s_{1}^{2}+\left(N_{2}-1\right) s_{2}^{2}}{N_{1}+N_{2}-2}\right]\left[\frac{1}{N_{1}}+\frac{1}{N_{2}}\right]}} \\
& t=0.924 \\
& t_{.05}(7)=2.365>0.924 .
\end{aligned}
$$

At the 57 significance level there is no reason to belleve that the mean are different. 
Table 26

TEST FOR DIFFERENCE IN BATCH STRENGTHS

BAFORE AND AFTER FATIGUE TESTING

Batch HL 6

Raw Strength

$$
\mathrm{Y}_{1}=\mathrm{X}_{1}
$$

After

Fatigue

Testing

5720

6100

6040

5280

5640

6260

$F=1.16$

$F_{.025}(4,4)=9.60>1.16$

Coded Strength

$$
Y_{1}=\frac{x_{1}-5750}{10}
$$

$\begin{array}{r}\text { Before } \\ \text { Fatigue } \\ \text { Testing } \\ \hline\end{array}$

$+25$

$+52$

$+51$

$-31$

$+51$

5

148

$\sum_{i} Y_{i j}$

$\sum Y_{1 j}^{2}$

$\bar{Y}_{j}$
$s_{j}^{2}$

9492

29.6

1277.8
After

Fatigue

Testing

$-3$

$+35$

$+29$

$-47$

$-11$

5

3

4405

0.6

At the $5 \%$ significance level there is no reason to belleve that the two variances are different.

$$
\begin{aligned}
& t=\frac{\bar{y}_{1}-\bar{y}_{2}}{\sqrt{\left[\frac{\left(N_{1}-1\right) s_{1}^{2}+\left(N_{2}-1\right) s_{2}^{2}}{N_{1}+N_{2}-2}\right]\left[\frac{1}{N_{1}}+\frac{1}{N_{2}}\right]}} \\
& t=1.330 \\
& { }^{.} .05(8)=2.306>1.330
\end{aligned}
$$

At the $5 \%$ significance level there is no reason to believe that the two means are different. 
APPBNDIX C

STATISTICAL ANALYSIS CF FATIGUE TEST DATA 
Table 27

CALCULATIONS FOR RUN TEST

Bof Streas Level

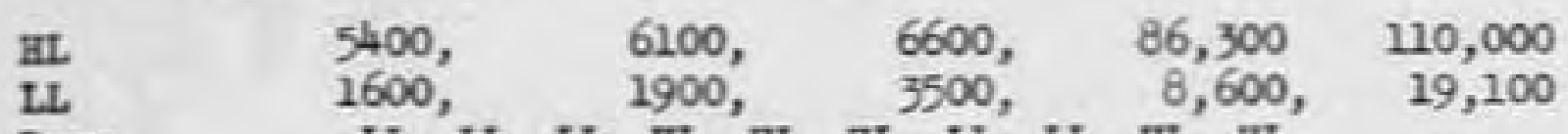

Runs

IL. LL LL HL HL HL LL LL HL HL

$$
\mu=4 \quad 2 \leq \mu \leq 9
$$

$70 \%$ stress Leve1

$$
\begin{aligned}
& \mu=2 \\
& 2 \leq \mu \leq 8
\end{aligned}
$$

606 stress Level

HL $\quad 720,500,736,400,4,116,700,6,737,500,9,673,500 \rightarrow(*)$

LL $\quad 396,600,688,700,1,217,000,1,610,600,2,262,500$

Runs LL LL HL HL LL LL LL HL HL

$$
\mu=4 \quad 2 \leq \mu \leq 8
$$

50 Stress Leve1
HII $\quad 4,751,300, \quad 5,957,200, \quad 10,474,400,-10,499,400,-$ $10,620,300, \rightarrow 12,196,100 \rightarrow$
LI $3,147,600, \quad 4,628,100, \quad 4,926,400 \quad 5,673,300$, $9,204,100 \rightarrow$

Runs LL LL HL LL LL HL

$$
\mu=4 \quad 4 \leq 5
$$

40 Stress Level

HL

$$
10,216,500, \rightarrow 10,458,700 \rightarrow
$$

LI

$$
\begin{aligned}
& 10,005,400, \rightarrow 10,304,600, \rightarrow 10,418,100, \rightarrow 10,464,100 \rightarrow \\
& 11,723,300, \rightarrow
\end{aligned}
$$

No run test can be made

(*) - Indicates that the specimen did not fall. No run test can be made using these specimens since the actual number of cycles which vili cause failure is unknown. 
Table 28

LINEAR RBERBSSION CALCULATIONS

LON-STREICTH CONCRETE - ALL BATCHES

Stress Level $-\mathrm{x}_{\mathrm{J}}$

608

여

806

Log of cyeles
to failure $-Y$.

5.83803

5.59635

6.20699

6.08529

6.35459

$x_{3}$

z $Y_{1 j}$

$\sum Y_{1}^{2}$

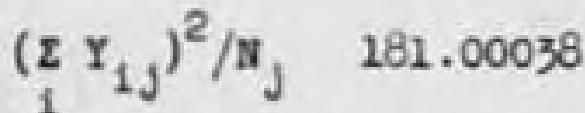

$\overline{\mathbf{y}}_{\mathrm{j}}$

6.01665

30.08325

181.36241

4.63347
4.72263

4.71096

5.02160

4.41996

5

23.50862

110.71794

110.53104

4.70172

3.34849

4.28103

3.54407

3.20412

3.93450

3.27875

5

18.24247

67.38453

66.55754

$s s_{x y}=\sum_{j} \sum_{i} x_{j} Y_{i j}-\frac{\sum \sum Y_{i j}}{\sum_{j} N_{j}}\left(\sum N_{j} X_{j}\right)=-118.40150$

$s s_{x}=\sum_{j} N_{j} x_{j}^{2}-\frac{1}{\sum N_{j}}\left(\Sigma N_{j} x_{j}\right)^{2}=1000$

$b=\frac{s_{x y}}{s s_{x}}=-0.11840$

$a=\sum_{j} \sum_{1} Y_{1 J} / \sum_{j} x_{j}=4.78895$

$\bar{x}=z_{j} s_{j} x_{j} / z_{j} x_{j}=70$

$\hat{y}=a+b(x-\bar{x})$

vhere $y=\log$ of the cycles to fallure and $X$ - the stress level. 
Table 28 (cont1nued)

$$
\begin{aligned}
& \widehat{\log N}=13.07695-0.11840 \mathrm{~s} \\
& 3 s_{1}=\sum_{j} \frac{\left(\Sigma Y_{1 J}\right)^{2}}{N_{j}}-\frac{\left(\Sigma \Sigma Y_{1 J}\right)^{2}}{\sum \mathbb{N}_{J}}=14.07747 \\
& 8 S_{e}=\sum_{j} \sum_{j} Y_{1 J}^{2}-\sum_{j} \frac{\left(\Sigma Y_{1 j}\right)^{2}}{N_{j}}=1.37592
\end{aligned}
$$

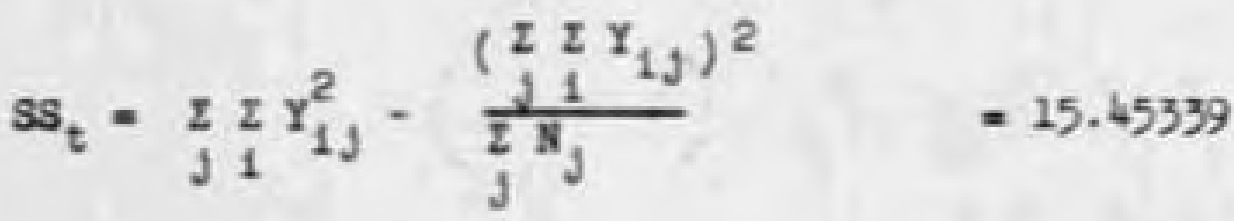

\section{ANOVA TABLE}

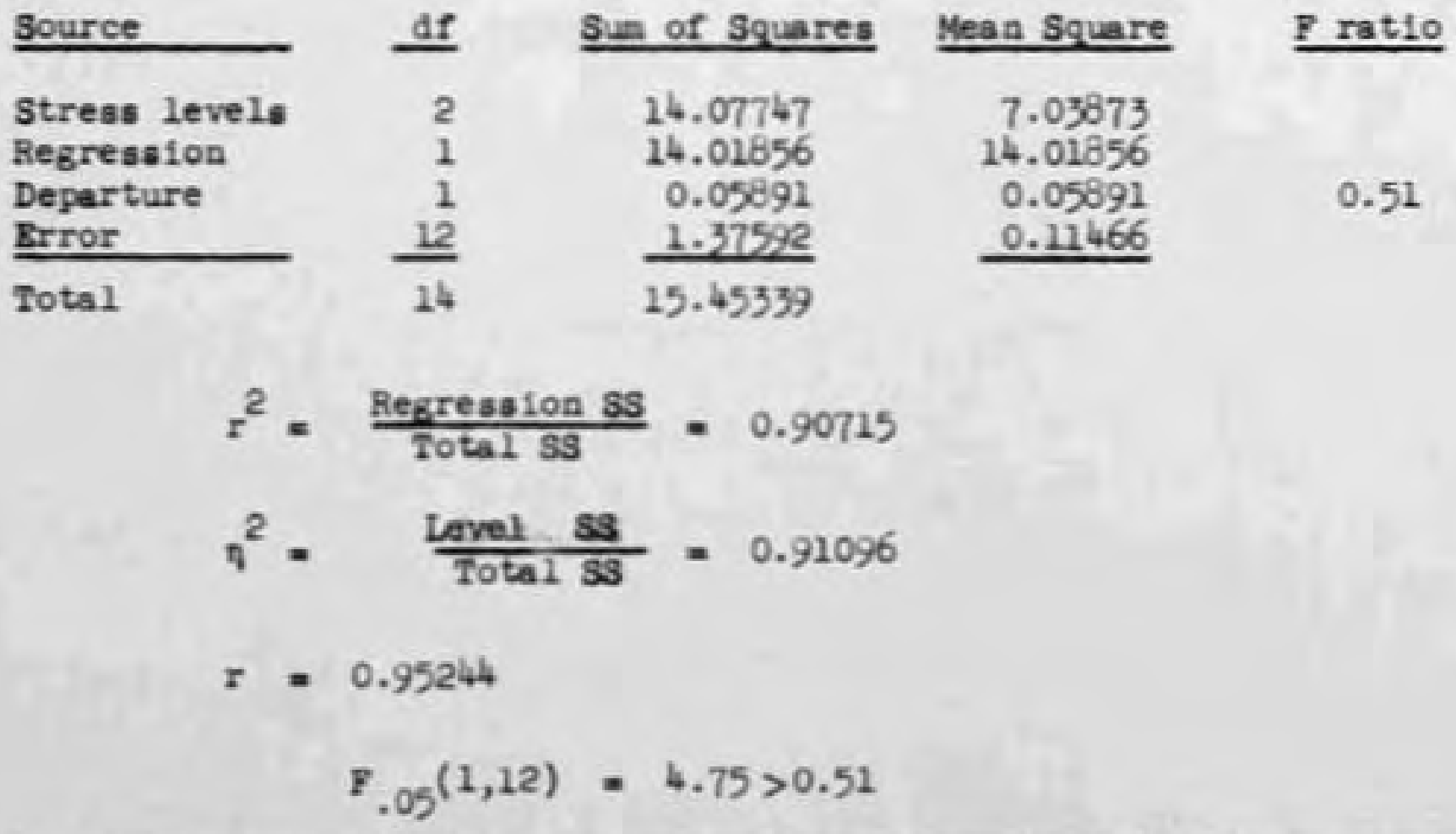

$\begin{array}{r}2 \\ 1 \\ 1 \\ 12 \\ \hline 14\end{array}$

At the 5 s ignifleance level there is no reason to belfeve that the $8-8$ relationship is not 11 near. 
Table 29

LINEAR RBGRESSION CALCULATIONS

HIGH-STREMTH CONCRETE

Batches HL 2, HL 3, HL 4

$$
\text { Stress Level }-x_{j}
$$

604

5.85763

5.86711

2

11.72474

68.73481

68.73476

5.86237
704

5.17869

5.22037

2

10.39906

54.07109

54.07022

5.19953
8영

3.78533

3.81954

3.73239

3

11.33726

42.84834

42.84448

3.77908

$$
s s_{x y}=\sum_{j} \sum X_{j} Y_{1 J}-\frac{\sum \sum Y_{1 J}}{\sum N_{j}}\left(\sum_{j} N_{j} X_{j}\right)=-51.67560
$$

$$
\begin{aligned}
& s s_{x}=\sum_{j} x_{j} x_{j}^{2}-\frac{1}{\sum n_{j}}\left(\sum x_{j} x_{j}\right)^{2} \\
& b=\frac{s_{x y}}{s s_{x}}=-0.10639 \\
& a=\sum_{j} \sum_{1} Y_{1 j} / \sum_{j} \mathrm{~s}_{j}=4.78015 \\
& \bar{x}=z_{j} s_{j} x_{j} / z_{j} x_{j}=71.42857
\end{aligned}
$$


Table 29 (continued)

$$
\widehat{Y}=a+b(X-\bar{X})
$$

vhere

$$
Y=\log \text { of the cycles to fallure }
$$

and $X=$ the stress level

$$
\begin{aligned}
& \widehat{\log 8}=12.37944-0.10639 \mathrm{~s} \\
& s s_{1}=\sum_{j} \frac{\left(\sum Y_{i j}\right)^{2}}{\mathbb{N}_{j}}-\frac{\left(\sum_{j} Y_{1 J}\right)^{2}}{\sum_{j} \mathbb{B}_{j}}=5.70053 \\
& S s_{e}=\sum_{j} \sum_{j} Y_{1 j}^{2}-\sum_{j} \frac{\left(\Sigma Y_{1 j}\right)^{2}}{\Delta_{j}}=0.00478 \\
& 3 s_{t}=\sum_{j} \sum_{1} Y_{1 j}^{2}-\frac{\left(\sum \Sigma Y_{1 J}\right)_{2}}{\sum j N_{j}}=5.70531
\end{aligned}
$$

\section{ANOVA TABLE}

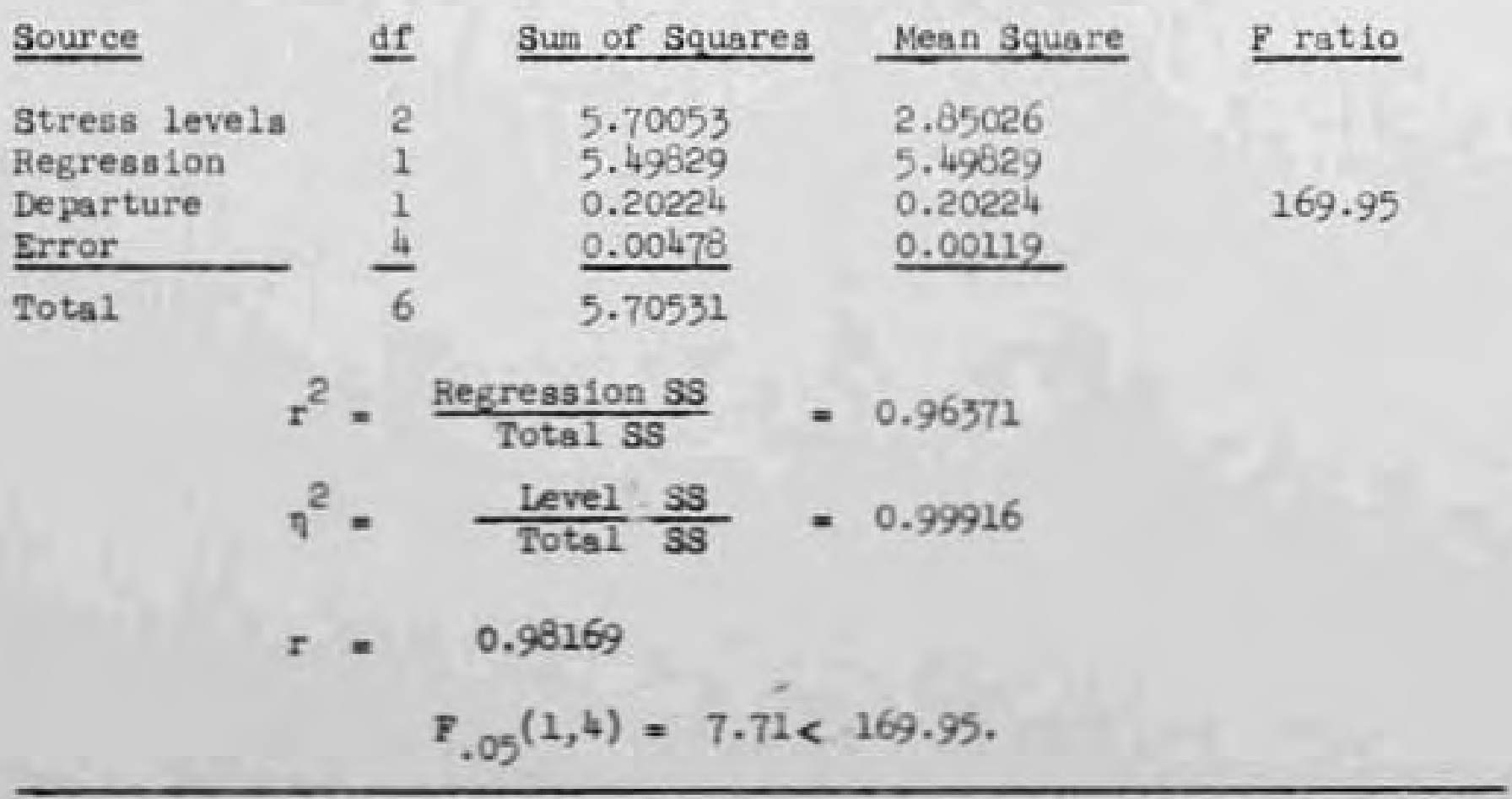

At the 5 significance level there is reason to belleve that the S-8 relationahip is not 11 near. 
Table 30

\section{LINEAR RBGRBSSION CALCULATIONS}

HIGH-STREIGTH CONCRETE

Batches HL 5, HL 6

$$
\text { Stress Level }-x_{j}
$$

$$
\begin{aligned}
& 608 \\
& 708 \\
& 6.82850 \\
& 6.61455 \\
& 5.78669 \\
& 5.87714 \\
& 805 \\
& 2 \\
& 2 \\
& 5.04139 \\
& 4.93601 \\
& n_{3} \\
& 13.44305 \\
& 11.66382 \\
& 2 \\
& \begin{array}{ll}
\boldsymbol{Z} & \mathbf{Y}_{1 \mathrm{~J}} \\
\mathbf{1} &
\end{array} \\
& 90.38068 \\
& 68.02644 \\
& 9.97740 \\
& \begin{array}{ll}
z & y_{1 J}^{2}
\end{array} \\
& \left(z_{1} Y_{1 j}\right)^{2} / \mathbb{N}_{j} \\
& 90.35779 \\
& 68.02235 \\
& 49.77425 \\
& \overline{\mathbf{Y}}_{\mathrm{J}} \\
& 6.72152 \\
& 5.83191 \\
& 4.98870 \\
& S s_{x y}=\sum_{j} \sum X_{j} Y_{1 j}-\frac{\sum \sum Y_{1 J}}{\sum_{j} N_{j}}\left(\sum_{j} N_{j} X_{j}\right)=-33.95580 \\
& \text { ss }=\sum_{j} N_{j} x_{j}^{2}-\frac{1}{\sum N_{j}}\left(\sum_{j} N_{j} x_{j}\right)^{2} \\
& =400 \\
& \mathrm{~b}=\frac{\mathrm{ss}_{x y}}{\mathrm{ss}_{\mathrm{x}}}=-0.08488 \\
& \text { a } \quad=\sum_{j} \sum_{1} Y_{1 J} / \sum_{j} \mathbb{x}_{j}=5.84571 \\
& \bar{x}=\Sigma_{j} \mathbf{x}_{j} x_{j} / \Sigma_{j} \mathbf{s}_{j}=70 \\
& \widehat{Y}=a+b(X-\bar{X})
\end{aligned}
$$


Table 30 (continued)

$$
\begin{aligned}
& S_{1}=\sum_{j} \frac{\left(\sum Y_{1 j}\right)^{2}}{N_{j}}-\frac{\left(\sum \sum Y_{1 j}\right)}{\sum_{j} N_{j}}=3.12032 \\
& S S_{e}=\sum_{j} \sum_{i} Y_{i j}^{2}-\sum_{j} \frac{\left(\sum Y_{i j}\right)^{2}}{N_{j}}=0.03254 \\
& S S_{t}=\sum_{j i} Y_{1 j}^{2}-\frac{\left(\sum \sum Y_{i j}\right)_{j}}{\sum N_{j}}=3.15288
\end{aligned}
$$

\section{ANOVA TABLE}

Source

Stress levels Regression Departure Error Total df Sum of Squares Mesn Square

1.56016

2.88184

0.23848

0.01084

3.12032 2.88184 0.23848

0.03254
F ratio

3.15286

$$
\begin{aligned}
& r^{2}=\frac{\text { Regression SS }}{\text { Total SS }}=0.91403 \\
& \eta^{2}=\frac{\text { Leve1 SS }}{\text { Total SS }}=0.98967 \\
& r=0.95605
\end{aligned}
$$

$$
F_{.05}(1,3)=10.1<22.0
$$

At the $5 \%$ significance level there is resson to believe that the S-N relationship is not linear. 
Table 31

TEST FOR DIFFERENCE IN CORRELATION COEYFICIENTS

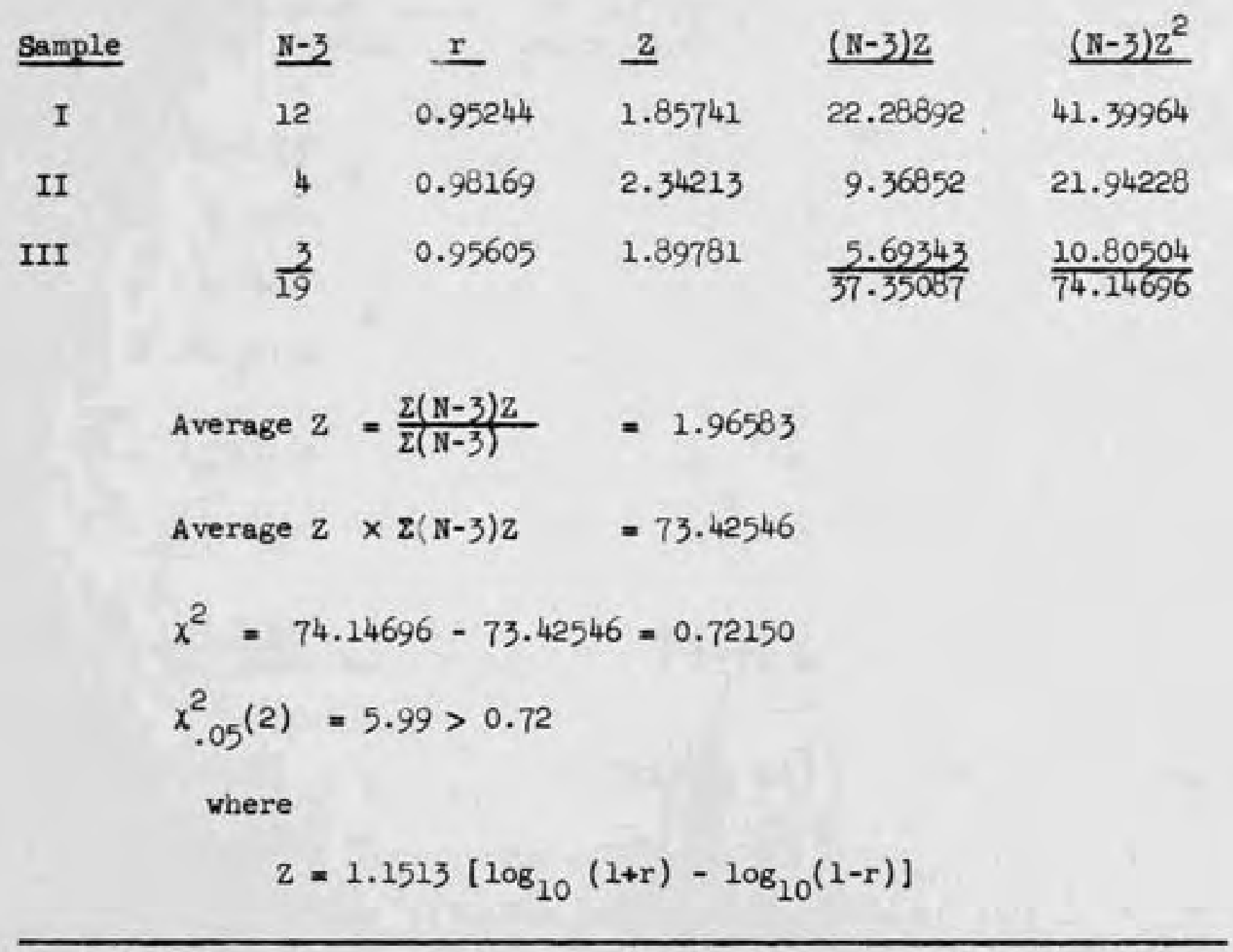

At the $5 \%$ significance level there is no reason to belleve that the three correlation coefficients are different. 
Table 32

\section{COMPARISON OF SLOPES}

All of the folloving values can be found directly in the linear regression calculations and are only sumarized in this table. The definitions of the symbols used are found in Table 107 of Reference 23.

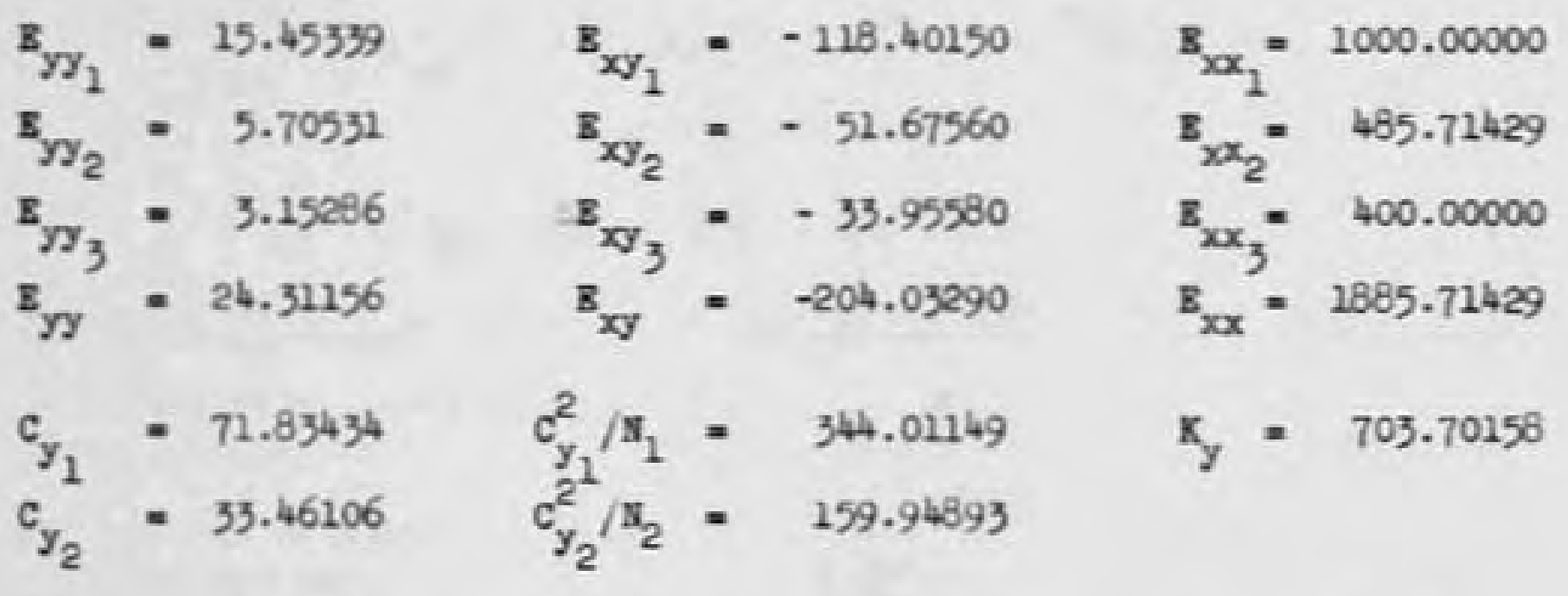

$c_{y_{3}}=\frac{35.07427}{140.36967} \operatorname{tota1} c_{y_{3}}^{2} / \mathbb{s}_{3}=\frac{205.03407}{708.99449} \operatorname{Total} c_{y y}=5.29291$

$$
\begin{array}{lll}
c_{x_{1}}=1050 & c_{x_{1}}^{2} / N_{1}=73500.00000 & k_{x}=138703.57142 \\
c_{x_{2}}=500 & c_{x_{2}}^{2} / N_{2}=35714.28571 & \\
c_{x_{3}}=\frac{420}{1970} \text { Total } & c_{x_{3}}^{2} / N_{3}=\frac{29400.00000}{138714.28571} \text { Total } c_{x x}=10.71429
\end{array}
$$

$$
\begin{aligned}
& c_{x_{1} y_{1}} / N_{1}=5028.40380 \quad k_{x y}=9876.00892 \\
& c_{x_{2} y_{2}} / N_{2}=2390.07571 \\
& c_{x_{3} y_{3}} / s_{3}=\frac{2455.19890}{9673.67841} \text { Total } \quad c_{x y}=-2.33051 \\
& \sum_{j} \Sigma_{1} Y_{1 j}^{2}=733.30605 \quad s_{y y}=29.60447 \\
& \sum_{j} x_{1 j}^{2} \quad=140500.00000 \quad s_{x x}=1896.42858 \\
& z_{j} z_{1 j} x_{1 j}=9669.63780 \quad s_{x y}=-206.37112 \\
& z \frac{\mathrm{s}_{x y_{1}}^{2}}{\frac{\mathrm{s}_{x x}}{x_{j}}}=22.39921 \quad \frac{\mathrm{s}_{x y}^{2}}{\mathrm{~s}_{x x}}=22.07620
\end{aligned}
$$


Table 32 (continued)

$$
\frac{c_{x y}^{2}}{c_{x x}}=0.50691 \quad \frac{s_{x y}^{2}}{s_{x x}}=22.45749
$$

General Model

$$
Y_{1 j}=\mu+\theta+B_{m}\left(\bar{x}_{j}-\bar{x}\right)+B_{a}\left(x_{1 j}-\bar{x}_{j}\right)+B_{j}\left(X_{i j}-\bar{x}_{j}\right)+\epsilon_{1 j}
$$

\section{ANALYSIS OF COVARIANCE TABLE}

Source of variation

Deviation from regression

vithin groups

Differences between regresslons

within groups

Deviations vithin classes

from $B_{a}$

Devintions between groups

from $B_{n}$

Difference between $B_{a}$ and $B_{m}$

Conson oversil regression $B_{0}$

Total
Sum of Squares $\underline{\text { af }}$

1.91235

22

0.08692

0.32301

2

0.16150

2.23536

24

0.09314

4.78600

1

4. 78600

0.12562

1

0.12562

22.45749

1

22.45749

29.60447

27

Test for departure from a coeson over-all regression

$$
\begin{aligned}
s^{2} \text { over-si1 } & =\frac{0.32301+9.78600+0.12562}{2+1+1} \\
& =1.30865 \\
F=\frac{1.30865}{0.00692} & =15.056 \\
F_{.005}^{(4,22)} & =5.017<15.056
\end{aligned}
$$

At the 56 aigniflcance level there is reason to belleve that the three slopes deviate from a common over-all slope. 
Table 32 (continued)

Test for difference in slopes

$$
F=\frac{0.16150}{0.08692}=1.858
$$

$$
F_{.005}(2,22)=6.806<1.858
$$

At the $5 \%$ significance level there is no reason to believe that the three slopes are different. 
Table 33

TEST FOR DIFFERENCES BETWEEN INIERCBPTS

This test is a two-way anslysis of variance in which the sums of squares have been calculated from the linear regression equations

\section{ANOVA TABLE}

\begin{tabular}{|c|c|c|c|c|}
\hline Source & af & Sum of Squares & Mean Square & F-ratio \\
\hline Samples & 2 & 5.19265 & 2.59632 & \multirow[t]{6}{*}{34.9} \\
\hline Stress levels & 2 & 22.61248 & 11.30624 & \\
\hline Interaction & 4 & 0.28534 & 0.07146 & \\
\hline Error & 19 & 1.41324 & 0.07438 & \\
\hline Total & 27 & 29.504 .21 & & \\
\hline${ }^{\mathrm{F}} .0$ & & $094<34.9$ & & \\
\hline
\end{tabular}

At the $5 \%$ significance level there is reason to belleve that the intercepts are not equal.

$$
\begin{array}{rlrl}
\bar{Y}_{1} & =4.78895 & S \bar{y} & =\sqrt{\frac{0.07430}{2}} \\
\bar{Y}_{2} & =4.78015 & & =0.1928 \\
\bar{Y}_{3} & =5.84571 & R_{2}=0.570
\end{array}
$$

Difference Table

\begin{tabular}{ccc}
\hline Sample & 2 & 1 \\
\hline 3 & 1.06556 & 1.05676 \\
1 & 0.00880 & \\
\hline
\end{tabular}

At the 56 significance level there is reason to believe that the intercept of sample III is different than the intercepts of the other two samples. 
Table 34

CALCULATION FOR PRBDICTION INIERVALS

Bquation for prediction Interval

$$
L=y \pm \pm^{T} \cdot 05(\pi-2) s_{y x} \sqrt{\frac{1}{\pi}+\frac{\left(x_{y}-\bar{x}\right)^{2}}{S S_{x}}}
$$

vhere

$$
s_{y x}=\sqrt{\frac{\text { Departure SS Brror SS }}{\mathbb{N}-2}}
$$

Low-Strength Concrete

$$
\begin{aligned}
& s_{y x}=0.33222 \\
& s s_{x}=1000 \\
& T_{.05}(13)=2.1064 \\
& x_{j}=608 \\
& \begin{array}{l}
L_{1}=5.97295-0.29301=5.67994 \\
L_{u}=5.97295+0.29301=6.26596
\end{array} \\
& x_{y}=70 \% \\
& \begin{array}{l}
L_{1}=4.78895-0.18532=4.60363 \\
L_{u}=4.78895+0.18532=4.97427
\end{array} \\
& x_{j}=808 \\
& \begin{array}{l}
L_{1}=3.60495-0.29301=3.31194 \\
L_{u}=3.60495+0.29301=3.89796
\end{array} \\
& N=15
\end{aligned}
$$

\section{High-Strength Concrete}

$$
\begin{aligned}
s_{y x} & =0.20349 \\
s s_{x} & =485.41429 \\
x_{J} & =60 \% \\
x_{J} & =706 \\
x_{J} & =80 \%
\end{aligned}
$$


Table 34 (continued)

\section{High-Strength Concrete}

$$
\begin{array}{cc}
s_{y x}=0.26029 & N=6 \\
s s_{x}=400 & t_{.05}(4)=2.7789 \\
x_{j}=60 \% & L_{1}=6.69451-0.46647=6.22804 \\
L_{u}=6.69451+0.46647=7.16098 \\
x_{j}=70 \% & L_{1}=5.84571-0.29502=5.59065 \\
x_{j}=80 \% & L_{u}=5.84571+0.29502=6.14073 \\
& L_{1}=4.99691-0.46647=4.53044 \\
& L_{u}=4.99691+0.46647=5.46338
\end{array}
$$


Table 35

TEST TO DEIERMINE DIFFERERCE IN FATIGUE LIFE

WHEN TESTIN AT DIFERENT SPERDS

Coding: $\quad Y_{1}=\frac{x_{1}}{1000}$

vhere

$x_{1}$ is the number of cycles to cause fallure of specinens from batch HL 1 which vere tested at the $80 \%$ stress level.

The average batch strength vas $5,130 \mathrm{pal}$.

\section{Teating Machine}

Ansler

500 cycles/minute

33.7

17.2

1.1

20.8

5.8

71.7

13.6

4.8

86.4

9

255.1

14712.87

28.34

935.55
Krouse-Purdue 1,000 cycles/miaute

45.4

9.7

3.2

7.8

6.3

33.3

23.4

23.2

145.4

9

297.7

25601.87

$30 . \infty$

1969.46

$$
F=2.015
$$$$
{ }^{P} .05^{(8,8)}=3.44>2.015
$$$$
t=0.264
$$$$
{ }^{t} .05(16)=2.12>0.264
$$

At the 56 signiflcance level there is no reason to believe that there is any difference in the fatigue life of lightweight aggregate concrete vhen it is tested at speeds of 500 cycles per al nute and 1000 cycles per minute. 
APPBNDIX D

STATISTICAL COMPARISON OF LIGHTWIOHT CONCRBTE WITH NORMAL WEIGHT CONCRETE 
Table 36

TEST FOR DIFFERENCE IN CORRELATION COEFFICIEIIS

\begin{tabular}{|c|c|c|c|c|c|}
\hline Sarple & $\underline{n-3}$ & $\underline{r}$ & $\underline{z}$ & $(n-3) z$ & $(\mathbb{N}-3) \mathrm{z}^{2}$ \\
\hline I & 12 & 0.95241 & 1.85741 & 22.28892 & 41.39964 \\
\hline II & 4 & 0.96169 & 2.34213 & 9.36852 & 21.94228 \\
\hline III & 3 & 0.95605 & 1.89781 & 5.69343 & 10.80504 \\
\hline FS & 13 & 0.61863 & 0.72280 & 9.39640 & 6.79172 \\
\hline \multirow[t]{2}{*}{ FA } & 13 & 0.93632 & 1.70735 & 22.19555 & 37.89557 \\
\hline & 45 & & & 68.94262 & 118.83425 \\
\hline
\end{tabular}

Average $z=\frac{\Sigma(\mathbb{z}-3) z}{\Sigma(\mathbb{N}-3)}=1.53206$

Average $\mathrm{Z} \times(\mathrm{N}-3) \mathrm{Z} \quad=105.62454$

$x^{2}=118.83425-105.62454=13.20971$

$x^{2} \cdot .05^{(4)}=9.49$

At the 5 significance level there is reason to believe that there is a difference between the five correlation coefficients. 
Table 37

\section{COMPARISON OF SLOPES}

The values sumarized in this Table can be found from Appendix C or Reference (22) and Table 31 of Appendix C of this thesis.

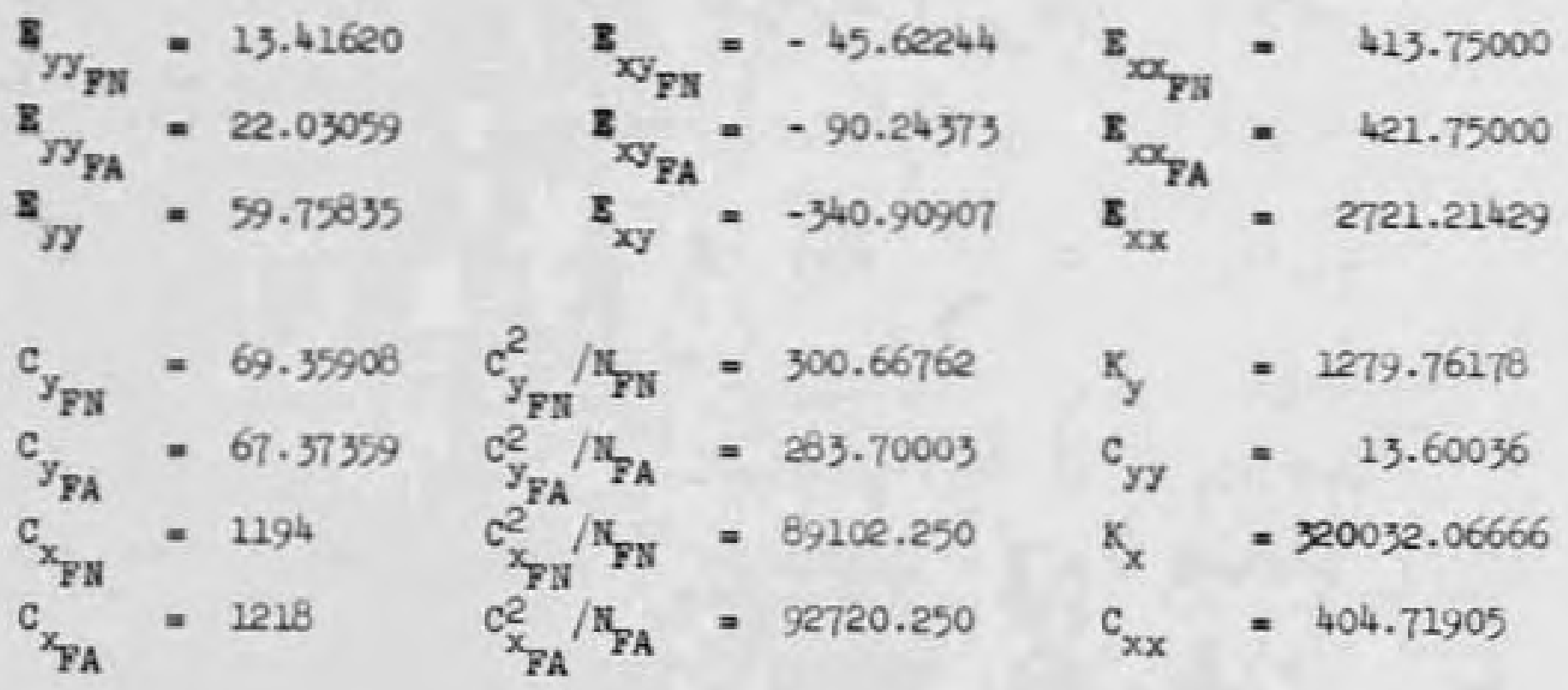

$\frac{c_{x_{F N}} Y_{F N}}{N_{F N}}=5175.92134$

$$
K_{x y}=20237.69734
$$

$\frac{c_{x_{F A}} Y_{F A}}{r_{F A}}=5128.81453$

$c_{x y}=-59.28306$

$\sum_{j} \sum_{1} Y_{1 j}^{2}=1353.12050$

$s_{y y}=73.35872$

$\sum_{j} \sum_{1} x_{1 j}^{2}=323158.00000$

$s_{x x}=3125.93334$

$\sum_{j} \Sigma_{1} X_{1 j} Y_{1 j}=19837.49751$

$s_{x y}=-400.19963$ 
Table 37 (cont1 nued)

\section{ANALYSIS OF COVARIANCE TABLE}

Source of variation

Deviation from regression

within groups

Difference between regreasions

vithin groups

Deviation within classes

from $B_{a}$

Devistions between groups

from $B_{m}$

Difference between $B_{a}$ and $B_{n}$

Coamon over-all regression B

Total

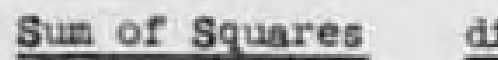

12.77316

50

0.25546

4.25857

$4 \quad 1.96459$

17.03153

54

0.31539

4.91661

3

1.63887

0.15639

1

0.15639

51.23586

$1 \quad 51.23586$

Test for departure from a cocmon over-all regression $\mathrm{s}^{2}$ over-a11 $=\frac{4.25837+4.91661+0.15632}{4+3+1}$

$$
=1.16639
$$

$$
\begin{aligned}
& F=\frac{1.16639}{0.25546}=4.56595 \\
& F_{.005}(8,50)=3.24<4.57
\end{aligned}
$$

At the if signiflcance level there is reason to believe that there is a departure from an over-all regression. 
Table 37 (continued)

Test for difference between slopes

$$
\begin{aligned}
& F=\frac{1.06459}{0.25546}=4.16734 \\
& F_{.005}(4,50)=4.26>4.17
\end{aligned}
$$

At the $5 \%$ significance level there is no reason to believe that there is any difference between the five slopes. 